THE EXPERIENCES OF BLACK AMERICAN LIVING KIDNEY DONORS

\author{
Dissertation presented to \\ Faculty of the Graduate School \\ University of Missouri \\ In Partial Fulfillment of \\ Requirements for the Degree \\ Doctor of Philosophy of Nursing
}

by

Sheila Adams-Leander, MSN, RN

Dr. Larry Ganong, Dissertation Committee Chair

July, 2011 
The undersigned, appointed by the Dean of the Graduate School, have examined the dissertation entitled

\section{THE EXPERIENCES OF BLACK AMERICAN LIVING KIDNEY DONORS}

Presented by Sheila Adams-Leander

A candidate for the degree of Doctor of Philosophy of Nursing And hereby certify that in their opinion it is worthy of acceptance.

Professor Lawrence Ganong

Professor Bill Bondeson

Professor Cindy Russell

Professor Eileen Porter

Professor Jane Armer 


\section{ACKNOWLEDGEMENTS}

My sincere thanks are extended to the following:

Dr. Joanne Banks-Wallace for suggesting that I research the topic of living kidney donation with a Black American population.

The social work staff in the Abdominal Transplant Unit of Saint Louis University Hospital for assistance with recruiting participants.

All study participants for taking time to share their experiences with me.

Dr. Lee Smith and the Interpretive Research Group at Saint Louis University School of Nursing for collaboration in reading de-identified data.

Dr. Deirdre Wipke-Tevis for advocating for me within the School of Nursing and the Graduate School.

Dr. Larry Ganong for facilitating my progression through the doctoral program

Dr. Eileen Porter for her expert advice about data analysis and presentation of findings. 


\section{TABLE OF CONTENTS}

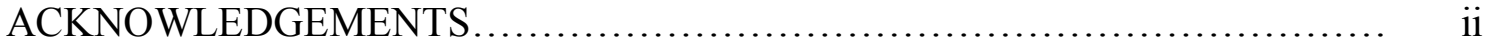

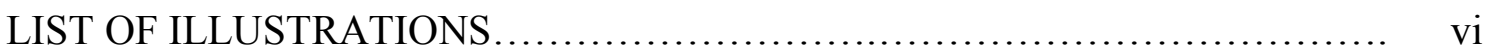

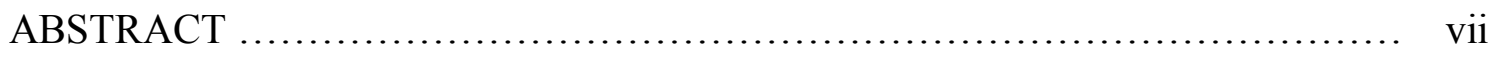

\section{CHAPTER}

1. INTRODUCTION TO THE RESEARCH $\ldots \ldots \ldots \ldots \ldots \ldots \ldots \ldots \ldots \ldots \ldots \ldots \ldots$

Research Problem, Aim, and Definitions ............................ 1

Overview of Living Kidney Donation ......................... 2

Kidney Transplant Issues for Black Americans ................... 3

Qualitative Knowledge Base ................................ 5

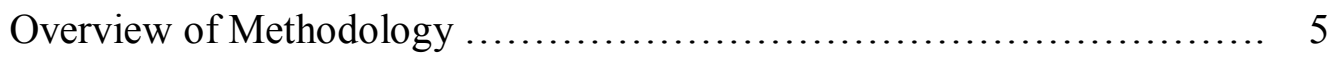

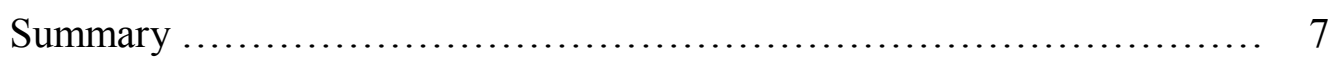

2. REVIEW OF THE LITERATURE .............................. 8

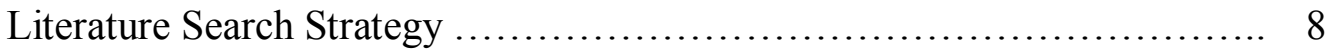

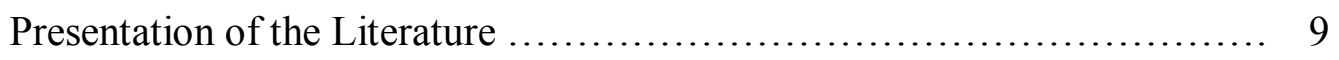

National Databases ........................................ 9

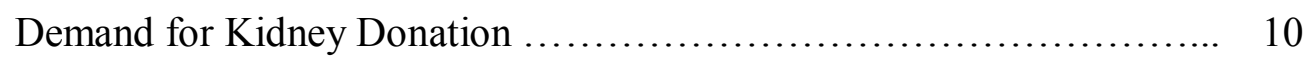

Long-term Living Donor Follow-up ......................... 10

Issues of Particular Concern for Black Americans.................. 11

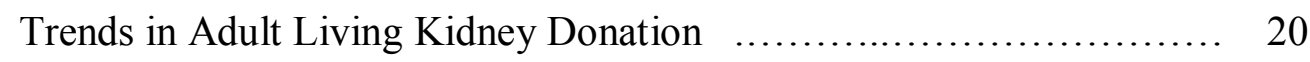

Physical Aspects of Living Donation ........................... 23

Psychosocial Aspects of Living Donation ........................ 24 
Making a Decision to Donate

Ethical Issues and the Decision to Donate .......................... 33

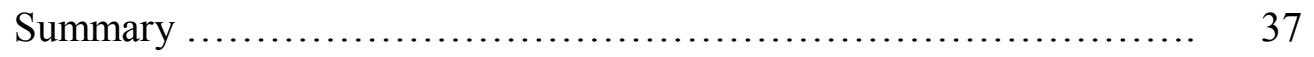

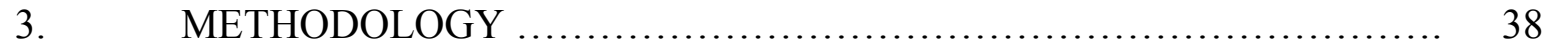

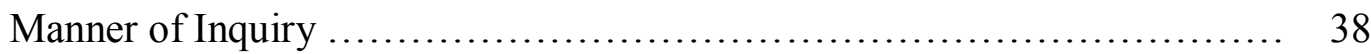

Researcher Reflexivity and Management of Bias $\ldots \ldots \ldots \ldots \ldots \ldots \ldots \ldots \ldots . \ldots \ldots$

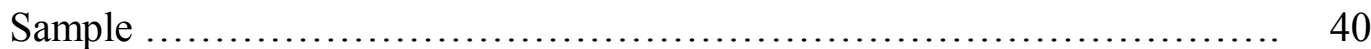

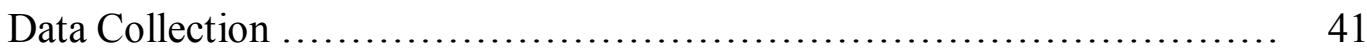

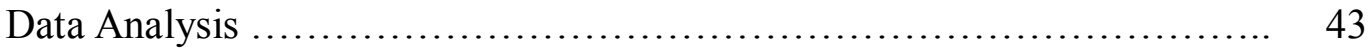

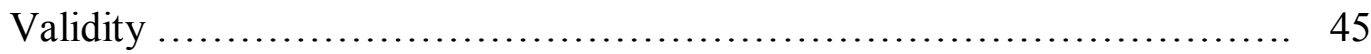

Protection of Human Subjects ..................................... 46

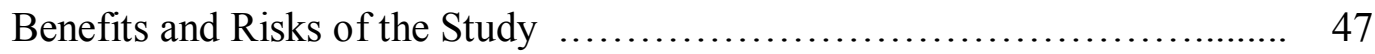

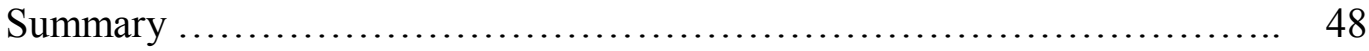

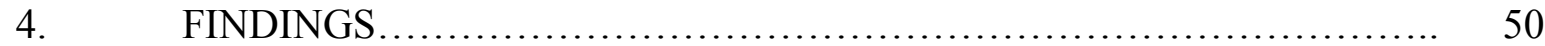

Description of Participants ..................................... 50

Context of Living Kidney Donation ................................. 52

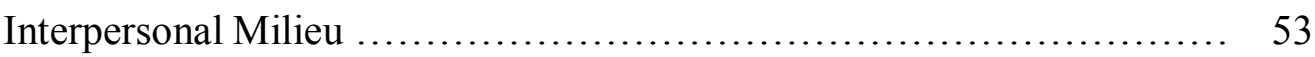

ESRD Threatens the Family's World ............................. 57

Facing an Uncertain Future ...................................... 59

Spiritual and Religious Beliefs and Values............................. 61

Continuum of Caring .............................................. 63

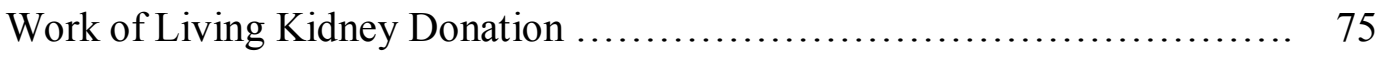

Making the Decision to Donate .................................. 75 


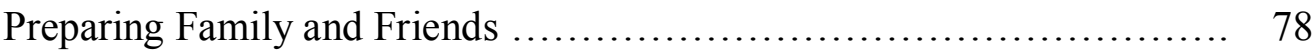

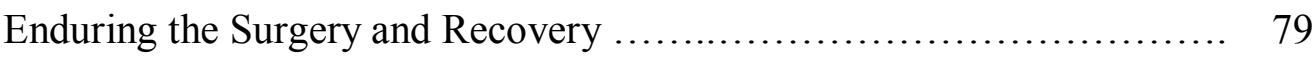

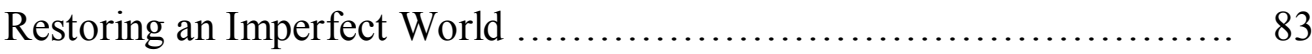

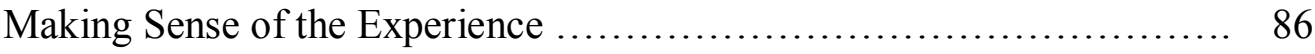

5. DISCUSSION AND RECOMMENDATIONS ....................... 91

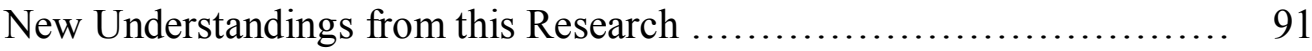

Similar Themes in Other Qualitative Research....................... 94

Context of Living Kidney Donation ................................ 95

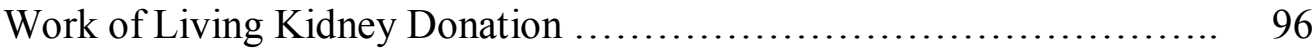

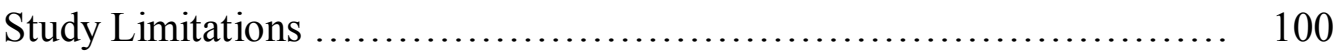

Recommendations for Research................................... 100

Recommendations for Clinical Practice ......................... 103

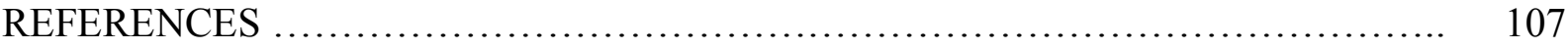

Tables $\quad$ Table 1. Overarching Themes, Themes, and Sub-themes................ 131

Table 2. Demographic Information ............................... 132

Figure 1. Key Events and Overarching Themes in Living Kidney Donation......... 133 APPENDIX

A. Black American Participation in Research Cited in this Study .......... 134

B. International Research Cited in this Study .......................... 138

C. Informed Consent for Research Participation............................. 140

D. Demographic Data Collection Tool................................... 143

E. Interview Guides .............................................. 144

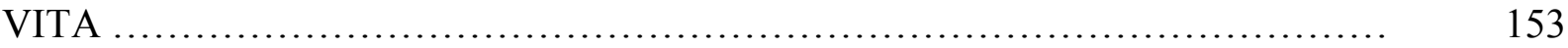




\section{LIST OF ILLUSTRATIONS}

Table Page

1. Overarching Themes, Themes, and Sub-themes........................ 131

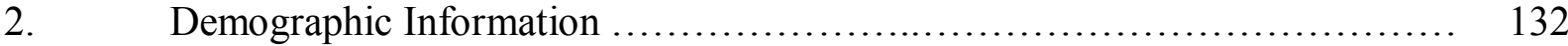

Figure

1. Key Events and Overarching Themes in Living Kidney Donation........... 133 


\begin{abstract}
End stage renal disease (ESRD) is a chronic illness of significant concern in the United States and throughout the world. In many cases, the optimal treatment for ESRD is living kidney donation. A qualitative investigation into the experiences of Black American living kidney donors was conducted. Black Americans are of particular interest because they have a high incidence of ESRD, they have experienced discrimination regarding kidney transplantation, and they are under-represented in research related to living kidney donation. Five areas of new understanding were identified; three which may be unique to Black Americans or other minority living donors, and two that may apply to living donors regardless of race or ethnicity. Recommendations for research include improved understanding of pain management needs for living donors with history of substance abuse, and improved understanding of the importance of spiritual and religious practices for Black American living donors. Differing interpretations between health care providers and living donors about the meaning of donation to the donor and their family should be further investigated. Clinical implications include consideration of unique social and economic concerns of Black American living donors and continued efforts to reduce racial discrimination in provision of health care.
\end{abstract}




\section{Chapter 1: Introduction to the Research}

Throughout the world, end stage renal disease (ESRD) is a chronic illness of significant concern (Schieppati \& Remuzzi, 2005). In many instances, the optimal treatment for ESRD is living kidney donation (Delmonico \& Dew, 2007). Living organ donation is a complex phenomenon that involves the person who donates (donor), the person who receives the kidney (recipient), their families, and many health care professionals (Sanner, 2005; Scheper-Hughes, 2007; Simmons, Klein, \& Simmons, 1977).

Black Americans are of particular interest in terms of living kidney donation for three reasons. First, end stage renal disease (ESRD) disproportionately affects this group (United States Renal Data System [USRDS], 2010). Second, Black Americans have experienced discrimination throughout the United States health care system, and specifically in relationship to kidney transplantation (Ayanian et al., 2004; Navaneethan \& Singh, 2006; Organ Procurement and Transplant Network [OPTN], 2008; Siminoff \& Arnold, 1999; Smedley, Stith, \& Nelson, 2003; USRDS, 2007). Third, this group is notably under-represented in research related to living kidney donation (Ayanian et al., 2004; Ellison, McBride, Taranto, Delmonico, \& Kauffman, 2002; Jacobs, Johnson, Anderson, Gillingham, \& Matas, 1998; Najarian, Chavers, McHugh, \& Matas, 1992; Olson \& Bogetti-Dumlao, 2001; Peters, Repper, Jones, Walker, \& Hunter, 2000; Simmons et al., 1977).

\section{Research Problem, Aim, and Definitions}

Given the unique experience of the Black American living kidney donor and the lack of research in this area, the overall aim of this qualitative study is to gain a better 
understanding of Black American living kidney donation when the recipient is a genetically- or emotionally-related person. Genetically-related people are those with current genetic ties to one another such as parents, siblings, aunts, uncles, grandparents, or cousins. Emotionally-related individuals are those with strong emotional ties to each other and may include spouses, stepparents, very close friends, single-sex or gay partners, or in-laws.

For purposes of this investigation, Black Americans are individuals who selfidentify as being Black and who are self-reported citizens of the United States. Although researchers use several terms to refer to African-Americans and Caucasian-Americans, the terms Black Americans and White Americans are used throughout this dissertation.

\section{Overview of Living Kidney Donation}

There are clear advantages of kidney transplantation over renal dialysis. These include a significantly prolonged life expectancy, improved quality of life, and greater post-transplantation participation in the workforce and society in general (Gjertson \& Cecka, 2000; Jacobs et al., 1998; Johnson et al., 1999; Karrfelt, Berg, Lindblad, \& Tyden, 1998; Schover, Streem, Boparai, Duriak, \& Novick, 1997; Young \& Gaston, 2002). Compared to kidney donation from a deceased individual, living donation has superior outcomes for the recipient (Binet et al., 1997; Spital, 2001). The rate of anuria in the first post-operative day is less, the need for post-transplant dialysis is diminished (Teraskai, Cecka, Gjertson, \& Cho, 1997), and ultimately, the transplanted kidney graft survival is longer. The survival rate for deceased donor kidney recipients at 10 years post-transplant is $40 \%$, compared to a 10 year rate of $58 \%$ for living donor recipients (USRDS, 2010). 
Physiologic studies demonstrate that living kidney donation is generally safe for the donor (Bay \& Hebert, 1987; Fehrman-Ekholm, Elinder, Stenbeck, Tyden, \& Groth, 1997; Johnson et al., 1999). The rate of peri-operative complications is low (Alfani et al., 1997), and the 20-year survival of donors is high (Fehrman-Eckholm et al., 1997). Postsurgical development of hypertension and proteinuria (D"Almeida et al., 1996) appear to have little impact on long-term renal function (Najarian et al., 1992). Researchers report that donors rate their quality of life following donation as higher than that of the general U. S. population (Corley, Elswick, Sargeant \& Scott, 2000; Jacobs et al, 1998; Olson \& Bogetti-Dumlao, 2001).

Living kidney donation to a genetically- or emotionally-related recipient is more than a physical event. It is a process that includes repeated contacts with the health care system, and it affects the psychosocial dynamics of families (Olbrisch, Benedict, Haller, $\&$ Levenson, 2001). Because this is an elective procedure (the donor chooses to have the surgery), individual and family attitudes and beliefs about organ donation are of paramount importance (Boulware et al., 2005; Scheper-Hughes, 2007).

\section{Kidney Transplant Issues for Black Americans}

The prevalence of ESRD is rising worldwide, and Black Americans have the highest rate in the United States at 5,205 per million, compared to 1,248 per million for White Americans (USRDS, 2010). This trend is attributed, in large part, to a high incidence of hypertension and diabetes among Black Americans (Morbidity and Mortality Weekly Report, 2007).

Black Americans represent less than 13\% of the United States population but make up almost 33\% of those diagnosed with ESRD (USRDS, 2010). Despite a high 
demand for donor kidneys, Black Americans receive them at a lower rate than White Americans (Siminoff \& Arnold, 1999). The rate of deceased donation is higher for White Americans than for Black Americans (USRDS, 2010). With a largely white donor pool, Black American candidates are at a disadvantage from the standpoints of blood type and tissue matching (Young \& Gaston, 2002). Within one year of registration on a transplant waiting list, it is estimated that $16.2 \%$ of White Americans versus $10.1 \%$ of Black Americans are organ recipients (OPTN, 2008). To some extent, this may be explained by the fact that nephrologists across the United States are less likely to believe that transplantation improves survival for Black Americans compared to White Americans (Ayanian et al., 2004). This and other possible factors result in Black Americans waiting considerably longer for kidney transplants. White Americans have an overall median wait time of 2.3 years compared to 3.7 years for Black Americans (USRDS, 2010).

Black Americans are not well represented in the research literature related to living kidney donation. For instance, in an early meta-synthesis Bay and Hebert (1987) indicated that they could not determine the race and ethnicity of participants in the studies they analyzed because those data were not reported. More recently, racial or ethnic data were not reported in five studies relating to the physical effects of living donation (Ellison et al., 2002; Ibrahim, et al., 2009: Johnson et al.,1997; Najarian et al., 1992; Terasaki et al.,1997). Among studies in which the psychosocial aspects of living donation were examined, Black Americans were included, but their participation rates were relatively low (Corley et al., 2000 [29\%]; Fisher, Kropp, \& Fleming, 2005 [12.8\%]; Jacobs et al., 1998 [2.8\%]; Johnson et al., 1999 [15\%]; Olson \& Bogetti-Dumlao, 2001 
[1.7\%]). Black Americans "eparticipation rates in studies related to living transplantation are more fully listed in Appendix A.

\section{Qualitative Knowledge Base}

The living kidney donor experience has been explored using several qualitative methods including grounded theory, narrative analysis, empirical phenomenology, content analysis, and ethnography (Andersen et al., 2004; Franklin \& Crombie, 2003; Haljamäe Nyberg, \& Sjostrom, 2003; Heck, Schweitzer, \& Seidel-Weisel, 2004; Papachristou et al., 2004; Sanner, 2005; Yi, 2003). In the United States, only three qualitative studies relating to living donors have been published, and results from Black American participants were only reported in one. In that study, researchers inferred that Black American donors were more concerned than White American donors about their post-donation health (Lunsford, Shilling et al., 2007).

\section{Overview of Methodology}

The experiences of Black Americans with respect to living kidney donation have not been thoroughly investigated, and they appear to be different than the experiences of White Americans. For this reason, the living kidney donation experience among Black Americans needs to be explored. In particular, the following questions were investigated.

1. What is the experience of Black Americans who donate a kidney to a genetically- or emotionally-related person? Specifically, what is it like to:

1.1. Learn that a loved one needs a kidney transplant?

1.2. Offer to donate a kidney?

1.3. Prepare for and undergo surgery?

1.4. Recover from surgery and resume previous activities and relationships? 
2. What is the overall context of the donation experience? Contextual elements investigated include, but are not limited to:

2.1. Changes in the relationship between the donor and the kidney recipient before, during, and after surgery.

2.2. Family, financial, social, and employment concerns.

2.3. The donores perceptions of health care providers and the health care system preand post-surgery.

3. How has the overall experience affected the living donor's life?

Qualitative methods are ideally suited for studying the Black American living donor experience because they facilitate better understanding of culturally and contextually unique groups (Bailey, 2000). Black Americans are a minority population in a majority culture, and research tools validated in the majority culture may miss important aspects of the phenomena under study. Findings from this investigation will broaden the knowledge base from which to launch further investigations of Black American living donors. The findings have the potential to inform the ways in which Black American living kidney donors receive care before and after donation.

Data were collected from Black Americans who are living kidney donors to a genetically- or emotionally-related kidney recipient (e.g., spouse, in-law, close friend). Eight participants were interviewed, and data saturation occurred (Munhall, 2001). Prospective respondents were contacted through a transplant center in St. Louis, Missouri. Using a purposive sampling method, I consulted with transplant center staff to identify Black American living donors willing to discuss their experiences. Interviews 
were conducted at a time and place of the participants ${ }^{\text {ee }}$ choice; they were taped and transcribed. The complete interview guide can be found in Appendix E.

Data analysis occurred in a series of steps, including reading and re-reading taped interviews, correcting transcripts, and discussing the transcripts with participants and dissertation committee members. Themes and exemplars of themes were identified, and interpretive summaries were written in regard to each participant. A reflexive journal was kept to aid analysis and to provide a research audit trail. The analysis was to be circular and iterative, continuing until a clear understanding of the phenomenon of Black American living kidney donation was made. All of these steps are explained in detail in Chapter 3, Methodology.

\section{Summary}

ESRD is a chronic illness of significant concern, particularly among Black Americans. Kidney transplant is the treatment of choice in most instances, and transplant from a living donor has superior outcomes for the recipient. Living donation to a genetically- or emotionally-related person is the phenomenon of interest in the current study. The experience of living kidney donation is complex, and to date, Black Americans have not been well represented in the research literature. I used a qualitative method to learn more about the experiences of Black Americans who donate a kidney to a genetically- or emotionally-related person.

In Chapter 2, the professional literature related to living kidney donation and Black Americans is more fully explored. The study methodology, including the philosophical underpinnings and study procedures, is presented in Chapter 3. Findings are in Chapter 4, and Chapter 5 contains discussion with recommendations. 


\section{Chapter 2: Review of Literature}

It is widely accepted that kidney transplant is the primary therapy for ESRD in all patients except those who are unlikely to tolerate the transplant surgery or immunosuppressive therapy (Delmonico \& Dew, 2007; Young \& Gaston, 2002). In the United States, once a person is informed that they will need a kidney transplant, there are two choices: Join a national waiting list for an organ from a deceased donor or find a living donor.

The focus of this study is the experiences of Black American adult living kidney donors who are genetically- or emotionally-related to the kidney recipient. Published theories and research findings of particular relevance to this group are discussed in this literature review. The following situations are not the focus of this investigation, and the associated literature is not reviewed: (a) living donation from a parent to a minor child, (b) living donation from an unknown or genetically-unrelated individual, (c) living donation in which a swap occurs among incompatible donors through a paired or domino exchange program, and (d) living donations that are known to be financially reimbursed. In addition, recipient outcome, including function of the donated kidney, is not the focus of this study.

\section{Literature Search Strategy}

The professional literature was searched using electronic databases such as the Cumulative Index to Nursing and Allied Health Literature, Medline, PsychInfo, Cochrane Systematic Review, and Dissertation Abstracts. The majority of the literature reviewed was published within the last 20 years. Living kidney donation has increased considerably during this time period, and researchers have focused more on the 
physiologic and psychosocial aspects of donation since 1988. Keywords used to search include living kidney donors, Black American and African-American kidney donors, kidney transplant, kidney or organ donation, ethics of organ donation, family, and organ transplant. Relevant documents were also located using reference lists from articles and books. OVID and AMEDEO automated literature search services provided regular search updates throughout the research period.

\section{Presentation of the Literature}

National databases, demand for kidney donation, and the need for long-term donor follow-up are described first. Because the focus of this study is Black Americans, issues of concern for this population are presented in detail, and possible contributions of the study are mentioned throughout. General trends in adult living kidney donation are

presented, including topics pertaining to unrelated donors, older donors, laparoscopy, and gender disparities. Literature about physical and psychosocial aspects of living kidney donation is described. Finally, the literature about donor decision-making in regard to family dynamics and ethical issues is presented.

\section{National Databases}

ESRD and its treatment are tracked epidemiologically through three national databases. They include the United States Renal Data System (USRDS), the Organ Procurement and Transplant Network (OPTN), and the Scientific Registry of Transplant Recipients (SRTR) (OPTN, 2008; SRTR, 2011; USRDS, 2010) . These tracking systems are unique in the United States multi-payer health care system, and the resultant data provide a thorough look at ESRD within the country. Much of the demographic information that is presented in this chapter is drawn from these three databases. 


\section{Demand for Kidney Donation}

In 1990, the United States kidney transplant deceased-donor waiting list included approximately 15,000 patients (Gaston et al., 2003). By 2008, the numbers had risen to 77,000 (USRDS, 2010). With the number of patients on the waiting list outpacing the number of deceased donors, access to transplants has become inequitable (USRDS, 2010). Patients living in the Southeastern states wait longer than those in the North Central states, women and people of color experience longer waiting periods (USRDS, 2010), and patients who get transplants from deceased donors are generally sicker because of extended wait times (Rodrigue, Bonk, \& Jackson, 2001).

ESRD patients are frequently encouraged to find a living kidney donor, and currently, almost half of all kidney donors in the United States are living donors (Truog, 2005). This is despite that fact that only $51 \%$ of ESRD patients are willing to ask for a living donation (Lunsford, Simpson, Chavin, Hildebrand et al., 2006).

\section{Long-term Living Donor Follow-up}

Between 1990 and 2000, the number of living donor kidney transplants more than doubled (Ellison et al., 2002). This increase has prompted transplant professionals to call for establishment of a living donor registry as a repository for demographic and clinical outcome data on all living organ donors (Abecassis et al., 2000; Ethics Committee, 2004). Single-center studies about long-term outcomes for living donors are presented in this chapter, but there are few broad, population-based data about living donor outcomes. A living donor registry has potential to evaluate the impact of changes in criteria for donor eligibility on the outcome of donors and to provide long-term follow-up data on donor well-being (Abecassis et al., 2000; Zink, Weinreib, Sparling, \& Caplan, 2005). 


\section{Issues of Particular Concern for Black Americans}

Black Americans have unique concerns related to the development of ESRD, dialysis treatment, and transplant that are different than the experiences of White persons in the United States (Young \& Gaston, 2002; Young \& Kew, 2005). Moreover, it does not appear that these experiences have been fully examined (Nolan, Walton-Moss, Taylor \& Dane, 2004). Such concerns include the incidence of ESRD, awareness of and access to kidney transplant, trust in health care providers and the health care system, and longterm health concerns for living kidney donors. Following is a discussion of research about the Black American donor/transplant experience.

The incidence of end stage renal disease varies across populations. In 2008, the prevalence ESRD among Black Americans was 5,205 per million, compared with 1,248 per million for White Americans (USRDS, 2010). New cases of ESRD among Black Americans reached 983 per million compared with 272 per million for White Americans in 2008 (USRDS, 2010). Primary causes of ESRD in the United States are hypertension and diabetes (Morbidity and Mortality Weekly Report, 2007). Particularly concerning is the incidence of hypertension among Black Americans who are 30 to 39 years of age (49 per million population), which is almost 15 times higher than among White Americans (USRDS, 2010).

The Black American transplant experience differs from that of White Americans. The Center for Medicare Services (CMS) pays for the majority of medical care for people with ESRD in the United States (OPTN, 2008) and mandates annual transplant evaluation for all renal dialysis patients (Centers for Medicare and Medicaid Services, 2007; Young \& Gaston, 2002). Access to transplant can be divided into four main steps. First, the 
patient decides to seek a transplant, and second, the nephrologist refers the patient to a transplant center. In the third step, the transplant team approves the patient for transplant and places him or her on a waiting list. During the final step, a donated kidney is allocated through the United Network for Organ Sharing (UNOS) or a living donor is identified (Gordon, 2002).

Awareness of transplantation in the Black American community appears close to that of White Americans, around the $90^{\text {th }}$ percentile (Siminoff \& Arnold, 1999). In 2002, Black Americans donated $13 \%$ of deceased donor kidneys, while comprising only $12 \%$ of the population (USRDS, 2007). Despite these donation rates, it is estimated that $40 \%$ of Black Americans versus $30.7 \%$ of White Americans characterize the system of organ distribution as unfair (Siminoff \& Arnold, 1999). Race appears to explain the greatest amount of variation in terms of willingness to become a deceased donor followed by trust in hospitals (Boulware et al., 2002). Based on a national study involving 845 respondents, of which $12 \%(n=102)$ were Black Americans; $71 \%(n=591)$ reported that the organ allocation system is biased owing to race, income, age, education level, gender, and religion (Boulware, Troll, Wang, \& Powe, 2007). There is also concern among Black Americans that physicians are less likely to save their lives if they are known to be organ donors (Siminoff \& Arnold, 1999).

Access to transplant can be complicated. Out of 114 dialysis patients (71\% Black American participants), 21\% preferred another type of treatment (Klassen, Hall, Saksvig, Curbow, \& Klassen, 2002). All of the study participants were transplant-eligible, but only $61 \%$ of these individuals were on the transplant waiting list. In this study, 20 individuals who desired a transplant were not on the waiting list, and 4 were listed but 
reported they preferred to remain on dialysis. Some unlisted patients did not understand how to get on a waiting list. Others reported wanting a transplant but avoided the transplant evaluation process (Klassen et al., 2002).

Once fully informed of the options, Black Americans on dialysis prefer transplant over dialysis as often as White Americans, but they are less likely to proceed rapidly to transplant (Ayanian, Cleary, Weissman \& Epstein, 1999). Although almost all eligible White Americans are referred for transplant, only 94\% of Black American women, and $86 \%$ of Black American men are referred for transplant (Epstein et al., 2000). Using USRDS data, Garg, Deiner-West and Powe (2001) determined that Black Americans are up to $50 \%$ less likely to be placed on transplant waiting lists than Whites. Such disparities are particularly notable in Georgia and the Carolinas, where $67 \%$ of dialysis patients but only $37 \%$ of kidney transplant patients are Black Americans (USRDS, 2007).

Immunologic and blood type variables contribute to delaying organ donation for Black Americans (Childress \& Liverman, 2006; Young \& Kew, 2005). It is medically necessary for blood types $(\mathrm{ABO})$ to be compatible between donor and recipient. Black Americans have a higher frequency of the less common $\mathrm{ABO}$ types that are associated with longer waits for kidney transplant.

Immunologic variables which tend to give White American candidates an advantage include human leukocyte antigen (HLA) matching and histocompatibility complex reactivity or presentizationin. HLA matching is critical for insuring transplant compatibility, reducing the chances of the recipient"s body rejecting the transplanted organ (Childress \& Liverman, 2006). Until 2003, candidates who had no HLA mismatches with available donor organs were given priority (more points) on the 
transplant waiting list. Because there were more White American than Black American donors, there were more close or identical HLA matches for White Americans. In 2003, a change in the point algorithm for HLA matching was implemented to reduce racial disparities in allocation of kidneys to Black Americans (Childress \& Liverman, 2006).

Presensitization exists when antibodies are detected in the potential recipient that may react to a specific transplanted organ. For reasons that are not well understood, there is a greater likelihood for Black American candidates to have presensitization or antimajor histocompatibility complex (MHC) than White American candidates (Young \& Kew, 2005).

Currently, rates of non-donation due to medical ineligibility, such as co-morbidities of hypertension and diabetes, do not appear to differ between Black Americans and White Americans (Epstein et al., 2000; Lunsford, Simpson, Chavin, Menching et al., 2006). Rather, disparities appear to be more associated with the fact that physicians believe that Black Americans prefer to stay on dialysis. Physicians also perceive that transplant does not improve the survival or quality of life of Black Americans (Ayanian et al., 2004).

Information about surgery, recovery, and life with one kidney is frequently needed in order to make conscientious decisions about donation. Unfortunately, patientphysician and family-physician discussions about living transplantation for Black Americans do not always occur (Boulware et al., 2005). Based on a sample of 91, of which 13\% were Black Americans, potential donors discussed donation most often with their immediate family and the recipients, not with physicians (Waterman et al., 2004). 
In this study, up to $37 \%$ of potential donors expressed fear and lack of understanding about the medical procedures they may be undergoing (Waterman et al., 2004).

Among a sample of 10 Black American female potential living donors, kinship and social factors, specifically family ties and religious and philosophical factors were found to be important when discussing organ donation decisions (Wittig, 2001). The women expressed that God would take care of them, regardless of their decisions related to organ donation, that organ donation was unnecessary for those who took care of their bodies, and that they would not donate after death, even if the recipient was a family member. This qualitative study, using an ethnonursing method, was set in a rural town in the southern part of the United States. Findings from the current dissertation study will help to validate or refute these findings among a mixed-gender sample of urban-dwelling Black Americans.

Black Americans might cope with the need for transplant differently than white Americans, and this may affect their willingness to ask someone to be a kidney donor. For example, Lunsford, Simpson, Chavin, Hildebrand and colleagues (2006) found Black Americans to be less accepting of ESRD and more likely to deny the need for transplant $(\mathrm{N}=333 ; 61 \%$ Black American). Perceptions such as these might weaken pleas for living donation. In the current dissertation study, participants were asked to discuss how they learned a donor was needed, including the circumstances surrounding the request for a kidney.

In recent years, culturally relevant strategies have been used to improve access to living kidney donors and referrals among Black Americans. Strategies include off-site testing, ethnically-appropriate teaching for potential recipients, and particular attention to 
immunologic factors. As a result, rates of living donation have increased and waiting times are shorter (Foster et al., 2002). In light of these findings, participants in the current dissertation study were asked if similar strategies were utilized at the center where they received services.

Trust in health care providers and the health care system is important. When discussing Black Americans ${ }^{\text {ee }}$ willingness to be living donors and to get involved in the transplant evaluation process, the issue of trust in the health care system needs to be addressed (Ayanian et al., 2004; Rodrigue, et al., 2001; Shilling et al., 2006). In particular, bias and unjust treatment by health care providers, perceptions of past experimentation on slaves, and the more recent Tuskegee syphilis experiment have contributed to diminished levels of trust among Black American patients (Gamble, 1997; King, 2003; Van Ryn \& Fu, 2003; Washington, 2006; White, 2005).

The roots of friction between health care providers and Black Americans run deep. In the $18^{\text {th }}$ and $19^{\text {th }}$ centuries, slaves were subjected to dangerous physiologic and surgical experiments that were of no benefit to the subjects (Washington, 2006). Consent was not deemed necessary because the subjects were property, not people (Gamble, 1997; Washington, 2006). After slavery ended, Black Americans were vulnerable as they were seen as clinical specimens for medical students, and grave robbing was a source of bodies for anatomical study through 1912 (Washington, 2006).

The Tuskegee syphilis study was conducted by the United States Public Health Service between 1932 and 1972 (Gamble, 1997). Six hundred Black American men were deceived and became part of a study in which they were denied treatment for a curable disease (Gamble, 1997; Washington, 2006). Today, Black Americans are at risk of 
receiving less effective pain control than White Americans; they are more likely than Whites to be prescribed anti-psychotic medications, and they are less likely to receive cardiac tests and related procedures (Smedley et al., 2002; Van Ryn \& Fu, 2003). Based on historical events and more current experiences, it is understandable that Black Americans might not trust the health care system (King, 2003).

Trust in physicians, health insurance plans, hospitals, and the organ procurement system differ based on race and ethnicity (Boulware et al., 2003; Saha, Arbelzez, \& Cooper, 2003; Siminoff \& Saunders-Sturm, 2000). In a cross-sectional survey of 385 people, Boulware et al. (2002) found that over half the respondents agreed that rich and White patients receive better care at hospitals than other people. This is evidence that perceptions of unequal treatment persist in the general population, and these perceptions might affect a person s s willingness to become a living organ donor.

Discriminatory action by individuals and groups is subtle but pervasive in todayes society (Feagin \& Sikes, 1994). Racism, belief in the inherent superiority of one group and its right to dominate others (Gove, 1986), is a continuing issue for Black Americans. Racism has a cumulative effect on individuals and families that significantly affects a Black American's behavior and understanding of life (Feagin \& Sikes, 1994). In addition, Black Americans who experience racism exhibit physical consequences such as hypertension, which contributes to the development of ESRD (Steffen, McNeilly, Anderson, \& Sherwood, 2003). Perceptions of discriminatory treatment were explored in the current dissertation study.

There are long-term health concerns. In the United States, a registry of all living organ donors does not exist (Abecassis et al., 2000), and there is little population-based 
data available about their long-term outcomes. For this reason, discussion of living donor outcomes is limited to findings that are available from single-center studies.

Long-term health concerns have been documented for living donors, including elevated serum creatinine for those over age 50 , proteinuria, and eventual development of ESRD (Ellison et al, 2002; Gibney, King, Maluf, Garg, \& Parikh, 2007; Johnson et al., 2005). Conflicting findings exist in terms of increased blood pressure. The incidence of hypertension has been reported to be no higher than among the general population (Karakayali, Moray, Demirăg, Yildrim, \& Bilgin, 1998; Najarian et al., 1992). Black donors had an increased risk of hypertension, as compared to White donors in a recent study (Lentine, et al., 2010).

Black American donors account for $14.3 \%$ of all living kidney donations, but they make up $44 \%$ of donors who are eventually added to kidney transplant waiting lists. This is due to the eventual development of ESRD (Gibney et al., 2007). Consequently, Black American donors express more concern than White American donors about their future health, and an increased vulnerability to premature death (Griffin \& Bratton, 1995; Lunsford, Shilling et al., 2007).

Among Black American living organ donors, decisions to donate are also influenced by the potential for developing serious health problems in the future. Mortality rates due to heart disease are more than $40 \%$ higher among Black American versus White Americans, and death rates from all cancers are 30\% higher among Black Americans than White Americans (Baldwin, 2003; Diseases and Conditions, 2006). The incidence of prostate cancer is more than double among Black Americans, and the rate of 
HIV/AIDS is more than seven times higher among Black Americans versus White Americans (Baldwin, 2003).

Hypertension following donation is of particular concern for Black Americans. Based on a meta-analysis of 48 studies, Boudville et al. (2006) concluded that within 5 to 10 years after donation, donors had a $5 \mathrm{~mm} \mathrm{Hg}$ increase in blood pressure over what was anticipated due to the aging process. Among a total of 56 living donors who were suffering from renal failure, the causes were found to include malignant hypertension (43\%), glomerulosclerosis, and chronic glomerulonephritis (Ellison et al., 2002). All of these conditions are known to occur at higher rates among Black Americans (Diseases \& Conditions, 2006).

Transplant kidney function at various time intervals is a measure of graft survival (USRDS, 2006). Graft survival rates among Black Americans are worse than among White Americans at 1, 3, and 5 years (USRDS, 2006). Reasons for this difference are multi-faceted and could include delayed graft function post-surgery, sensitivity to immune suppressant medications, longer periods of dialysis before transplant, elevated blood pressure after transplant, and medication noncompliance (Braun, 2007; Young \& Gaston, 2002). Conversely, researchers in France concluded that immunologic and/or pharmacologic factors cannot be held responsible for inferior graft survival rates in the United States (Pallet et al., 2005). Due to these types of conflicting reports, Black Americans might be less inclined to become living donors. These proclivities were explored in the current investigation.

There are far fewer studies about living donation from the Black American perspective than the White American perspective. Studies cited in this dissertation are 
listed in Appendices A and B, with the percentage of Black American participants in Appendix A, and participant nationality for international studies in Appendix B. Among 100 studies, 35 were conducted outside of the United States, and did not identify the race of participants, only the nationality. The remaining 65 studies were conducted in the United States. Ethnicity or racial data were only reported in 37 studies, however.

Given that Black Americans have a high incidence of the most common causes of ESRD and living kidney donors are in high demand, it is important to learn more about the experiences of Black American living kidney donors. The current dissertation study is intended to fill this knowledge gap.

\section{Trends in Adult Living Kidney Donation}

It is important to review trends in practice because transplant professionals are seeking innovative methods to meet the growing demand for kidneys. Current trends in practice include unrelated living donors, older living donors, laparoscopic surgical procedures, and gender inequity with more women than men becoming living donors. These trends might affect all living donors, and particular concerns affecting Black Americans are discussed next.

Practice trends in adult living kidney donation have emerged since 1954, when the first living kidney donation was carried out (Childress \& Liverman, 2006). One trend has been the increased use of kidneys from unrelated donors for transplantation. Initially, only genetic relatives were considered for living kidney donation. Siblings were preferred donors, because they are generally the best genetic match (Bratton \& Griffin, 1994; Simmons, Hickey, Kjellstrand, \& Simmons, 1971). Throughout the 1980s and 1990s, distant relatives and unrelated, but emotionally-connected donors became more 
accepted at transplant centers in the United States (Spital, 2000; Terasaki et al., 1997). By 2000 most United States transplant centers accepted spouses and close friends as living donors (Spital, 2000). Today, the long-term graft survival rate for spousal kidneys is comparable to that for kidneys from other sources (Simforoosh et al., 2006; Terasaki et al., 1997).

There is a trend toward using older donors. The lengthening list of people in need of kidney donation has prompted efforts to increase the donor supply, including the use of older living individuals who are 55 to 75 years of age (Gill, Gill, Rose, Zalunardo, \& Landsberg, 2006). Positive outcomes for recipients of living kidney donation from older donors have been documented in the United States (Gill et al., 2006; Mandelbrot et al., 2007), Turkey (Sahin, Manga, Turkmen, \& Sever, 2006), Italy (Gambino et al., 2006), and Norway (Fauchald et al., 1991).

From the donor"s perspective, being older is of concern for two reasons. First, older people might be under subtle pressure to donate because they might be viewed as having lived long lives with an obligation to help the younger generation (Kallich \& Merz, 1995). Second, of particular concern for Black Americans, is the increased risk of chronic or hereditary conditions with renal complications that might not be detected prior to donation, despite normal findings on pre-donation screening tests (Bia et al., 1995; Ingelfinger, 2005). Black Americans are affected to a greater degree by diabetes, heart disease, hypertension, terminal cancer, crippling arthritis, kidney disease, and HIV/AIDS (Diseases \& Conditions, 2006). Based on positive results from a small investigation ( $\mathrm{N}=$ 22) in which the race and ethnicity of participants was not reported continued use of older donors (> 50 years) is recommended (Johnson, et al., 2005). 
Laparoscopic procedures have been introduced. In recent years, the availability of laparoscopic procedures has influenced peoples ${ }^{\text {ee }}$ willingness to be living kidney donors (Clayman, 2005; Dahm et al., 2006; Pradel, Lincango, Mullins \& Bartlett, 2003; Shokier, 2007). Traditionally, an open flank procedure with a long diagonal incision on the torso was used to carry out the donation nephrectomy. Currently, laparoscopies allow for a small abdominal incision, which is less painful and results in reduced hospital stays with shortened recovery periods (Shokier, 2007). Recipient graft function is comparable with both procedures, and the rate of donor complications is similar (Dahm et al., 2006). Gender disparity among donors seemed to disappear after a laparoscopic procedure was introduced at one center (Tuohy, Johnson, Khwaja, \& Pavlakis, 2006). Because this study was conducted at a single center, generalizations from the findings are limited and further study is necessary to determine if similar results occur across genders, ethnic and racial groups, and geographic settings.

There is gender inequity. Nationally and internationally, more women than men are living kidney donors, and there are more men than women kidney recipients (Bloembergen, Port, Mauger, Briggs, \& Leichtman, 1996; Kayler et al., 2002; Kayler et al., 2003; Khajehdehi, 1999; Zimmerman, Donnely, Miller, Stewart, \& Albert, 2000). These trends hold within the Black American community, wherein women wait longer for a kidney than men, and they are donors more often than men (USRDS, 2010). Reasons for these differences have been explored with limited success. Men might be more ambivalent about donating than women, and they might regard living donation as an unusual gift, whereas, women see it as an extension of usual family obligations (Corley et al., 2000; Franklin \& Crombie, 2003; Simmons et al., 1977). 
Psychosocial characteristics that are believed to influence donation, including altruism, endorsement of gender-stereotyped roles, and perceptions of family pressure have been investigated. Psychosocial profiles do not appear to differ between men and women donors (Achille, Soos, Fortin, Paquet, \& Hebert, 2007). Instead, there is evidence that economic factors contribute to gender disparity among living donors in the United States (Zimmerman et al., 2000), and full-time employment might be a partial barrier to living donation (Kayler et al., 2003). In a report of 42 donors from unidentified racial or ethnic backgrounds, there was a return to activities of daily living within a mean of 4.8 weeks (Peters et al., 2000). It is speculated that men, as primary breadwinners for families, are more likely to be precluded from donation to minimize time off work. The current dissertation study includes men and women, and gender-specific factors related to donation are explored.

\section{Physical Aspects of Living Donation}

A controversial and possibly limiting factor surrounding living kidney donation relates to the fact that the donor undergoes an intervention that carries a risk of mortality and morbidity that is not balanced by direct benefits to his or her own physical health (Binet et al., 1997; Childress \& Liverman, 2006). The current dissertation study explores donors ${ }^{\text {ee }}$ concerns related to physical outcomes.

In an early meta-analysis Bay and Herbert (1987) reported that the mortality rate from events related to donation nephrectomy is $0.04 \%$ or 1 death per 1,600 donors. Causes of death were not delineated by Bay and Herbert, but pulmonary embolus was identified as a cause of death in a later survey of transplant centers (Najarian et al., 1992). Less severe post-operative problems include wound infections, nausea, intra-abdominal 
abscesses, pneumothorax, urinary tract infections, pneumonia, and pain; which tend to resolve with appropriate intervention. (Alfani et al., 1997; Andersen et al., 2004; Johnson, Anderson et al., 1999; Johnson, Remucal et al., 1997). Of particular interest is the fact that Swedish donors report that post-nephrectomy pain is the most severe discomfort they have ever experienced (Sanner, 2005).

\section{Psychosocial Aspects of Living Donation}

Psychosocial issues related to living donation such as depression and anxiety, pressure to donate, post-donation self-esteem, and relationship stresses have been investigated (Achille et al., 2007; Andersen et al., 2004; Haljamäe et al., 2003; Heck et al., 2004; Smith, Trauer, Kerr, \& Chadban, 2004; Walter et al., 2005; Walter et al., 2006). Generally, donors do not appear to regret the donation decision (Binet, 1997; FehrmanEckholm, et al., 2000; Franklin \& Crombie, 2003; Jacobs, et al., 1998; Johnson, et al., 1999). However, they tended to ask for more psychosocial support than they actually received before, during, and after transplant (Fehrman-Eckholm, et al., 2000; Franklin \& Crombie, 2003; Jacobs, et al., 1998; Kaarfelt, et al., 1998). Psychosocial issues that pertain to racial or ethnic donor groups must be understood before effective support can be provided.

Self-esteem might be affected by living donation. Donors often report heightened perceptions of well-being and self-esteem after donation (Achille et al., 2007; Corley et al., 2000; Fehrman-Eckholm et al., 2000; Franklin \& Crombie, 2003; Heck et al., 2004; Jacobs et al., 1998; Lennerling, Forsberg, Meyer, \& Nyberg, 2004; Olson \& BogettiDumlao, 2001; Simmons et al., 1977; Walter, 2005). Changes in self-esteem appear 
similar among men and women who are donors, but, they appear to be weak incentives for donation (Achille et al., 2007; Lennerling et al., 2004).

Assessment of living donor self-esteem among Black Americans is limited. Selfesteem and self-image were measured among living kidney donors, of which $29 \%$ were Black American (Corley et al., 2000). Based on this sample, higher levels of self-esteem were reported among Black Americans, those with higher levels of education, and individuals who had more recently donated. This is the only known investigation of donor self-esteem in which Black American participation was greater than $2.8 \%$.

There might be emotional effects following donation. In general, the psychological health of donors appears unchanged or improved, but negative psychosocial outcomes can affect a small proportion (Heck et al., 2004; Smith et al., 2004). Estimates of depression following donation range from $10 \%$ (Rodrigue et al., 2001 ) to $23 \%$ (Johnson et al., 1999). Reports of depression are common in the general U. S. population, with a mean established at $29 \%$ by the Short Form 36 -item health survey (Johnson, et al., 1999). Although most donors in one study would make the same choice again and would strongly encourage others to donate; $15 \%$ of 167 donors reported that donating had negatively impacted their health, and $23 \%$ reported negative financial consequences (Schover et al., 1997). Of 55 living donors (29\% Black Americans), 25\% felt they had given up something by donating without getting anything in return (Corley et al., 2000), and in a German study, 33\% of 106 donors expressed anxieties about the future and thought that psychological follow-up was inadequate (Giessing et al., 2004).

Living donors might have psychological reactions when the organ recipient does not regain health or dies (Andersen et al., 2007; Haljamäe et al. 2003; Heck et al., 2004; 
Johnson et al., 1999; Schover et al., 1997; Walter et al., 2006). They might demonstrate guilt, sorrow, and diminished self-esteem that are associated with feelings of failure (Haljamäe et al., 2003; Walter et al., 2006). Five (1.4\%) of 370 Swedish living donors regretted their donation, and in all five cases the transplanted kidney failed or the recipients died (Fehrman-Ekholm et al., 2000). When recipients die within the first year after transplant, donors report that the donation experience is extremely stressful, and suicidal ideation has been reported (Johnson et al., 1999; Schover et al., 1997).

In studies related to the psychosocial aspects of donation, Black American participation ranged from $10 \%$ (Rodrigue et al., 2001) to $29 \%$ (Corley et al., 2000). Only two investigations of donor reaction to poor recipient outcomes have included Black Americans, albeit in small percentages (e.g., 11\% [Schover, et al., 1997]; 15\% [Johnson et al., 1999]). It appears that researchers might not have fully captured the psychosocial aspects of living donation that are unique to Black Americans.

There are financial considerations related to living donation. While medical expenses related to evaluation, surgery, and short-term follow-up are paid by the recipient"s carrier, there are other financial considerations associated with living donation. Nearly one-fourth of participants in three studies reported that donation caused financial hardship (Cabrer et al., 2003; Schover et al., 1997; Smith et al., 1986). Travel; lodging; time away from work and family for evaluation, surgery, and recovery; incidental medical costs; and costs for household services are primary sources of expense (Clarke, Klarenbach, Vlaicu, Yang, \& Garg, 2006). Donors also report concerns about being able to obtain health insurance in the future (Johnson et al., 1999). Black Americans"e participation in these types of studies has been minimal (11\% [Schover 
et al., 1997] and 6.7\% [Smith, et al., 1986]), and little is known about this group in terms of how they deal with the financial hardships of donation.

\section{Making a Decision to Donate}

When a person is diagnosed with ESRD and needs a kidney transplant, all genetically- and emotionally-related family members face the potential of becoming a living donor. Family dynamics, motives of the donor, and patterns of decision-making have been researched relative to living donation (Corley et al., 2000; Hilton \& Starzomski, 1994; Lennerling, Forsberg, \& Nyberg, 2004; Simmons et al., 1977).

Donor motives vary. Altruism is the principle or practice of unselfish concern for or devotion to the welfare of others, and altruism is often invoked when considering the motives of living donors (Farley, 1982; Glannon \& Ross, 2002). That said, donor motives are usually thought to involve more than pure altruism (Spital, 2000). Although United States law bans monetary payment for organ donation, there are other rewards, such as admiration from others, and seeing one"s loved one regain health. In fact, transplant professionals argue that donor benefit is the only ethical justification for living donation (Spital, 2000).

The expectation of reciprocal benefit is not always conscious (Farley, 1982) and might be buried deep within the context of family and interpersonal relationships (Rodrigue et al., 2006; Yi, 2003). For example, donors who are spouses and siblings receive the personal reward of seeing the recipient"s well-being restored (Yi, 2003). In addition, donors gain admiration from family and friends, and they fulfill a perceived moral duty (Corley et al., 2000; Johnson et al., 1999; Lennerling, Forsberg, \& Nyberg, 2003; Lennerling et al., 2004; Papachristou et al., 2004; Smith et al., 2004; Switzer, Dew, 
Butterworth, Simmons, \& Schimmel, 1997; Yi, 2003). Although these findings add to our understanding of donor motives, as noted above, it cannot be assumed that they explicate the motives of Black Americans to participate in living donation.

Donor decision-making models have been identified. Decisions regarding donation vary from those without any deliberation to a conflicted decision-making process (Hilton \& Starzomski, 1994; Johnson, et al., 1999; Schover, et al., 1997; Simmons et al., 1971; Yi, 2003). Conflicts may present as direct refusal, avoidance of the transplant center, or considerable ambivalence about donation (Hilton \& Starzomski, 1994; Simmons, et al., 1971).

Three donor decision-making models have been published: Moral, deliberative, and postponement (Simmons et al., 1977). Using the moral model, a person becomes aware of the need for a decision, accepts the moral norm, and perceives donation as an act of virtue or a moral obligation. The deliberative model involves a period of weighing the outcomes of each alternative and reaching a conscious decision. For instance, Swedish and Korean donors reported that they considered interpersonal, familial, and financial concerns before reaching the decision that donation was their only option (Lennerling et al., 2003; Yi, 2003). Changes in the socioeconomic climate, the increase in single parent families, and increasing geographic distances among family members contribute to use of the deliberative model (Hiller et al, 1998).

Within the postponement model, decision-making is characterized by avoidance rather than gathering information to make a decision (Simmons et al., 1977). A final decision against donation might result when the deliberative and postponement models are used. It is estimated that close to $30 \%$ of potential donors decline to donate for 
non-medical reasons (Stothers, Gourlay, \& Liu, 2005; Trevitt, Whittaker, Ball, \& FitzGerald, 2001).

The majority of donors in three studies reported making rapid and easy choices, and from this, the researchers identified use of the moral model (Hilton \& Starzomski, 1994; Schover et al., 1999; Simmons et al., 1977). Among 167 participants, 82\% reported making an easy decision to donate (Schover et al., 1999). Based on another sample of 130 individuals, 70\% reported using a similar decision-making process (Simmons et al., 1977). Ten out of ten individuals who participated in a grounded theory study also reported making rapid and easy choices (Hilton \& Starzomski, 1994).

Despite this apparent consistency, a consensus does not exist regarding the type of decision-making model that most donors tend to use. For example, findings from a fourth study $(\mathrm{N}=61)$ indicate that as many as $75 \%$ of donors use the deliberative model (Hiller, et al., 1998) and weigh alternative outcomes before reaching a decision. Participants in Norwegian and Swedish studies appeared to use a combination of immediate and deliberative decision-making, resulting in delayed announcement of their decisions (Andersen et al., 2007 [N = 12]; Sanner, 2005[N = 39]). Based on a study of non-donors $(\mathrm{N}=185), 31 \%$ of the participants indicated that they used the deliberative model, gathering information and evaluating alternatives (Simmons et al., 1977).

Again, there have been few Black American study participants, and specific decisionmaking patterns among Black Americans donors have not been thoroughly investigated. Based on the studies relating to decision making that were reviewed for this investigation, Black American participation ranged from 0 to 11\% (Hiller et al., 1998; Hilton \& Starzomski, 1994; Schover et al., 1999; Simmons et al., 1977). In a comprehensive 
literature review of living donor decision-making, the authors point out that these types of studies have been limited in scope, focusing on whether the donor would be willing to donate if they had to make the decision over again, and are retrospective in nature. Other study limitations include small samples, selection biases in favor of donors whose recipients had positive outcomes, and inconsistently reported findings related to racial and ethnic status (Nolan, et al., (2004).

Family dynamics can be affected by the decision to donate. The search for a living kidney donor can be a source of stress for families, involving sibling or parental pressure that effects family communication and cohesion (Simmons et al., 1971). Moreover, with a growing need for deceased or living donation in the Black American community, it is possible that family members of Black American ESRD patients feel increased pressure to become living donors (Truog, 2005).

Decisions relating to living-related donation appear to be family-based and take into consideration the overall effects on the family, not just the individual (Hilton \& Starzomski, 1994; Hiller et al., 1998; Yi, 2003). Family pressure to donate can be subtle, and many in the transplant community are naively unaware of the strength of such family pressures (Kallich \& Merz, 1994). Negotiation occurs among family members, and the complexity of the decision can be affected more by family member concordance than by the number of people involved (Hilton \& Starzomski, 1994; Simmons et al., 1971).

Most donors claim that they feel no pressure from family or the recipient to donate, but this is not always the case (Andersen et al., 2004; Jacobs et al., 1998; Reimer et al., 2006; Sanner, 2005; Schover et al., 1997). Many emotionally- or geneticallyrelated donors might feel obligated to donate (Franklin \& Crombie, 2003; Shelton \& 
Balint, 2001; Simmons et al.,1971). Particular difficulties have been reported in relationship to dominating recipients (Biller-Andorno \& Schauenburg, 2001), and women and men appear to be equally affected by this type of family pressure (Achille et al., 2007).

Unspecified family conflicts surrounding donation appear to arise in $10 \%$ of families (Reimer et al., 2006). Conflicted relationships with the recipients and conflicts between the birth family and family of marriage might account for some of these situations (Franklin \& Crombie, 2003; Schover et al., 1997). For instance, older children, siblings, and wives might feel obligated to donate (Jacobs et al., 1998; Sanner, 2005). In some cases, adult sibling donors might have partners who believe they should be more loyal to the family of marriage than their family of origin (Franklin \& Crombie, 2003). Accordingly, when White American middle-class men support their wives who donate to others, such as friends or family, the men perceive themselves to be "fulfilling their vows" (Taylor \& McMullen, 2008, p. 236).

Family pressure can be exerted by another person, or it can result from an intrapersonal sense of duty or guilt (Corley et al., 2000). Black sheep donors are persons who offer to donate a kidney to compensate for past family wrongs, and to restore their position in the family (Corley et al., 2000). In these instances, guilt and concerns about family disapproval have been noted as reasons for donating (Corley et al., 2000; Franklin \& Crombie, 2003; Simmons et al., 1977).

After donation, relationships with recipients, family cohesion, and donor status within the family might improve (Andersen et al., 2004; Fehrman-Ekholm et al., 2000; Jacobs et al., 1998; Schover et al., 1997). Researchers report that half of marriages 
involving spousal donation improve after donation, with the remainder having no change or negative changes (Teraskai et al., 1997).

Potential living donors can also be pressured not to donate. Based on a study of 536 donors, including 40 Black American participants, 14\% indicated that they were pressured against donation (Smith et al., 1986). This pressure came from both family and friends. These findings suggest that there might be a need to recognize the influence of a potential donor"s social network on the donation decision. Pressure not to donate, perceived by Black Americans, is explored in the current dissertation research.

Research findings relating to family dynamics and living kidney donation have been generated internationally, however, there has been minimal data collected from Black Americans (Andersen et al., 2004; Fehrman-Eckholm et al., 2000; Reimer et al., 1997; Sanner, 2005). Given the relatively small percentage of Black American participants (2.8\% [Jacobs et al., 1998], 61\% [Lunsford, et al., 2007], and 11\%, [Schover, 1997]) in studies about family aspects of donation, and the fact that Black Americans come to living donation as a minority group, their unique perspectives might be obscured within the context of White American perspectives.

The traditional approach to studying family life among Black Americans has been to define behavior among members on the basis of standards set by the majority White community (Johnson \& Staples, 2005). When facing the stress of kidney donation and transplant, Black American families might function in unique ways that can be misunderstood by healthcare providers using traditional approaches. Patterns of response to ESRD among ethnic and racial groups are thought to be different enough to warrant separate examination (Chesla \& Rungreangkulkij, 2001). 


\section{Ethical Issues and the Decision to Donate.}

Unique ethical dilemmas arise in association with living organ donation, because the surgeon risks the life of a healthy person to save or improve the life of a sick patient (Scheper-Hughes, 2007; Truog, 2005). Living kidney donation is the topic of the current dissertation research and the literature review is limited to ethical dilemmas regarding living kidney donation. Autonomy with informed consent, nonmalficence, and beneficence are frequently mentioned in the literature in regard to living donation (Aulisio et al., 2007; Kallich \& Merz, 1994; Olbrisch, et al., 2001; Steiner \& Gert, 2000; Walton-Moss, Taylor, \& Nolan, 2005). In the United States, the Living Organ Donor Consensus Group published practice guidelines which emphasize that true voluntary informed consent is necessary, and benefits to both the donor and recipient must outweigh the risks associated with donation and transplantation (Abecassis et al., 2000).

Autonomy is an issue of concern. Justification for living donation is often based on the principle of autonomy, the donores ability to make choices based on one s own reflection about alternatives (Beauchamp \& Childress, 2001). Three essential criteria of an autonomous choice include a person acting: (a) with understanding, (b) without influence that controls and determines their action, and (c) with intentionality (Beauchamp \& Childress, 2001). Without an autonomous choice, living donation would be ethically impermissible (Walton-Moss et al., 2005).

In the context of living donation, autonomy involves balance and decision-making capacity. A balance must be found between the donor's autonomy and the societal need not to inflict harm upon him or her (Gutmann et al., 1994). The way in which a donor's obligation to an emotionally-related recipient interferes with his or her autonomous 
choice must be explored. A genetic relative who says no to donation risks forsaking the potential recipient, their shared family of origin, and the potential recipient"s family of marriage (Bratton \& Griffin, 1994). Perceived pressure to donate among family members can even provide an argument for only accepting volunteer donors who are strangers (Veatch, 2000).

Autonomy may be viewed from a relational standpoint, seeing humans as interconnected beings rather than isolated individuals making decisions that affect only themselves (Biller-Andorno et al., 2001). Approaching autonomy from a relational standpoint might be pertinent to kidney donation, because families are intimately involved in the process. That said, a potential recipient's perceptions of family closeness $(\mathrm{N}=328 ; 61 \%$ Black Americans) does not appear to influence that person"s willingness to ask for a living-related donation (Lunsford, Simpson, Chavin, Menching et al., 2007). Informed consent is essential. Requirements for informed consent include information, comprehension, and voluntariness (Beauchamp \& Childress, 2001; Belmont, 1979). One"s obligation to provide information is not just limited to facts; it includes a duty to help potential donors understand the information, correct misinterpretations, and support well-considered judgments (Hilhorst, Kranenburg, \& Buschbach, 2007). Transplant teams vary widely in terms of the type of written information that is presented to potential donors, (Lennerling et al., 2004). Crucial issues, such as length of hospital stay, both short- and long-term donor risk, birth following donation, risk of graft loss, and uncovered expenses are often overlooked (Lennerling et al., 2004). Due to the emotional nature of the donation decision, facts that are presented might be distorted or ignored, which could impede full comprehension. In addition, perceptions of urgency could 
interfere with the charitable nature of donation, especially when the potential recipient is emotionally- or genetically-related (Lennerling et al., 2004). The phrase "myth of informed consent" has been mentioned in cases of donation between relatives because of the potential pressure that related donors might feel to alleviate the ESRD patient"s suffering (Gutmann et al., 1994, p. 356).

High-risk kidney recipients, those with significant medical issues other than ESRD, are at greater risk for serious adverse outcome such as graft loss or death. Donors for these recipients must receive detailed information about the increased risks during the process of informed consent (O־Hara, Bramstedt, Flechner \& Goldfarb, 2007). In such cases, the donor"s risk might be far greater than the recipient"s potential benefit, because the recipient"s medical problems may limit the graft survival.

Potential concerns for Black Americans include previous repeated violations of informed consent related to both treatment and research (Dula, 1994; Washington, 2006). In the past, experiments were performed on slaves without their consent. More recently, Black Americans perceived that family planning efforts were aimed at reducing their numbers (Washington, 2006). Other concerns include difficulty understanding technical and medical vocabulary, perceived lack of choice, and doubt about information relating to risks and benefits (Earl \& Penney, 2001). Black Americans $(\mathrm{N}=55)$ currently report that the purpose of consent documents is to protect doctors and hospitals from legal responsibility (Corbie-Smith, Thomas, Williams, \& Moody-Ayers, 1999).

Nonmaleficence is particularly relevant to living donation. Living donation appears to challenge the principle of nonmaleficence, which is also known as doing no harm. Reverence for this principle has led some surgeons to oppose any living organ 
donation, while others maintain harm is minimized by donor screening and evaluation (Olbrisch et al. 2001; Walton-Moss et al., 2005). The principle of nonmaleficence is not absolute and may be superseded by the expected benefit of a procedure (Spital, 2004). A traditional reason for acceptance of living-related donation is that donation occurs in the context of a family, and the choice for harm is mitigated by benefits to the family (Aulisio et al., 2007). In regard to unrelated donors, donor benefit is less clear (Spital, 2004).

More Black Americans than White Americans perceive that the principle of nonmaleficence has been violated in regard to their health care (Gamble, 1997; Washington, 2006). In a multi-ethnic study ( $\mathrm{N}=909 ; 57 \%$ Black Americans), Black Americans were more likely than White Americans to believe that their physicians exposed them to unnecessary risks (Corbie-Smith, Thomas, \& St. George, 2002).

Beneficence is an integral part of the ethical concerns. Beneficence is defined as the obligation to act in the best interest of the individual (Beauchamp \& Childress, 2001). In the context of the current dissertation study, the living donor is the individual of interest. This principle is connected to those of autonomy and nonmaleficence in two ways. First, the transplant team is obliged to accept or reject the potential donor based on the donor"s best interests (Walton-Moss et al., 2005). Second, the donor"s best interests must be balanced by his or her autonomy. Benefits to the donor can be seen as best interests and can counteract the temporary harm of the surgery.

Conflict of interest adds complexity. A conflict of interest exists between potential living donors and transplant professionals (Truog, 2005). On the one hand, professionals have an altruistic desire to help ESRD patients. Conversely, organ 
transplants are sources of revenue, research opportunities, and prestige for medical centers (Steiner \& Gert, 2000). The latter incentives spur professionals to perform more transplants, which can be in direct conflict with the potential donor"s autonomous choice regarding donation. Donor counselors and social workers have the role of taking a neutral stance to protect the potential donor"s right to decide without undue influence (Bratton \& Griffin, 1994).

Donor autonomy would appear to be the basic ethical principle in regard to living donation. But the principles of nonmaleficence and beneficence are important, especially in terms of donation by members of a minority community. Black Americans have historically-based reasons to be concerned about true informed consent. This concern can be expected to include living kidney donation.

\section{Summary}

The demand for living kidney donations among Black Americans is high. Despite this need, physical vulnerabilities and racial disparities within the health care system might inhibit donation. Also of concern are the psychosocial and decision-making aspects of donation that have not been fully explored among Black Americans. 


\section{Chapter 3: Methodology}

Comprising approximately $13 \%$ of the United States population, Black Americans are a minority population in a majority culture, and this impacts daily life as well as the extraordinary event of living kidney donation (U.S. Bureau of the Census, 2009). Quantitative research tools that have been validated in the majority culture might miss important aspects of the Black American experience (Corbie-Smith et al., 1999; Topp et al., 2008). For this investigation, use of qualitative methods minimized the researcher"s preconceived ideas in an effort to more fully explore participants" perspectives and to explicate the lived experiences of Black Americans who are living kidney donors to emotionally- or genetically- related recipients. The qualitative methods were influenced markedly by Benner"s interpretive method (Benner, 1994).

\section{Manner of Inquiry}

Within the context of this study, the unit of analysis is the transaction between the participant and the researcher, in the form of interviews and field notes (Koch, 1995). Participants were encouraged to describe what was salient to them, including as much detail as possible. The goal was to capture respondents ${ }^{\text {ee }}$ stories and interpretations of their experiences within the context of everyday practical understanding (Johnson, 2000; Packer, 1985). Two to three interviews with each participant resulted in progressive descriptions that were accessible to organization and thematic description (Packer, 1985).

\section{Researcher Reflexivity and Management of Bias}

In qualitative methods the researcher"s orientation is critical to understanding the topic under investigation. This refers to the physical, geographic, temporal, historical, cultural, and/or aesthetic orientation of the individual. When researchers understand 
themselves and their own biases and strengths, they are better prepared to learn from participants ${ }^{\mathrm{ee}}$ interpretations of the phenomenon under study.

As a White American middle-aged female, I have had limited experience with Black Americans. I have worked alongside Black American health care professionals and support staff. I have hired and supervised Black American employees, and I have cared for many Black American patients and their families. I have also had a few personal friends who were Black Americans. As a teacher at a Jesuit baccalaureate nursing program for the past ten years, I have developed collegial relationships with Black Americans in the community.

Based on my experience as a nurse, it is my perspective that Black Americans are often misunderstood by health care providers. Missed appointments, miscommunication, poor teaching, and lack of comprehension are all examples of such misunderstandings. I have no reason to believe that the process of living kidney donation is any easier for Black Americans than other encounters with health care professionals.

I became a living kidney donor for my husband in 1995. At the time, we had been married for 18 years. I had been a practicing nurse for over 20 years, and this was my first major experience as a health care consumer, aside from childbirth. During the process of kidney donation, I realized that while the transplant team was excellent at delivering physical care, they did not understand how to work with the living kidney donor, integrating psychosocial and physical issues. I am a nurse and I am comfortable with the health care system. If I felt misunderstood in this process, it stands to reason that a non-health care professional within a minority culture might feel the same. 
Review of the professional literature about living kidney donation heightened my awareness of several issues that Black American living kidney donors and their families might face. Such issues include, stress associated with the decision to donate, psychosocial effects of donation, post-donation health concerns, emotional costs of donation, and financial considerations associated with donation (Achille et al., 2007; Andersen et al., 2007; Bay \& Hebert, 1987; Bloemenbergen et al., 1996; Bratton \& Griffin, 1994; Clarke et al., 2006; Clemens et al., 2006: Corley et al., 2000; Gibney et al., 2007; Haljamäe et al., 2003).

Although my understanding of the professional literature provides background, adds substance to the inquiry, and enhances the validity of the study (Angen, 2000), it also contributes to my subjective prejudice (Gadamer, 1975). Thus, before beginning data collection, I documented my beliefs and values about living kidney donation in a research journal. These journal entries helped me clarify biases and interpret feelings and reactions influencing data collection and analysis (Smith, 1999).

Throughout the research process, I continued to document reactions and new insights about the experiences of Black American living kidney donors. This ongoing process of reflexive journaling created an accessible audit trail to enhance trustworthiness of the findings (Smith, 1999).

\section{Sample}

The setting for this study was a large Midwestern metropolitan area. Participants resided within urban, suburban and small city locations. The sample includes Black Americans, ages 18 to 70, who donated a kidney to an emotionally-or genetically related person. They were able to read, confirmed by self report, and verbally communicate in 
English-language interviews lasting 60 to 90 minutes. Efforts were made to collect data from both genders in a balanced way.

The sample includes eight participants, a number sufficient to capture the phenomenon of interest but small enough to allow for in-depth analysis. Two or three tape-recorded interviews were conducted in a private location at each participant"s convenience. After interviewing seven individuals, the data were reviewed and themes were identified. One additional male participant was recruited to help with gender balance and to determine if additional themes would emerge.

Recruitment of a purposive sample occurred in cooperation with the Abdominal Transplant Unit of Saint Louis University Hospital. Social workers helped to identify individuals who met inclusion criteria for the study and were willing to talk about their experiences as a living kidney donor. Transplant social workers contacted individuals by telephone to ask about their interest in the study, and they notified the researcher when it was appropriate to follow-up. I contacted interested people to describe the study in detail, and arrange a meeting at a time and place of the participant"s choice to further discuss the study and obtain informed consent. I used a snowball recruitment technique to access additional participants (Family Health International, 2009). In this process, I provided information about the study and asked if I could contact the potential study participant. If individuals agreed, I proceeded to meet the participant, obtain informed consent (see Appendix C), and start the interviews.

\section{Data Collection}

A structured data collection form (see Appendix D) was used to gather demographic information at the end of the first interview. These data include contact 
information, birth date, date of surgery, relationship to the recipient, and current health concerns.

An open-ended interview guide (see Appendix E) was developed with advice from my doctoral dissertation committee. The interview guide was designed to elicit comprehensive descriptions and stories related to the experience and context of living kidney donation. A qualitative interview guide is different than a quantitative questionnaire because each item or question might not be addressed with each participant (Yin, 2010). In addition, as participants talked about their experiences, additional questions were added to insure that full descriptions were elicited from respondents regarding the living donor experience (Benner, 1994).

I asked questions related to the: (a) chronological events leading up to donation, (b) context of the donation, (c) experiences within the health care system, and (d) postsurgery recovery period. Each participant engaged in two to three interviews. With each subsequent interview, the participants and researcher became more comfortable with each other, and further details about the donation experience emerged.

I have the living donor experience in common with the participants. When asked, I shared my experiences, but kept the focus of the interview on the participants. Briefly acknowledging commonalities between interviewers and interviewees has the potential to diminish interpersonal barriers and build trust (Benner, 1994).

Field notes were audio-taped as soon as possible following each interview, to preserve the context of the interview experience (Ulin, Robinson, \& Tolley, 2005). These notes included observations related to the participants (e.g., distracted, attentive, open to talking, restless) and contextual data about the interview (e.g., noisy 
environment, interruptions, interview starting late or ending early). They contain my thoughts about the progress of the interview and notes regarding topics for further investigation. The field notes are part of the each participant ${ }^{e s}$ electronic research file.

\section{Data Analysis}

Data for analysis included demographic information plus transcribed interviews and field notes. Descriptive statistics were generated from the demographic data. Qualitative analysis of the transcribed interviews and field notes was conducted in a series of iterative steps. The first step involved immersion in the data by listening to the taped interviews, reading the interview and field note transcriptions several times, and correcting the transcripts. This process helped the researcher gain a "global understanding of the story" (Benner, 1994, p. 113).

In the second step, interpretive summaries were developed for each participant (Benner, 1994). These were written after reading each interview text and field note for the first time. They were modified after subsequent interviews and as new understandings developed in the iterative data analysis process. The summaries were used to develop a complete synopsis of each participant's response over time, and reflected my emergent understanding of the data.

Another step of the data analysis process involved thematic analysis of the interviews to identify emergent themes or patterns (Yin, 2010). This step was accomplished without predetermined coding and focused on context, meanings, and concerns that surfaced; not on elemental units such as words or phrases. The aim of this analysis was to articulate broad understandings generated from reading and re-reading the interview texts. Codes were identified and formed into themes and patterns in the data, 
which were labeled. Memos were written for themes to indicate which codes comprised the themes. Codes were identified for all the data in at least two completely separate data analysis processes.

Qualitative software, ATLAS.ti, version 5.7.1, was used to facilitate data management (Atlas.ti, 2008). The transcribed interviews and field notes were downloaded, and journals entries and summaries were saved directly into ATLAS.ti software files. From there, codes and themes were identified, grouped, sorted, annotated, and memos were written. Search, hyperlink, and coding hierarchy functions were used to assist with data management.

After summaries were started for all participants, and themes or patterns identified, I reviewed the data for exemplars and paradigm cases. Exemplars are parts of stories that characterize common meanings that might be evident within interviews from more than one participant (Crist \& Tanner, 2003). Exemplars assist researchers to understand themes in varied situations and are intended to help others understand themes by providing contextual examples (Mischler, 1990). I examined similarities and differences among participants (Benner, 1994).

In contrast to exemplars (i.e., parts of stories), paradigm cases are particularly strong examples of the phenomenon of interest when considering the whole text of an interview or series of interviews (Benner, 1994). Several exemplars were identified in the data and found to be more useful than paradigm cases for explicating the experiences of participants.

Even though discrete steps were outlined, the data analysis process was circular and iterative in nature. I started with the whole, examined specific parts, and reexamined 
the whole to consider the influence of the specific parts. I compared the field notes, interpretive summaries, and exemplars to identify commonalities and differences (Benner, 1994). The iterative analytic process continued until I felt I had a clear understanding of the experience of Black American living kidney donors.

\section{Validity}

Validity in qualitative research is judged by the trustworthiness of the interpretation (Angen, 2000). Trustworthiness was enhanced by interviewing in a place of the participant"s choosing, by using a conversational interviewing style, and by conducting repeated interviews to expand on topics and clarify statements. Confirming understandings with participants helps to ensure that interpretations are faithful to participants ${ }^{\text {ee }}$ experiences. During the second and third interviews, participants were encouraged to read transcripts of their previous interviews, to further confirm understandings. I assisted them in reading the transcripts when they haed questions. Participants had no changes in the transcripts and four of the eight participants requested copies of the full interview transcripts for their personal records. One participant did not want the transcripts, but asked for a copy of the fully completed dissertation.

To enhance rigor, I maintained a reflexive journal throughout the research process. Reflexivity involves iterative examination of the researcheres perceptions in conjunction with the research data (Koch \& Harrington, 1998). The purpose of the journal was two-fold. First, making reflexive journal entries helps the researcher engage in an internal dialogue to enhance understanding of the participants ${ }^{\text {ee }}$ lived experiences (Smith, 1999). Second, journaling serves as a method of documenting study decisions so that an audit trail of the research process could be maintained (Smith, 1999). 
Reflexive journaling started prior to data collection and continued until the study was complete. Journal entries were made on days of data collection and on a regular basis throughout data analysis. An audit trail took shape that illustrates methodological and ethical decisions made throughout the study.

In keeping with the philosophical underpinnings of qualitative research methods, findings will always be partial and subject to the researcher"s biases (Gadamer, 1975). To counter this proclivity, qualitative researchers were asked for advice as data analysis and interpretation progressed (Benner, 1994). A group of qualitative researchers at Saint Louis University School of Nursing read de-identified texts of two different participants interviews and discussed them. This served to help uncover interpretations of the text that I might not have considered, due to my own biases. The two interviews were chosen because one described a donation experience with positive outcomes for the donor and the second participant was articulate about difficult situations she encountered, related both to her race and her health.

\section{Protection of Human Subjects}

Institutional Review Board Approval to conduct the study was obtained from the University of Missouri Health Sciences Center, Saint Louis University Hospital, and Saint Louis University. Approval from Saint Louis University was necessary because the researcher is employed at the University"s School of Nursing. Formal informed written consent was obtained from each participant before data collection.

Participants "etrue identities are only known to me as the researcher. Two pieces of contact information, participant name and contact phone number, were collected and are stored in a locked file drawer, in a locked office, on a locked floor. To maintain 
anonymity, codes were used to link study data to participants. Only the transcriber and I heard the audiotapes. The trained transcriptionist inserted titles to identify individuals such as son, wife, or pastor that were mentioned on the audiotapes. Study materials including audiotapes, transcripts, field notes, interpretive summaries, journals, and demographic forms are stored in a locked cabinet in a locked office, on a locked floor, when not in use. All computer files are password protected. The audiotapes will be destroyed two years after the research is concluded. The list of codes that links the participants to their true identities will be destroyed one year after completion of the study.

\section{Benefits and Risks of the Study}

The primary benefit for participants is that they are able to tell their story in detail to an interested listener (Benner, 1994). Living donors have expressed concern about the lack of recognition for the sacrifice they have made (Hilton \& Starzomski, 1994). Society might benefit from this study if the findings about the experiences of Black American living kidney donors contribute to improving the care such donors receive.

Risks to the participants included possible loss of confidentiality, inconvenience of participating in three interviews, and possible discomfort if participants chose to share sensitive information about their experiences. Being part of the study involved releasing participant contact information to the researcher. The list of participants, their contact information, and identifying codes for data analysis are kept in a locked file cabinet in the researcheres locked office, on a locked floor. Codes were used to identify the audio-taped interviews, and the transcriptionist was not aware of the participantse names. Pseudonyms were assigned to participants. 
The inconvenience of participating in three interviews was minimized by keeping the interview length no longer than 90 minutes. The day, time, and location of the interviews were chosen by the participants.

The participants occasionally experienced emotional discomfort when talking about particularly sensitive issues, such as instances of racial discrimination. Important to note is respondents were able to choose what they talked about, and their choices had no effect on participation in the study. When psychological discomfort occurred, I used interpersonal communication techniques to acknowledge the feelings of the individual and how difficult the experience must have been. My focus was on the participant as an individual and the treatment they received. I allowed the participant to explore details of the experience in order to validate the impact the experience had on the participant. In preparation for the study, I met with a prominent member of the Black American religious community. We discussed appropriate actions for addressing emotional distress among participants. Such actions included taking participants"concerns at face value, allowing participants to express their feelings without judgment, and communicating to participants that their experiences and their feelings are important.

\section{Summary}

Generic qualitative methods were used to illuminate the world of Black Americans who donated a kidney to an emotionally- or genetically-related recipient. Eight participants were recruited and interviewed two to three times. Interviews and field notes were audio-taped, transcribed, and analyzed using an iterative approach. Validity was insured based on repetitive interviews, reflexive journaling, participant review of their own interview texts, consultations with dissertation committee members, and partial 
data analysis by qualitative researchers. The anonymity of participants was protected through the use of codes, pseudonyms, secure data storage, and a plan for data destruction following the study. 


\section{Chapter 4: Findings}

Data analysis resulted in the explication of the experience of living kidney donation among Black Americans. Two overarching themes and ten themes are subsumed under this core process (Table 1). Subthemes are presented within the themes. The two overarching themes include the context of living kidney donation and the work of living kidney donors. The context of living donation relates to the background and daily life of participants throughout the experience of living kidney donation. Five themes of this overarching theme include the interpersonal milieu, the threat of ESRD, facing an uncertain future, spiritual and religious beliefs and values, and a continuum of caring by health care providers. The second overarching theme is the work of living kidney donors. This includes experiences related to the many tasks that participants completed during the process of living kidney donation. Under this overarching theme, five themes emerge: Making the decision to donate, preparing family and friends, enduring surgery and recovery, restoring an imperfect world, and making sense of the experience.

The experience of living kidney donation is temporal in nature and key events in the process are illustrated in Figure 1. A brief overview of the study participants is provided; this is followed by a detailed presentation of the experience of living kidney donation, including the overarching themes.

\section{Description of Participants}

The research participants lived in the Midwestern United States. At the time of donation, participants ranged in age from 30 to 52 years. At the time of the study 
interviews, they were 30 to 70 years of age. Demographic information is displayed in Table 2. Each participant is introduced using a pseudonym.

Jane is 51 years old and married. She donated to her son in 2004, when he suddenly developed renal failure of unknown cause at age 18 . She lives in a city with her husband and three children. Both she and her husband work full time.

Beth is a 37-year-old single woman with two children who donated to her mother in 2003. Her mother had diabetes and renal failure for many years. Beth lives in a small town with her mother and children. Her adult brothers live nearby with their families. Although Beth works in retail management full time, economic distress is evident.

Cheri is a 31-year-old woman, who lives in a suburban area. She donated to her husband in 2009. The marriage is less than two years old, and she has a son, aged 13. This was her husband"es second kidney transplant; his renal failure was a long-term condition. She and her husband work full time.

Gerald is a 52-year-old divorced father of three, who lives in a city. He donated to his sister- in-law in 2001, after she had several years of renal failure, with a failed transplant. She died from cancer six years after the donation. He described economic distress during the interviews, as his work in construction is not steady. He openly talked about a history of drug and alcohol abuse.

Rose is a 62-year-old married woman with four children, who donated to her eldest son in 1989. At age 19, he suddenly developed renal failure, of unknown cause. She lives in a suburban area and was working as a nurse at the time of the donation. Several years after donation, she developed renal failure, which led to a kidney transplant in 2008 . 
Marilyn is a 45-year-old married woman with three children living at home. She donated to her husband in 2005. His renal failure developed suddenly, of unknown cause. The family lives in a suburban area, and both she and her spouse were working at the time of donation.

Patricia is a 52-year-old widowed mother of three, who donated to her uncle in 2009. His renal failure was from long-term diabetes. She lives in a city with her youngest daughter and five grandchildren. Patricia is disabled and does not work outside the home. She is the primary caregiver for five of her grandchildren. There is economic distress in the household, and Patricia openly spoke about her history of drug abuse.

Robert is a 70-year-old retired Baptist minister and father of six. He is a widower and lives in a small city with his second wife. In 1974, he donated to his daughter, age 18, who was diagnosed with nephritis at age $7 \frac{1}{2}$. His daughter died from rejection within days of the kidney transplant. Many years after the donation, he developed renal cancer and required a kidney transplant.

\section{Context of Living Kidney Donation}

The themes in the context of living donation provide a background for the participants $^{\text {ee }}$ donation experience. Common to all research participants is the experience of being a Black American in the Midwest. The first four themes emerging in this context consist of the interpersonal milieu, the threat of ESRD, uncertainty about the future, spiritual and religious beliefs and values. The last theme is the continuum of caring and explicates context when participants have encounters with health care providers, including trust issues with those providers. 


\section{Interpersonal Milieu}

As participants described their experiences, the interpersonal background of their lives became apparent. At the time of living donation, participants ${ }^{\text {ee }}$ family circumstances varied widely. There are single parents, people involved in long-term marriages, newlyweds with step-children, and one widow. Participant donors elaborated on relationships with their potential recipient. Some families have extensive local social networks, having lived in the same area for decades. Others recently moved into the communities with many family members living far away. Subthemes include relating to the potential recipient, engaging in family and social life, support from community members, and support from church congregations.

There were ongoing relationships with the potential recipients. All participants described their relationships with the potential kidney recipient as generally good. They described strong family bonds, and mentioned sharing family activities, beliefs, and values with the potential recipients. The following paragraphs are examples illustrating the relationships between donors and recipients.

Cheri donated to her husband, and was married only 18 months when the donation surgery occurred. She had known of her husband's health condition for a few years. Her husband accompanied her to the first interview, and they described a close, loving relationship.

The relationship between Robert and his daughter was very close. She was diagnosed with kidney disease at a young age, and Robert drove her many miles to and from dialysis three times a week for over several years. 
Beth donated to her mother, with whom she lives. Her adult brothers and their families lived within walking distance, and she described regular meals and activities within the multi-generational family.

Gerald donated to his sister-in-law. He revealed that he had a history of substance abuse, which resulted in four years in prison. He alluded to difficulties encountered by his family during his years of substance abuse. Geraldes words demonstrated how a strong relationship through difficult times can connect a potential donor with a potential recipient:

She was one of the sister-in-laws that I always liked because she was a sweet, kind person. She didnet ever do anything to anybody, talk about anybody behind their back. They gossiped, I don't gossip. When I fell into the drugs and all that, she was the only one out of my ex-wife"s family that didn't turn their back on me besides her mother. All the rest of them looked at me like I was no good.

Patricia donated to her uncle and explained that he is "like a brother" to her. His mother died when he was young, and her mother raised him as her own child. They have a close relationship and keep in regular contact as adults.

Participants engaged in active family and social life. All of the participants have children, although not all of these children were living at home at the time of kidney donation. Participants reported varying degrees of family openness to the community about the renal disease and the need for kidney transplant. One participant did not tell her child's teachers about what was happening. Three participants were careful to inform all teachers about the donation and transplant events. One participant only informed close friends and her pastor about the upcoming donation surgery.

Participants described multiple social activities, including attendance at local school sporting events, and participation in tennis, softball, and women"s groups. Beth, a 
single mother, and Patricia, a widow, were involved in dating other single people. The minister had an active congregation, and he described his work with several youthoriented ministries.

Two participants donated to their husbands and report a closer relationship following donation. Aside from the two spousal donations, marital relationships did not seem to be affected either positively or negatively by the living donation. Existing arrangements such as step-parenting continued, but they did not seem to be affected by the living donation.

There was support from community members. Support from the wider social community was extraordinary for several participants. They reported being surprised to receive help from people they did not personally know. This is especially true for participants who had been longtime members of their communities. Beth received benefits from three community fundraisers that were held by her children"s school, her employer, and her church. This support was very meaningful to her, and she became tearful during the interview when describing it. Gerald had a colorful way of describing the community support. "It was beyond gold. People would bring me gifts and pies, dinners in my honor. We gonna have a party and throw a dinner for you. I'm like a star. People would tell me what a blessing I am."

General community support was not consistent for all participants. They recalled people who did not contact them or visit. Participants reported these people indicated that they heard about the need for kidney transplant, but were scared about what was happening and did not know what to expect. 
There was support from church congregations. All participants had been active in a church at some time in their lives. All but one was active in a church at the time of donation. Study participants reported receiving tangible and intangible support from churches in varying degrees. Tangible help included meals, assistance with housecleaning, laundry, and running errands following the surgery. Cheri reported her pastor "had us get up and talk to the church and tell the congregation" the Sunday before the surgery. In that way, all members in attendance were aware of the upcoming events for Cheri and her husband.

Intangible support came in the form of intercessory prayer, or praying for another person. Participants reported they knew that church members prayed for them and their families, both during services and privately. Participants described this knowledge to be spiritually comforting. For two participants, church members came to the hospital and prayed on the day of surgery. Jane reported that her pastor and his wife who came to the hospital on the morning of surgery. She found this especially strengthening from a spiritual standpoint and stated, "I had a peace." The last thing Jane remembered before surgery was the pastor praying for her in her hospital room, after she received the preoperative medication.

As a minister with an active congregation, Robert was prominent in his community. He described little support from his church before the donation surgery, but much support following surgery, after his (recipient) daughter passed away. He told of how they arranged the funeral, and that church and community members literally picked him up to carry him to the funeral and cemetery. He received substantial monetary 
support following his daughter's death and used the monies to build a church camp and community teen center.

There was one exception to the tangible help from a church group. Rose was active in her church, but received little support from the congregation or pastor. She informed her pastor and church members about the family crisis and asked for volunteer blood donors. No one offered to donate blood and few people offered to help. She speculated it was because they had little experience with serious illness in that congregation.

\section{ESRD Threatens the Family's World}

In the context of a family, the onset or exacerbation of serious illness such as renal failure can be disruptive. Participants ${ }^{\text {ee }}$ narratives illuminate how ESRD threatened the familyes everyday activities and their overall way of life, their world. The illness trajectory of their loved one included but was not limited to ambiguous physical symptoms, severely restricted renal diet, hemodialysis or peritoneal dialysis, multiple physician visits with unplanned hospitalizations, time lost from work, and general fatigue. Subthemes emerged concerning the disruption in family routines, and worries that "something could happen" to their loved one. Cheries words reflected the familyes threatened world.

So it was a constant, constant thing. He was in and out of the hospital every week, something was happening. So he was going back to the hospital and I had taken a leave from work, the first and second time he was in the hospital. So there was just all this different stress that was on us.

Family routines were disrupted. All participants described how the equilibrium of the family changed. Activities once taken for granted, such as taking a child to an after school activity, sharing a family meal, or traveling on vacation, were disrupted. All 
participants mentioned difficult personal and social experiences related to the illness and suffering of their loved ones with ESRD.

A shocking and sudden onset of renal failure was described by four of the eight participants. For these families, the sudden diagnosis led to rapid and unanticipated changes in daily routines. Two participants reporting a sudden diagnosis described that their families and friends went into "emotional shock," not knowing what to do or say, and unable to provide emotional or material support. The following exemplar illustrates how abruptly events occurred when renal failure was identified in Rosees son:

... she was calling to give me results, and the only thing that she said was „Get M. to the hospital right away. "So that's what I did, and we went to the admitting department and they, without notification or anything, was admitting him to a transplant floor.

Four participants reported that their loved ones had renal failure for many years, but it reached a point where transplant was necessary. Long-term accommodation for the ill family member allowed these families to achieve some degree of stability. When adult family members were on dialysis for many years, participants described how the rest of the family was called on to help with household activities such as cleaning, cooking, child care, and moving to live with the ill family member. Participants provided details about how families adjusted their activities around the illness, and how accommodations were made when the kidney transplant became inevitable.

There was concern "something could happen" to their loved one. As the ESRD progressed, participants described how the threat of death became apparent. This threat triggered worries about the future, concerns that "something" would happen to the ill family member. Participants spoke of being lonely and scared as they saw their loved 
one suffer, and they encountered the prospect of kidney transplant for that person. Gerald graphically described the suffering he observed in his sister-in-law:

...she was on her last leg. She had nowhere else to be stuck. She went through so many different surgeries getting what they call them grafts...put in her arms, her legs, her chest. She was just running out of places to get stuck.

\section{Facing an Uncertain Future}

Perceptions of an uncertain future were mentioned in conjunction with the inevitable need for kidney transplant. Participants recounted feelings of fear when facing the need for their loved one"s surgery. They described concerns about possibly dangerous medical interventions and they wondered about family outcomes. For Marilyn and Cheri, their husbands (potential recipients) were the primary breadwinners. They both expressed concerns about the family"s financial well-being if something happened to them. Anxious and frightened that his daughter would die without a transplant, Robert described facing the immediate necessity of living donation, "I got a situation here that it"s my move." In this theme, there were two subthemes - searching for living donors, and financial concerns.

All participants described the search for living donors as difficult. They mentioned how potential recipients were reluctant to ask for living donation. Of the eight participants, only two were the sole family members tested for donation. In both cases, there were other potential donors, but no one else offered to be tested, or openly refused to consider donation. One participant explained that none of the "blood relatives" in the large family had offered because they were afraid. Some family members offered to be tested and did not pass the medical evaluation. One person matched for donation but did not qualify because he "could not stop smoking weed." People declined to be tested with excuses such as having "a coffee shop to run." 
Participants reported that existing family relationships that were discordant or difficult remained that way. People promised things they did not deliver, and had excuses for not being able to help during this time of stress. There were ongoing difficult family relationships that might have prevented others from being tested. There were long-held resentments and difficult communication patterns. Marilyn gave details about communication with her (recipient) husband"s family:

I wouldn't say they were unsupportive, there was just an unreal . . there was just a silence. And there was such a silence for so long that I took it on myself to make a conference call and explain the situation, and I was told not to make the call by one of the sisters, ,don't do it, don't do it." I did it and still silence. So I think I'1l never understand it.

There were financial concerns. Financial data were not collected, but all participants spoke openly about financial concerns and the economic challenges they faced. As living donors, the participants volunteered to help a family member and did not initially expect to jeopardize their own financial situation. Economic issues arose, however, including the likelihood of time lost from work and potential job loss.

All employed participants lost time from their jobs, and not all were paid for the time away from work. Participants in two-income families relied heavily on both incomes and explicitly recall their financial worries. A single mother, Beth was holding down two jobs and was fired from one because they would not allow her time off for the surgery. Rose went through months of evaluation before being approved for donation and, during that time, was told by her employer that they would hold her job if she opted for surgery. She was laid off from her position before the surgery occurred. Even though Rose was a nurse working in health care, she perceived her layoff was related to the impending living kidney donation. 
After donation surgery, Patricia returned home to mounting financial concerns. The week before surgery, she had been given custody of five grandchildren because their mother, Patricia's daughter, was sentenced to several years in prison. In addition, she regularly cared for five other grandchildren. She had one adult daughter who helped her with the childcare, three days each week.

\section{Spiritual and Religious Beliefs and Values}

A consistent subtheme emerged concerning spiritual and religious beliefs and values. Each participant mentioned that they believed their God had something to do with their experience. There was one question in the interview guide about spiritual beliefs, but there was no question that mentioned "God" or a higher power. Participants described how they relied on spiritual beliefs to guide them through the living donor process. Narratives included subthemes of reliance on spiritual beliefs, and using spiritual and religious practices to cope with the experience.

Participants relied on spiritual beliefs. For most participants, the topic of spiritual beliefs first arose when describing how they made a decision to be tested for donation. All participants mentioned private, personal prayer as helping them discern their actions in the face of the family crisis. Jane"s statement was similar to all participants when she said, "This was what the Lord wanted me to do." Gerald had a more colorful expression, "God wanted to use me as a tool to keep her life going. I was the salvage car in the salvage yard; they took one of my parts and fixed her."

Participants were careful to acknowledge their spiritual foundation when describing the process of living donation. Beth stopped the interview to state, "The first 
thing I should have said was thank God, because He"s the one that saved my mom"s life, not me. He s the one that done it. Now I feel better."

More than one participant expressed thoughts similar to Marilyn, who stated, "I had turned it over to God and said, „Whatever you want me to go through. I' 11 do whatever you want me to do ee",

Participants used spiritual and religious practices to cope. All participants brought details about their spiritual practices, such as daily prayer, into the interviews. Reliance on personal prayer was reported by all participants to give them strength to deal with difficult situations they encountered in the process of donation.

At least two participants stated they do not believe that health care providers respected their spiritual beliefs. When her son was suddenly diagnosed with renal failure, Rose recalled that a physician told her, "Don't pray for the kidney, for it to rejuvenate itself, because it won ‘q." Regardless of his intentions, Rose saw the physician as trying to undermine her spiritual beliefs. She interpreted the physician trying to "take away" the support she could get from her prayers, when he did not even know her. She disregarded his advice, saying, "I've always listened to the voice of God, other than just people." Participants used their religious practices to cope, and three examples are presented. Advised to only take Tylenol for pain because of her substance abuse history, Patricia used her own prayer and that of her fiancé to help endure significant discomfort after surgery. Although she could have easily purchased illegal drugs, she relied on prayer for pain control. Rose spoke of praying to be able to continue with the living donor evaluation, when she perceived she was treated badly by the nursing staff. When his daughter died shortly after his donation, Robert described "anguish" and a spiritual 
crisis, wondering "why did God take her from me." He used prayer to help him through the worst days of grief.

\section{Continuum of Caring}

Findings in this theme concerned participants "experiences of caring behaviors by health care providers. When participants volunteered to donate a kidney they did not necessarily understand the amount of time they would be devoting to the process. Participants had many encounters with health care providers and gradually increasing contact throughout the donation experience. Participants described caring by the health care providers along a continuum from attentive, connected, and skillful care to their perceptions of providers exhibiting a deliberate lack of caring. References to caring were not limited to physicians and nurses, as participants noted activities by all hospital staff, and rarely identified individual disciplines. Data in the theme of the caring continuum sorted into two subthemes; communication and skilled tasks. Issues related to trust in the health care providers also emerged in the data and are part of this continuum.

Caring included communication. Throughout the donation process, participants recounted multiple experiences of communication, from learning about the need for transplant and living donation, through surgery and follow-up care. They reported communication that varied in completeness of the information provided, their level of understanding, and their perceptions of the overall effectiveness of health care providers ${ }^{\text {ee }}$ communication. Communication was reported to be most thorough early in the process, when preparing for living donation. Participants reported that communication problems mainly arise in their experiences during the surgical hospital stay and in follow-up care. 
Participants described detailed and thorough communication with health care providers when first learning of the need for kidney transplant in their loved one. They received information about renal failure, why transplant would help, and how interested people could be evaluated for living donation.

According to most participants, communication about pre-surgical information, including the risks of anesthesia and preparation for surgery, was thorough. Jane recalled, “. . . the young lady had came and explained everything to me and my son about the surgery." Beth received details about the surgery, how long it would take, the length of her hospital stay, and was given the option of epidural or intravenous medication for pain management. She described an evaluation process that lasted over three months and included orders to stop drinking soda, stop smoking, and watch any weight gain. Cheri described being told about "all the risks that were associated with it ... about the surgery and even some emotional risks that were associated with it."

In describing the living donor evaluation, participants included experiences of careful and complete communication with providers. Robert mentioned how a nurse helped him interpret the physicians ${ }^{\text {ee }}$ discussion during radiology testing. Rose related that a social worker listened to her and was "a real problem solver." Beth explained, "then you have to do, they take so many tubes of your blood and you're wondering why are they taking so many of them but they explained everything to me, what all the tests was." Patricia“s words were similar, "Every test I had, when I came back for the next test they informed me about the past test."

Participants mentioned effective and clear communication with providers during the hospital stay. In all cases, providers promptly informed participants about the post- 
surgery status of their recipients. Jane states, "They kept me informed about my son." Most communication from the providers was clear about direct patient care, such as obtaining vital signs, delivery of meals, and safe physical movement after surgery. Attentive listening was evident in Rose"s observation, "There was one male nurse who saw to it that I finally got the pain under control ... He was really fantastic."

Throughout the donation process, two of the eight participants described a feeling of being thoroughly informed by their providers. Gerald reported he had been well informed about what to expect in healing from surgery. He was not surprised by the degree of post-operative pain. Gerald found the providers"e advice closely matched his experience. He recalled that they told him "everything I needed to know ... They told me what was gonna happen ... they told me exactly what it was." He was told there would be a 10 year healing process, and he was gauging his full recovery on that timeline. Marilyn was the second participant who described satisfactory communication with her health care providers during the hospital stay.

Although many of the early communication experiences were helpful, participants also described how medical jargon interfered with their understanding. Participants used materials such as brochures and videotapes from the health care providers to help them learn about donation. Cheri stated, “... I had to go off and do my own research because the doctors were talking in their terminology, and it wasn"t making sense to me."

All participants described experiences early in the process of donation that led to miscommunication:

He tried to talk me out of it ...the one time I seen this doctor, he said if you really don't want to do it then you don't have to, we can just tell him that something is wrong or something. He really tried to talk me out of it; he said sometimes people do it out of obligation. 
In this case, the physician's intentions were to offer her a way to refuse donation, but Jane did not understand that. The physician did not communicate effectively enough to understand her interpretation of his suggestion.

Robert's decision to donate to his daughter was delayed because of miscommunication with the health care providers. From the physicians, he understood that a transplant would not help his daughter and, several years later, was told to get tested for donation as soon as possible. His lack of information was revealed in his words:

The way he spoke to me, ,Man don't you know if you all don't do something this child ${ }^{e e}$ gonna die ${ }^{e e}$... See, and I didn't know, and for me, I was waiting on them to tell me if there was something to be doing. You tell me what to do. I don't know what to do.

Communication about resuming daily activities, the degree and duration of pain, the healing process, and future health was not complete for most participants. Only three participants reported they received thorough advice about living with one kidney. Robert reported minimal communication, "They told me I would live a normal life." Rose recalled often being told she would have good health after donating, never receiving information about the possibility of renal failure. She stated, "There was nothing said about, with the question in mind about your health, you should be following up." Cheri mentioned, ". . . they didn't really talk about the problems I would have . . . do you have to change how you do certain things, and that never really came up." When asked about advice on future health, Jane responded, "I don't really remember being, as touching on that subject."

Additional gaps in communication include knowing how to talk with family, and unexplained delay in surgery. Participants reported they received no information about 
how to explain living donation to their family and children. More than one participant mentioned this would have been helpful in reducing family members"e anxiety throughout the living kidney donation process. For more than one participant, when surgery was delayed, the reason for delay was not well communicated and not well understood. Patriciaes surgery was delayed because her uncle (recipient) had more health problems. She recalled learning about this from family, not from the health care providers.

Communication by the health care providers related to participants ${ }^{\text {ee }}$ reports of post-operative pain was not consistently good. Marilyn recalled that the surgeon did not ask about her pain as he checked on her the day after surgery. Cheri believed the providers did not listen to her when she reported the pain medication was not helping and they continued to give her the same medication.

When participants realized they were not receiving complete information, more than one stated they thought they had to be "constantly on top of things." Every instance of encountering something for which they had not been prepared was disturbing to participants. Participants expressed concern about what would happen next and worried that harm would come to them during the process. They questioned if health care providers knew enough about the process of living donation to give them complete information. Cheri reported heavy reliance on her mother being present to communicate with the health care providers and be "sure things are done for me." Other participants relied on their spouses to advocate for them when communicating with the health care professionals. Robert elaborated, "They don't explain things to you anymore and those of us who are not medically trained, my wife had to ask questions." 
Three participants had laparoscopic procedures for removal of their kidney, and found three incisions, when they had been informed there would be two. None could recall the surgeons telling them about the extra incision or why it was needed, and they were "very, very shocked." Cheri states, "I was really surprised because they told me that I would only have two cuts ... I didnet realize I had the third one ... so I was really shocked by it." Beth expressed suspicion that they had taken "something else out" during the surgery.

Participants openly described what they wish had been communicated to them. Details about the degree and duration of pain, pain control measures, and accurate information about returning to work were identified as something they wished they had known. All participants wanted earlier contact with the surgeon; most met the surgeon for the first time the day before, or day of surgery. One participant wanted more communication with the anesthesiologist, as she met that physician just before being put to sleep.

Rose wanted to be better informed about the side effects she experienced from the evaluation testing. In addition, Rose wanted to be told more about the need for prolonged follow-up. "I wish they would"ve been more straightforward as far as what possible repercussions would happen as a result of donating and encouraged more followup." She expressed wonder about people who might not understand the importance of staying in touch with providers, or the risk of losing function in their remaining kidney. Robert expressed regret that the physicians did not provide more detail about what could happen to his daughter (recipient). "I asked them suppose this kidney fails, it 
doesn't work, what"s our recourse? They said, ,it"s no problem, we go back to dialysis .". His daughter did not return to dialysis and died.

Cheri wanted more advice about the healing of her incisions. One incision opened up and she had not been informed that could happen, or what to do if it occurred. In addition, she wanted more accurate detail about the length of time until she could tolerate general household activities. She had been told she would be back to normal activities by the second week. "What I noticed happened was that the second week, I noticed myself starting to get depressed because I couldn't do the things that I had already thought in my mind that I would be doing by the second week." Patricia wanted more explanation about the procedure of going from "Point A to Point B." She had several ideas about possible support services, including an arrangement for potential donors to talk with experienced donors. Her choice of words was notable as she elaborated on the assistance she could have received:

I would 've learned the maintenance of the recovery, the state of the recovery, and I would 've also learned some of the dos and don'ts of the recovery. That"s all I needed. Plus I would "ve had somebody to call in the process of my recovery. If they would 've had something like that going on, I would 've been able to call them. ... Don't leave us out like that.

Caring included skilled care and skilled tasks. Participants"e experiences in the continuum of caring included reports of skilled care they received and skilled tasks that were performed on their behalf. Reports of skilled care and skilled tasks ranged from the basic bathing and repositioning of a patient to complex surgical procedures. Such tasks and care were described by participants beginning with the living donor evaluation and continuing through the surgical hospital stay, and post-surgical follow-up. 
Participants frequently referred to skilled care they received during the living donor evaluation process. Throughout the evaluation, some participants expressed belief that health care providers provided skilled care that focused on their well-being. This belief was reinforced when they were seen promptly, the correct test was performed, and service was provided in a courteous manner. Participants expressed a growing sense of confidence in their donation plans when they received skilled care. More than one participant stated that "things would work out for the better."

In contrast, when tests had to be repeated due to errors, participants" positive impressions of skilled care diminished. Several participants reported experiences in which tests were repeated without explanation. Such events made participants question if the health care providers "knew what they were doing."

During the donor evaluation, three participants described what they interpret as a deliberate lack of skilled care that left them with a sense of being treated as an object. This occurred for two participants when they were physically exposed in the presence of two or more health care providers, and not offered a drape. Marilyn stated that she felt like she was "treated as a model or a cadaver." Robert emphasized, "I am a modest man, and they left me with no clothes on.”

The third participant to report a deliberate lack of skilled care was Rose, who described feeling overt racial discrimination when the nurses did not clean stool from her body following an angiogram. A renal angiogram involves needle insertion into the femoral artery in the upper thigh, near the groin. Following the procedure, a patient must lie completely still with a weight on the insertion site for several hours, so an adequate 
blood clot forms. Rose had to call her husband to have him come to the hospital and physically clean her after the procedure.

So I was in the bed, and I was left like that, and it was like their nose was turned up at me, and it was like they didn't want to touch me. I would ring the bell, no one would come. I thought somehow I have to get to the phone and call my husband. So I just kind of like pushed the bed over to the phone and finally I could reach it without moving where I had the femoral puncture. And I called him, and he"s the one who cleaned me up. ... It was important because it really devastated me. It was a mental trauma to me to this day, actually. No, that was something I kept in because I felt it was racial. I felt very humiliated, very violated, very. I just felt really bad about that whole situation. . . I do think if it had been a white woman in that situation, she would have been treated differently.

The hospital stay narratives contained many stories of skilled care. Examples included providers that were attentive in surveillance for surgical complications, from the recovery room through hospital discharge. Participants reported skilled care and skilled tasks performed by nurses that were responsive to their needs; they felt safe with the skilled care related to medications, intravenous lines, and personal care. Marilyn expressed the sentiments of most when she states "everything just fell in place." Patricia recalled "there was a good nurse that would come in and bathe me ... she was just great."

While participants reported many episodes of skilled care and skilled tasks during their surgical hospital stay, that was not evident for all. Participants spoke about hospital staff that did not wash their hands before or after providing care. Following surgery, Cheri had prolonged vomiting and was discharged before the vomiting subsided. Two participants described an attitude of, "we "ve done this so many times, it"s routine," from the health care providers. These participants related the impression of being on "an assembly line.” Beth described panic during insertion of an epidural catheter and 
perceived a lack of concern by the physicians when she had a "spinal headache" lasting several weeks. Jane did not receive any food the day following surgery, although she asked. "I kept telling them I hadn't eaten anything that day ... I don't know what happened ... but they actually forgot about me that day."

Once participants were discharged from the hospital, they had limited interaction with health care providers. Positive descriptions of skilled caring and skilled tasks subside as a thread in the interview data. For participants who sought care before their scheduled follow-up appointments, perceptions of less than optimal caring continued. Participants described that providers "didnet have time" for them once the donation surgery was complete. About 10 days after hospital discharge, Patricia experienced chest pain and sought care at the emergency room. She identified discrimination that she interpreted to be of a racial nature:

I had been at the hospital since something like 12:00, and it was almost 7:00 at night. So they finally brought the charge nurse out and I"m asking her, „Ma"am when is somebody gonna see me because I"m in a lot of pain, plus I done had a kidney taken out and I don't know what the problem is ${ }^{e e} \ldots$ and she said, ,Well, what do you want me to do, bring you a stretcher, a wheelchair, or a doctor into the ER? ? . . I ended up calling the transplant line, and they ended up calling her and 15 minutes later I was in the back ... I thought that nurse should 've been fired but due to, she probably been there a long time and all that, and she Caucasian. Guess what? She can say what she want and go back to the back desk and sit back down, that"s how I felt.

Trust issues arose. All participants recounted experiences related to trust in the health care providers. In order to even consider donating their kidney, they expressed trust that living kidney donation would help their loved one with ESRD. Jane revealed this basic trust, as she talked about her eighteen-year-old son, “. . . the doctor told him that his best bet was having a donor, and so me and my husband both was tested." When considering living donation, Beth stated, "I thought I"d be feeling like I"m feeling right 
now eight weeks later, which is fine and healthy." It took her longer than eight weeks to feel that way.

As participants spoke about moving through the living donor evaluation, preparation for surgery, and the surgical hospital stay, issues of trust emerged in their narratives. Participants described a sense of trust that is fragile, and experiences either build the sense of trust or undermine the effect of positive, trust-building interactions.

In the living donor evaluation, some participants expressed the sense that the health care providers were accessible and their advice was reliable. Participants described feelings of trust that the health care providers have their "best interests" in mind. During the evaluation, participants described trust being built by basic functions such as efficient performance of tests, being seen promptly at time of appointment, and thorough information about the evaluation process. This reinforced to them that they were doing the "right thing." Cheri reported thinking "they know what they"re talking about."

However, experiences were reported in which some participants were given incorrect information about specimen collection. Little explanation about the tests, combined with extra time and travel for the repeat tests, tended to undermine trust in the health care providers. Patricia described repeated tests for sexually transmitted infections, and wondered why it was thought she would contract an infection when she was preparing to donate a kidney. Beth was told that she did not qualify to donate due to the results of one test. When she discovered she had been misinformed about specimen collection, she insisted on repeating the test and she passed it. She expressed concern that someone did not want her to qualify to donate, so she was not completely informed. 
Through the hospital stay, both trust-building and trust eroding experiences were mentioned. Gerald had a strong impression of trust. He stated, "I felt they was doctors and they didn't get to be a doctor overnight ... so I know they had a high number success rate." Marilyn mentioned, "I had full confidence in them." When participants were well informed about what to expect, and their experiences met their expectations, trust in the health care providers grew. For example, participants were informed about the length of surgery and that they would awaken in the recovery area. When the surgery lasted as long as expected, and they awoke in recovery, participants expressed a sense of trust.

In contrast to trust-building, six of the eight participants described being surprised by the degree and duration of pain after surgery. Participants wondered why they had not been informed before surgery that the pain would last so long and be so intense. They expressed suspicion that the providers had purposefully not told them "everything," so they would not decline to donate. One donor suspected the providers had deliberately not told her the "real healing time."

In the following situation, a key element of trust was reliability or reliance upon something. Health care providers recommended to Rose that she and her son arrange for directed blood donations, in preparation for the surgery. Directed donation was considered to be a safer source of blood and an assurance that blood would be available if needed, during a time of blood shortages. They made the necessary arrangements for friends and family to donate. Her son needed blood transfusions after surgery, but the directed donation blood was not used. Rose"s words include genuine disappointment and weakening trust. "... he got 13 units of blood without us ever knowing about it. That upset me. That upset me ... they didn't even use it." 


\section{Work of Living Kidney Donation}

Participants faced many tasks once they decided to donate a kidney. An overarching theme was the work of living kidney donation. Donor work consisted of five themes: Making the decision to donate, preparing family and friends, enduring the surgery and recovery, and restoring the family ${ }^{\text {es }}$ world. Lastly, the work included reflectively making sense of the experience.

\section{Making the Decision to Donate}

Once the pressing need for kidney transplant was recognized and fully understood, all participants considered the possibility of donating. Data relating to the decision to donate a kidney were categorized into two subthemes: Learning about donation, and deciding to be tested.

Participants had to learn about the living donor evaluation. Participants reported being deeply aware of the suffering of their loved one, but they knew little about kidney transplant or living kidney donation. Before offering to donate, only one participant, a nurse, reported knowing much about living donation. The participants had little in their worlds that they could draw on for coping with this particular experience. Seven of the eight participants stated they were only aware of cadaver or deceased donation. None of the participants personally knew a living donor for any type of organ. Marilyn"s thoughts were similar to others, "I had never heard the word renal before. I"d heard of the Kidney Foundation, that's all . . I had no idea. I didn't know a thing about it."

There was a process of deciding to be tested for donation. Each participant described a point when they thought it would be "selfish" not to be tested for donation. The decision to be tested was immediate for five of the eight participants. Both Jane and 
her husband were approved for donation, and they decided she would donate. He brought more income into the household than Jane. Jane stated, "We needed him for other stuff."

Two participants described spontaneous decisions to be tested. Both made public announcements about their decisions, one at a church service, and one at a family reunion. Gerald was in a church service when the pastor stated that his daughter needed a kidney donor. Gerald made the offer of a kidney in front of his wife, in-laws, siblings, and other church members. Patricia was at a family reunion when her uncle told everyone he would need a transplant. Patricia described how she offered her kidney, "He said dag, I think I might need a kidney. I said dag, I think I might be the one that donate it to you."

All parental donors did not seem to think the offer to donate was anything outside of what would be expected of any parent. For two parental donors, the decision to be tested was immediate. Rose expressed her viewpoint as, "He"s my son. I need to take care of him; this I can do for him.” She wondered why any parent would not be tested for donation.

Three participants delayed their decision to be tested, and their experiences differed substantially from one another. The delays include outright reluctance to donate, miscommunication with health care providers, and waiting for other family members to offer. Beth was forthcoming in saying she did not want to donate and found the decision to be "very hard." She waited until others in the family were tested and not accepted, before offering to donate. Robert described a delay that involved miscommunication with health care providers about his daughter"s eligibility for kidney transplant. 
Marilyn waited a year and a half for one of her husband ${ }^{\text {ee }}$ siblings to offer to donate.

Her exemplar illustrated the delicate communication when there was no willing donor among his siblings.

I actually thought someone in his family would just automatically come forward. It was just a lot of misconception, and they just drew back . . . he had two eligible sisters and nieces and nephews . . . and so we were kind of waiting, and I was just kind of waiting on a personal basis. I was just really kind of waiting, and it got down to about a year and some months and . . it its a real sensitive subject. Once you 've asked, the subject has been broached so, to ask again, realistically it's not something you want to do.

Once they decided to try and donate a kidney, participants had a general momentum towards surgery, a goal. They were focused, and they were "not going to let anything stand in the way" of their donation. More than one participant described the driving force of wanting to "save the life" of their potential kidney recipient.

Participants expressed concern related to the evaluation procedures and health issues that might be discovered during the exams. For all participants, the living donor evaluation included multiple blood tests, psychological evaluation, a general physical exam, and a renal angiogram. For at least three participants, it also involved collecting a 24-hour urine specimen.

The evaluation occurred over several weeks or months and involved time taken from work for seven participants who were employed. They described problems getting approval for time away from work to be tested. Participants reported a lack of concern on the part of health care providers about the time they invested in the medical evaluation. None of the participants received support for time or travel expenses related to the living donor evaluation. 


\section{Preparing Family and Friends}

Participants described their actions as they moved toward the donation surgery. They report it was necessary to inform family and certain friends about the expected events. There were two subthemes: Encountering support and objections, and preparing the household.

Participants encountered support and objections. Once the decision was made to donate, participants informed others. In most but not all cases, verbal support from the family was easily forthcoming. The offer to be tested was viewed as an immediate solution to the problem of ESRD that threatened the family. Participants recalled family members using phrases such as "going to save Grandma," and "super Dad," or "greatest hero" when talking about their offer. Beth and her family had considerable financial stress, but she described long distance phone calls that her mother made: "She called all the family telling them about it, and they even talked to me and told me they was proud of me doing that."

Participants reported trying to anticipate the responses to their decision. When Cheri expected her grandmother would not approve of her decision, she deliberately withheld information. Janees mother-in-law was in poor health, and the family did not inform her about the situation until the surgery was over. Aside from family, Marilyn reported she only informed very close friends that she expected to be supportive.

Not all participants had entirely positive reactions to their decision to donate. Patricia, a widow, described family members who were "ecstatic." This contrasted with her significant other, who expressed concerns about her health after donation. In addition, her children expressed reservations: 
My oldest was the voice for all of them, and she said that it was selfish and inconsiderate. That they had already lost my husband, which was their father, and I never, ever even gave them an opportunity to voice their opinion on the matter.

Work included preparing the household. The work of living donation continued with preparation of the household for the hospital stay and the recovery period. Employers were notified about the planned living donation and paid or unpaid leave was arranged, with anticipated changes in household income.

If the recipient was a child living with parents, donors reported decisions about who would be the primary caregiver for the recipient. When the recipient was a spouse, participants made plans for both adults in the household to be incapacitated for a few weeks. Participants described arrangements they made for childcare, shopping, laundry, and other household chores in the days following the surgery.

Female participants tended to express more worries about the familyes well being during the hospital stay. Female participants reported how they planned for the surgery in great detail, buying groceries, freezing meals for future use, and arranging transportation for children's activities. They reported reliance on their past experiences in household management to project future needs for the weeks following surgery. They explained how the extent of their household preparation helped following the donation surgery. In contrast, the male participants described their preparation for time away from work, and did not express concerns about family activities during their hospital stay.

\section{Enduring the Surgery and Recovery}

Participants reported entering the hospital the evening before, or day of surgery. Their hospital stays ranged from two to five days. Findings in this theme were related to experiences as inpatients and in the first few days at home following surgery. Three 
subthemes were identified: Experiences of pain, learning about their recipients ${ }^{\text {ee }}$ condition, and returning to daily activities.

Living kidney donation hurts! Living kidney donation is known to be painful and participants had much to say about their post-surgical pain. Participants tended to be surprised at the extent and duration of the pain.

Five participants had epidural catheters with patient controlled analgesia (PCA) pumps that worked well and needed little nursing attention. However, two of the five described hallucinations, including Beth who saw a "nurse angel."

Reports of intense surgical pain were more prominent among the women participants. All female participants had been through childbirth more than once, but they described the donation surgery as the worst pain they had ever experienced. With childbirth, they "knew the pain would go away." With kidney donation, they were not certain that the pain would subside.

The male participants did not find donation to be their worst pain, although they expressed surprise at its intensity and duration. The men had memories of greater pain in the past. Gerald broke both ankles and found that orthopedic rehabilitation was more painful. Robert recalled a toothache, with increasing pain intensity, as his worst pain. The pain experiences of three participants warrant special exposition. During evaluation, two participants with history of substance abuse were determined to be healthy enough to donate a kidney. Marilyn, the third participant, experienced a transplant coordinator's reluctant pain control care, in spite of race concordance.

Patricia was told by her surgeon that she could not have prescription pain medications because she was a recovering addict. Her epidural PCA pump was removed 
within two days after surgery, and she was discharged the following day. She experienced severe pain after returning home, but had no prescription medications for pain relief. When asked if she thinks the surgeon treated her differently because of her race, she responds, "No, I think he did it because he didn't know better. Because when we look at drug addicts we don't look at them with a healthy eye."

Gerald has a history of substance abuse, yet was able to pass the living donor evaluation. He reported he did not feel pain until about 10 days after surgery, and the prescribed medication did not help. He used crack cocaine for relief stating he knew it would control his pain "better." He continued to use the illegal substance for two years, as he worked in the construction industry and "never felt an inch of pain." At the time of the interviews, he has not used drugs for five years and regularly attended Narcotics Anonymous meetings. Gerald did not reveal his post-donation cocaine use to the transplant health care providers.

Being of the same racial background did not promote effective pain control for Marilyn when her Black American nurse was "very apprehensive" to give her a prescription refill, cautioning that the pain medication was addictive. Marilyn has no history of substance abuse, and did not smoke. She reports feeling "unsupported" when she had pain lasting longer than she expected. "I don't think she understood the level of pain ... I remember that not being a good thing."

Participants learned about the condition of their recipients. All participants described worry and uncertainty about the surgical outcome for their recipients. Participants reported their recipients "looked healthier" when they were able to see the recipient within hours after surgery. Each participant expressed feelings of relief, upon 
learning that the donated kidney was working well in their recipient. Robert expressed the sentiments of several participants when he recalled that the nurse told him his kidney was working for his daughter. "That"s when I knew that my mission was completed. I had given my daughter life, to sustain her life."

For three participants, feelings of relief changed as complications developed. Patricia"s uncle was admitted to intensive care with blood pressure problems, and Robert"s daughter developed rejection complications. Rose"s son developed a viral infection with internal bleeding and required blood transfusions. They described the burden of worry as heavy, while they, themselves, were trying to recover from surgery.

Returning to daily activities was important to participants. All participants expressed a sense of urgency to restore their family"s world; to return to activities of daily living and general family routines. All but one participant thought the advice they received about returning to daily activities was inaccurate. Cheri clearly recalled advice from the health care providers. "They actually told me I would be out for two weeks ... by the end of the first week, I knew there was no way and I was really shocked at that information that they gave me."

Participants admitted they had unrealistic expectations such as wanting to drive or return to work outside the home too soon. An example of unrealistic expectations was that Patricia asked me about joining a 75-minute aerobics class because she was feeling "flabby" nine weeks after surgery.

In the first few weeks after surgery, three participants described feeling depressed, although none reported this to their health care providers. The depressive thoughts faded for two participants as they became more active. Robert was the only 
male who reported feeling depressed. He described his depression and grief while trying to understand what had happened when his daughter died.

All participants noticed lasting physical changes following donation and surgical recovery. The changes ranged from lingering pain and limited flexibility to failure of their remaining kidney and the need for a transplant.

\section{Restoring an Imperfect World}

Participants described the ways living donation helped to restore the family"s world that had been threatened by ESRD. Narratives included subthemes with details about resuming family routines and relationships, and renewing both work and social connections.

Participants worked to restore family routines and relationships. Participants had much to say about family life after surgery. It was clear that they perceived restoration of family routines as essential to the process of donation. Participants described how important it was that their children know there would be no more unexpected trips to and from the hospital and that the upheaval in the family schedule was over.

All participants described striving to return to family routines as comforting and strengthening after the stress of donation and transplant. Family routines were especially important to Robert, as his family coped with their daughter"s death. Participants recalled a focus on events such as Thanksgiving, Christmas shopping, and children“s sports.

Marilyn worked hard to restore family routines. Even though her interviews occurred four years after donation, she carefully recalled details of being with her son: 
I remember this so vividly. My son ...was probably 14-15 at the time. It was Christmas ... and I so wanted to go shopping with him. So I remember him wheeling me in a wheelchair ... and I just remember, man, for him to be doing that, in a wheelchair with his mother, and I'm not really even shopping. It was just part of the thing that we went shopping ... and it was just something we did every year. We just went Christmas shopping, and we really didn't buy anything. We never really buy a lot; we just go and enjoy the hoopla.

Female participants were expected to resume family responsibilities, and several received minimal help from family members. Husbands helped with housework but tended to leave participants alone most of the day in the first few weeks post-surgery. The male participants received much family support and did not describe worry about meals and housework during recovery. They described feeling pressure to return to the family breadwinner role soon after surgery. All participants expressed impatience about being "off the job" while recovering from surgery.

Restoration of family routines encompassed supportive and non-supportive relationships. Family discord that was present before surgery did not stop with the donation. For some, the promised support from family members did not materialize. Cheries sister-in-law promised to help after surgery, but did not come around for five months. In the following exemplar, general household commotion and family discord was evident as Beth defused an argument while trying to resume the routine of an afternoon nap:

My brotheres girlfriend, she took off a whole month to stay there with me to cook and clean and watch my kids. But that didn't turn out so well because she did it for a couple of days, cooked and cleaned ... My younger son and my brotheres girlfriend, they had got into it. She was dragging him across the floor, and my older son told her that was enough, that she wasn't going to be dragging his brother across the floor, and if she does it again he was going to hit her. I'm like, "Come on you all, we can't be having this . . she ain't going to be dragging him, you two ain't gonna be fighting. Leave him alone, 
I"ve got him." So I got him in the bed, and he lay down with me and took a nap. She (the brother's girlfriend) didn't stay long.

Participants who perceived they needed more support from their families expressed anger and disappointment at the lack of assistance. Three participants had sentiments similar to Patriciaes:

I had totally felt, I don't know, I felt betrayed. I felt like they done me, you know. I was like wow. It s not an easy thing to do. It's depressing, it ie $^{\text {ec }}$

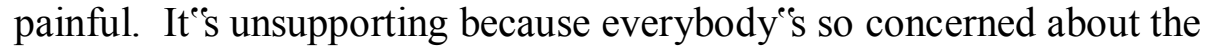
recipient. They forget all about the donor. You know, it's like the recipient is in so much pain, the recipient been waiting so long. Oh, God finally blessed you. What about the person that done lost something? They just leave them hanging and dangling like you did what you re supposed to do. No, I didn't supposed to do that. That was something I did from the kindness of my heart. I didn't supposed to do anything. And it can get real ugly, it can become a real ugly feeling, the recipient get too much attention to me, and the donor just left like, oh well, it's over, see you later, bye, bye.

Participants renewed social and work connections. The male participants recalled feeling pressure to return to work, but admitted this was pressure they put on themselves. Robert supplemented his minister's income with work in youth education. He reported that he returned to work and was sent home by his supervisor, because he was not physically ready to work a full shift. Although Gerald received a grant from the National Kidney Foundation to cover lost wages, he reports returning to work early. Gerald described using crack cocaine in order to return to his construction work. He used the illegal substance for two years with resultant marital discord, divorce, and family dysfunction.

Beth was advised by her surgeon not to return to her job at a nursing home and had trouble finding another job. As soon as potential employers learned that she had kidney surgery, notwithstanding that it was for kidney donation, they did not make her a job offer. 
Participants described renewing social connections through visits from friends and family. An activity as simple as friends sitting together with them was described by participants as deeply restorative and uplifting. Marilyn related that she was careful to take pain medication before friends visited, so they would not see her in pain.

\section{Making Sense of the Experience}

Participants offered reflective observations about the process of donation and the work they accomplished. A theme emerged about how participants make sense of the experience. In subthemes, they offered advice for other potential living donors, talked about their future health, explored their second thoughts, and described drawing personal meaning from living donation. Lastly, participants offered observations about the moral obligation to donate and "the good" of donating a kidney to a loved one.

Participants had advice for other potential donors. They varied when describing advice they might give to a potential living donor. Marilyn said she would not advise another person to donate, but would suggest they think about it and learn more before they make a decision for themselves. She had been called to give advice to someone in her network of friends. She told him what happened to her, to expect that people tend to focus more on the recipient than the donor, and that the donor goes through "far more discomfort" than the recipient. He later thanked her for the accurate information.

The other seven participants would advise people to donate, although they had reservations. Jane's statement reflected the comments of many when she says she wanted potential donors to know about the work of donation, "it"s something not to take lightly, to really think about it, everything that it involves and how you wouldn't be able to go to work, and you would have pain and stuff and you would have to do some recovering." 
Participants were looking toward future health. Even though few participants could recall being given detailed information about life with one kidney, they did not express feeling overly frightened or worried about this possibility. Four of the eight participants reported no particular worries about their health. They took an approach of being careful and expect no future complications from the donation surgery. Jane and Marilyn had a deliberative, practical approach to the donation and stated they purposefully did not dwell on health concerns, because they wanted to donate and get it done. The remaining four participants expressed worries that ranged from general uncertainty about health with one kidney, to specific concerns about diet, medications, disease, and activity that would damage their remaining kidney.

Second thoughts were rare. During the initial interviews, participants tended to describe their progress toward donation in a positive light. However, they also expressed hesitancy and doubt during the second and third interviews. One participant initially stated she was only concerned about her age, but in later interviews spoke openly about how unsure she was about the surgery, her future health, general household finances, and how she would pay bills during recovery from surgery. Most participants stated that they did not have long-term regrets about their donation. Even those who faced later health problems or the death of the recipient expressed no regrets. Gerald used a sports metaphor, "I had no turnbacks, it was all gold, all go, everybody was there, it was like getting in the ring, and all my family there..."

In contrast, regrets were expressed by two participants. Beth regretted the donation, but would do it again. She perceived the donation as changing her life course and sees herself as not able to "run and rip with the kids" like she used to. As a single adult, she 
described losing a relationship with a man during the donation process. He said she was spending too much time with her family, and she recalled that lost relationship as the loss of a potential life partner.

Patricia was interviewed within five months after donation and had second thoughts. She felt left out - people in the family were not helping her, she had serious financial concerns, and she was in great pain. Her words revealed her doubts, "I started thinking I should"ve never did it."

Participants draw personal meaning from living donation. Regardless of the difficulties with care, trust, and pain; all participants expressed a sense of gratefulness that they were able to donate to their loved one. Most of them drew personal meaning from their donations. This ranged from simple appreciation of everyday activities to deepened interpersonal relationships among family members. Cheries words expressed the sentiments of many:

For me to have been able to donate my kidney to my husband meant a lot of things. . I I can say that because of me doing something, he"s healthy and that makes me feel good. That makes me know that okay, our family can continue on.

They did not feel a moral obligation to donate. Participants were specifically asked if they thought there was a moral obligation for someone to donate, once they were medically approved. Most donors did not report feeling a moral obligation when they were found to be a match. For many participants, their worries about the recipient motivated their actions, not a perception of moral obligation. Parents donating to young adult children expressed a "sense of responsibility" as parents to "create a better life" for their child, but did not think it was a moral obligation. 
Participants reflected on "the good" of donating a kidney. At least three participants stated they did not think donation was brave - it was simply what one would do for another family member. To them, kidney donation was to be expected among family members who love and care for each other. More than one expressed pride because they were healthy enough to donate. Several said they would have been disappointed if they had not been approved for donation.

The physical act of donation with evaluation, surgery and recovery, was only part of the experience. Participants spoke of a sense that they did something of value that provided essential help to their loved ones. They had been told by the health care providers that the only benefit of donation was to the donor, and they should donate only if they wanted to. Participants reported this was not fully accurate and marginalized their act of living donation. Participants expressed feelings of being proud to be able to help their loved one. Gerald stated, "If anything I can do for my family that would save they life and I still can live afterwards, believe me, it" 11 be done ... Oh, it was an extremely great thing I did."

Participants expressed confidence that they were restoring a healthier lifestyle for their recipient and positively influencing the lives of family and loved ones. Gerald noted that his donation allowed the recipient to see her sons graduate from elementary and high school. He was very aware of the importance of those events to the entire family.

Participants described frequently telling others about their experience. On several occasions, Rose had been asked by a physician to counsel families that are struggling with a living kidney donation decision. She reported that she relies heavily on her 
spiritual background and beliefs when talking with these families. Gerald incorporated his experience into talks he gives at Narcotics Anonymous meetings. 


\section{Chapter 5: Discussion and Recommendations}

Black Americans experience the work of living kidney donation in the midst of complex lives. The overarching themes of context of living donation and work of living donation identified in this study are a new way to understand this experience. The two themes were identified for the studyes Black American participants, and might apply to living donors of all races and ethnicities. The two overarching themes can be used when looking at the existing body of knowledge about living donation, and when designing research and interventions with living kidney donors.

\section{New Understandings from this Research}

This research brings out additional new knowledge in five areas of the experience of living donation. Three areas might be unique for Black Americans: Spiritual and religious practices, socio-economic issues, and racial discrimination. Two areas might affect donors of any racial or ethnic group: Differing interpretation about the meaning of living donation, and pain management for donors with history of substance abuse. I now present the five areas of new understanding and connect them to their overarching themes.

The findings about spiritual and religious practices occurred in the overarching theme of context of living donation. Such findings are rarely found in the literature on kidney donors. Although Brown et al. (2008a) reported perceptions about the importance of religious practices of donors, racial and ethnic data were not reported for that research. Religion and church play central roles in the lives of African Americans (Taylor, Chatters, \& Levin, 2004). It is possible that reliance on spiritual and religious practices 
is more prominent among Black American living kidney donors than among White American donors.

The overarching theme of context encompasses socio-economic and financial effects of living donation. Our knowledge about the socio-economic and financial effects for Black Americans is increased through this research. Participants described the financial impacts of being a donor and job-related socio-economic uncertainty similar to other reports (Cabrer et al., 2003; Pradel et al., 2003; Reimer et al., 2006; and Schover et al., 1997). These findings are in contrast to Fisher et al. (2005), however, who reported financial problems to be a minimal consequence of donation in Black American donors. Financial hardships in the study included temporary loss of income, considerable unreimbursed expenses, and loss of job. Specific direct and indirect costs incurred by donors, including lost income, travel expenses, and household services are similar to those reported in two systematic reviews (Clarke et al, 2006; Morton, Tong, Howard, Snelling, \& Webster, 2010). Because Black Americans are, on average, at greater economic risk in the United States than White Americans, with lower overall income and higher unemployment rates (United States Bureau of the Census, 2009), financial issues for potential Black American donors might warrant special attention by providers.

In the current study, socio-economic stresses were not limited to employment. Patricia was awarded custody of grandchildren when their mother was sentenced to prison. This posed logistical complications and financial stress as she made arrangements for their care while planning for her hospitalization and recovery. Black Americans have a higher rate of incarceration than do Whites (Sabol \& Couture, 2008), and this complicates family life (Parke \& Clarke-Stewart, 2001). Multi-generational 
households are not unusual in Black American families, and the number of grandparents raising grandchildren is increasing in the Black American population. Based on the 2000 U.S. Census, Minkler and Fuller-Thomson (2005) reported more than 500,000 or 5.8\% of African Americans over age 45 were raising their grandchildren. Given these population data, it is reasonable to anticipate that other Black American living kidney donors might have similar family experiences that add complexity to the donation.

Within the overarching theme of work of living kidney donation, participants reported experiences of racial discrimination by health care providers, and these findings are not evident in current living donation research. The literature review for this dissertation included 42 U.S. studies of living donors. Researchers in only two of the studies used qualitative methods, and only one research team (Lunsford, Shilling et al., 2007) reported participation by Black Americans. Research using quantitative methods might not be sensitive enough to uncover some of the subtle experiences of racial discrimination. Investigations designed to explore both covert and overt racial discrimination might be necessary to better understand this marginalized population and to plan for their services.

The overarching theme of work of living donation includes making sense of the experience. Participants mentioned that they felt they did something of value that provided help for their families. According to these participants, the emphasis by health care providers that donation only benefits the donor minimizes what the donors perceived to be their generous and helpful action. The advice by health care providers is related to their ethical concerns about donations (Biller-Andorno et al., 2001; Mazaris \& Papalois, 2003). The differing interpretation by participants was not identified in previous studies 
and should be examined in a larger sample, because this interpretation might not be limited to Black Americans.

Living kidney donation work includes endurance of pain. Particularly notable are pain management issues for Black American donors with a history of substance abuse. Two study participants had such a history and their pain was not well managed. Researchers in two studies described working with living donors who test positive for Hepatitis C (Foster et al., 2002; Maluf, Archer \& Mas, 2010), but there was no mention in the literature about donors with substance abuse history or any considerations about their pain management. In an investigation of living donor evaluation practices, Rodrigue et al. (2007) stressed the need for consistent evaluation of psychosocial factors, but did not address substance abuse. Further research is necessary for living donors with history of substance abuse regardless of their race or ethnicity. In the current study, both participants were "clean" for several years prior to donation.

\section{Similar Themes in Other Qualitative Studies}

I found 8 qualitative studies about living kidney donation, published in 7 articles, in the literature review for this dissertation. Major themes identified in that qualitative research can be subsumed into the two overarching themes of this study (Andersen et al., 2007; Brown et al., 2008a; Franklin \& Crombie, 2003; Hilton \& Starzomski, 1994;

Lunsford, Shilling et al, 2007; Olson, \& Bogetti-Dumlao, 2001; Sanner, 2005; Yi, 2003). Several researchers explored family relationships among donors and recipients, and noted witnessing of the suffering of the loved one with ESRD (Andersen et al., 2007; Brown et al., 2008a; Franklin \& Crombie, 2003; Hilton \& Starzomski, 1994; Sanner, 2005; Yi, 2003). These findings easily fit into the overarching theme of context of living donation, 
as they contribute to the background against which living donation occurred. Only one other research team reported that spiritual and religious practices affected their participants (Brown et al., 2008a).

In my study, the overarching theme of work of living donation included tasks and experiences directly related to the act of donating. In other qualitative studies, researchers presented the themes of physical disincentive for donating (Andersen et al., 2007), unmet follow-up expectations (Andersen et al., 2007; Lunsford, Shilling et al., 2007; Olson \& Bogetti-Dumlao 2001; Sanner, 2005), and changing kinship perceptions because of donation (Franklin \& Crombie, 2003; Hilton \& Starzomski, 1994; Yi, 2003). These themes fit well into the overarching theme I identified as the work of living kidney donation.

\section{Context of Living Kidney Donation}

Results of previous quantitative research, with few to no Black American participants, are similar to many of the findings of this study. It is important to note that congruence of research results indicates many issues for living kidney donors might cross racial and ethnic lines. I now compare the quantitative results, and related qualitative findings, to my study within the two overarching themes, work and context of living donation.

Two obvious examples of similar findings are that there were more female than male participants, and prior to donation, relationships between participants and their kidney recipients were described as good (Achille et al., 2007; Corley, et al., 2000; Fisher et al., 2005; Clemens et al., 2006). In my study, there were 2 male and 6 female participants, and all described the relationship with their kidney recipient as good. 
Participants in my study expressed concerns about the progressive renal failure including possible loss of their loved one, the threat to their everyday lives, and threats to their future plans. Other researchers similarly identified the suffering and threat of death of a loved one with ESRD as an important factor affecting living kidney donors (Jacobs et al., 1998; Lunsford, Simpson et al, 2006). The personal significance of social support from family and friends described by my participants has also been noted in qualitative research (Brown et al., 2008a) and quantitative research (Sajjad, Baines, Salifu, \& Jindal, 2007).

Continuum of caring is a theme found in my study, with subthemes of communication, skilled care and skilled tasks, and trust issues with health care providers. The subthemes are similar to factors including communication, education, emotional support and quality of physical care identified by others as important to living kidney donors (Brown et al., 2008b; Smith et al., 1986; Walton-Moss et al., 2006). Participants in my study expressed a basic trust that living donation would help their loved one, and researchers in other qualitative studies identified a deep sense of trust in health services as a supporting factor for living donors (Brown et al., 2008a; Lennerling et al., 2003; Sanner, 2005). It is important that health care providers are aware of trust issues among all living donors.

\section{Work of Living Kidney Donation}

The perception that kidney transplant is inevitable for the loved one and the donors"e search for information about living donation has been reported by other researchers (Lennerling, et al., 2003; Sanner, 2005; Waterman et al., 2004; Yi, 2003). Although donors were aware of the threat posed by ESRD, almost half of participants in 
my study described a delayed decision-making process. While this is congruent with one report (Sanner, 2005), it differs from the rapid decisions described by other researchers (Andersen, et al., 2004; Fisher et al., 2005; Hilton \& Starzomski, 1994; Jacobs, et al., 1998; Schover et al., 1999). Regardless of the pace of decision-making, transplant professionals have a responsibility to support the process with timely counseling and education.

The majority of living donors do not regret their decision to donate (Dahm et al, 2006; Fehrman-Ekholm et al., 2000; Franklin \& Crombie, 2003). In the current study, six of eight participants did not have regrets. As in prior studies, donors felt abandoned, they had financial and health concerns, or they saw donation as changing their daily activities (Andersen et al., 2007; Fisher et al. 2005, Johnson et al, 1999; Schover et al., 1997). The work of preparing family and friends for the upcoming donation, the importance of their support in preparation of the household, and the greater burden of household work placed on female participants also is similar to earlier findings (Achille et al., 1997; Brown et al., 2008a, Walton-Moss et al., 2006). All transplant health care professionals should be aware that female donors might carry a greater burden of household work when providing care to those patients in preparation for living donation.

In the current study, participants reported being surprised by the degree and duration of surgical pain. While similar results have been reported (Andersen et al., 2004; Fisher et al., 2005; Sanner, 2005), this is in contrast to research in which the laparoscopic procedure has been documented as less painful than the open flank procedure (Bachmann et al., 2006; Dahm et al., 2006). My study participants reported considerable pain, regardless of the surgical procedure being open or laparoscopic. 
Differing results were reported in retrospective work by Bachmann et al. (2006) using a visual analogue scale with 206 living donors, and Dahm et al. (2006) using a mailed survey with 152 donors. In both studies, the research teams determined the laparoscopic procedure was significantly less painful. In my study, reports of pain did not differ based on the type of surgical procedure the participants endured.

There appears to be an emotional cost to donation, regardless of the surgical outcome for recipients. In the current study, three participants described post-donation depressive feelings of a sense of loss and sadness, but no participants reported depression to their health care providers. This is similar to feelings of loss, abandonment, exploitation, and mild depression reported by others in both qualitative and quantitative research (Andersen et al., 2007; Brown et al., 2008b; Clemens et al., 2006; Haljamae et al., 2003; Heck et al., 2004; Hilton \& Starzomski, 1994; Lunsford, Shilling et al., 2007; Sanner, 2005; Smith et al., 2004; Wiedebusch et al., 2009). Nurses should be aware that such feelings might not be brought to the attention of health care providers, but might interfere with recovery for living donors.

Participants found follow-up care to be helpful, and more than one expressed the need for prolonged follow-up. The importance of medical and psychological follow-up for donors has been mentioned repeatedly by health care providers (Davis, 2009; ReevesDaniel et al., 2010), and by living donors (Fehrman-Eckholm et al., 2000; Franklin \& Crombie, 2003; Giessing et al., 2004; Jacobs et al., 1998; Olson \& Bogetti-Dumlao, 2001). In the current research, two of the eight participants developed renal failure, and all other participants reported minor lingering physical effects. This is in contrast to several researchers who reported no detrimental health effects for living donors 
(D"Almeida et al., 1996; Ibrahim et al., 2009; Lumsdaine et al., 2005). Others concluded that living kidney donation might have long lasting health effects, such as hypertension, continuing fatigue, persistent pain, and even renal failure (Boudville et al., 2006; Gibney et al., 2007; Nogueira et al., 2009; Sanner, 2005). Specific differences in outcomes for minority living donors were identified in a study using OPTN and private insurance data (Lentine et al.,(2010).

Based on details presented in the paragraph above, the contradictory research results about health effects of living donation indicate further research is necessary. Nationally and internationally, there are calls for long term follow-up of living kidney donors, including a consensus statement to that effect among representatives of over 40 countries (Ethics Committee, 2004).

Participants were aware of the ways living donation helped to restore the family"s world that had been threatened by ESRD. They spoke of actively seeking to restore family routines and of a renewed appreciation for family relationships. This finding supports those from Andersen et al. (2007) and Brown et al. (2008a), related to resuming family and social connections. Several researchers have investigated self-esteem and quality of life for living donors, generally finding improvements in both areas (Andersen et al., 2007; Corley et al., 2000; Franklin \& Crombie, 2003; Lennerling et al., 2004; Olson \& Bogetti-Dumlao, 2001). While participants in my study did not specifically address self-esteem, they spoke about drawing personal meaning from donation and having a sense of gratefulness that they were able to donate to their loved one.

Overall findings in the current study underscore the report from Andersen et al. (2007) that being a living donor is a complex experience with recommendation that 
transplant professionals have a special responsibility to support a successful donation process for these individuals.

\section{Study Limitations}

Careful research design could not accommodate for the following limitations. Participants were recruited from one metropolitan area; donors might have different experiences at transplant centers in other cities. A selection bias might have occurred through using transplant center staff to identify potential participants. The staff might have avoided contacting donors who had a difficult experience. The staff members were encouraged to contact all donors who fit the selection criteria and let donors make the decision to participate. The study was retrospective, and this could have introduced recall bias. Two to three interviews were conduced to address this potential. At least one participant was interviewed within 6 weeks of donation. She recalled experiences in great detail, while having a little time to reflect on her experience. A White American researcher interviewing Black Americans presented a challenge. The researcher consulted with members of the Black American community when designing the study. In addition, the researcher informed all participants that she, herself, is a living kidney donor. This facilitated rapport during data collection.

\section{Recommendations for Research}

Qualitative research methods have often been used as an early step toward generating hypotheses that may be quantitatively measured in future research (Patton, 2002). In this section, I present ideas for improving current research about living donors. Black American living kidney donors have many concerns similar to all living donors. They also appear to have unique concerns related to socio-economic stresses, 
multi-generational family issues, and particular ways of coping with the stress of donation. The socio-economic concerns of two sub-groups from the study participants warrant further investigation: Grandparents raising grandchildren, and single parents. Such donors might face particular social and financial issues about the children that do not arise for donors who do not have responsibility for raising children. I recommend living donor research focused on these two sub-groups. I suggest the research be prospective, rather than retrospective, to capture socio-economic concerns as they occur, not as they are recalled. Schover et al. (1997) used standardized questionnaires about donor satisfaction and quality of life to conduct a follow-up study of living donors. The standardized tools were sensitive enough to uncover negative financial consequences in a primarily White American sample. The study was replicated by Fisher et al. (2005) using a retrospective design, with a primarily White American sample. Validating the tools for a minority population and designing a prospective study would deepen our understanding.

This study"s participants consistently mentioned the importance of spiritual and religious practices in their ability to endure the process of living kidney donation. In the current literature, Brown, et al. (2008a) is the only research team reporting how spirituality and faith influenced the experiences of living donors. Further research opportunities in this area include the following: Explore the significance of such practices in coping with the special stress of living donation; compare such practices among religious denominations such as Christian, Jewish, Muslim, and Buddhist. Intervention research could be designed so health care providers can foster the use of spiritual and religious practices in coping with living kidney donation. I recommend this 
intervention research to include hospital chaplain services for optimal interprofessional patient care.

Regardless of the surgical procedure used, pain is an issue for living kidney donors. Research reports vary in the degree and duration of pain and how it affects the living donors. It is not clear from current literature, that the difference in findings related to pain have any connection to the race or ethnic background of participants. Because my findings about pain are in agreement with some and different from other studies, I suggest continued investigations about pain and pain management interventions for living donors. Such research should be prospective and should include donors from a variety of races and ethnic backgrounds. A well designed, prospective study focused on psychosocial issues was conducted in Australia (Smith et al., 2004). This research could be replicated with design modifications to include factors about pain management and an ethnically diverse sample in the United States. Two recent studies in Switzerland (Dahm et al., 2006; Bachmann et al., 2006) retrospectively compared living donation surgical procedures using self administered questionnaires. Both research teams acknowledged the study limitation of time elapsed between donation and answering the questionnaire. Self administration was not mentioned as a possible study limitation by either research team.

In my investigation, participants with history of substance abuse reported special concern with pain management. This may not be unique to Black Americans, and might apply to donors of all ethnic backgrounds. In order to improve this care, nurses and other health care providers should research the pain management needs for living kidney donors with history of substance abuse. Several researchers have identified that pain 
management is problematic for living donors, but none specify living donor study participants who have a history of substance abuse (Bachmann et al., 2006; Cabrer et al., 2003; Dahm et al., 2006; Hiller et al., 1998; Kaarfelt et al., 1998; Sanner, 2005). This is an area of substantial opportunity for research.

The difference in meaning placed on donation between participants and health care providers is of concern. It is understandable that health care providers respect ethical principles of autonomy and beneficence, and avoid appearance of coercion. However, in my study, participants spoke of providers who emphasized that donation only benefits the donor. Participants interpreted that the providers minimized their work of living donation, and how living donation benefitted the family. These issues have not been presented by other living kidney donor research teams, but Mazaris \& Paplois (2003) address the issues in a theoretical discussion. Future studies should investigate this difference in interpretation, if this is limited to one racial or ethnic group, and should explore interventions to bridge the difference.

\section{Recommendations for Clinical Practice}

While qualitative research is not expected to result in specific interventions, greater understanding of a phenomenon might lead to modifications in clinical practice. Following are suggestions about clinical practice, based on the current study findings. Participants in my study described reliance on their spiritual and religious practices as they donated a kidney. Their practices ranged from private, personal prayer to material support by church congregations. The influence of spiritual and religious practices has been noted by one other research team, but no recommendations were made for changes in practice (Brown, et al., 2008a). When providing care, nurses should 
assess, acknowledge and support such practices as Black Americans prepare for, and cope with living kidney donation. Consulting with the pastoral care or chaplain services may be of considerable help in this area.

Participants reported socio-economic stresses related to donation, which might be different from those encountered by other racial and ethnic groups. In order to better understand the socio-economic issues faced by Black American living donors, nurses should inquire about the employment-related, personal, and multi-generational family issues both in preparation for donation and during the follow-up period. As cited earlier, Black Americans have higher rates of unemployment, greater numbers of grandparents raising grandchildren, and higher rates of incarceration in their families (Minkler \& Fuller-Thompson, 2005; Parke \& Clarke-Stewart, 2001; Sabol \& Coture, 2008; United States Bureau of the Census, 2009). This knowledge should be used when planning for the care of Black American living kidney donors. For example, concerns related to work might impact a person's availability for repeated pre-donation testing. Arranging for testing to be completed in one visit might be of considerable assistance to these donors. Following donation, documentation related to the donor ${ }^{\text {es }}$ health and work capacity might be essential to resuming job duties. Nurses can facilitate support in this way to mitigate socio-economic stresses. This support can include arrangements for experienced donors to communicate with those planning donation, a suggestion from donors in the current study, as well as previous studies by Sanner (2005) and Brown et al. (2008b).

Participants reported experiences of racial discrimination. This can impact quality of care, trust in health care providers, and the ongoing relationship between Black Americans and the health care system. Such impact has been identified previously by 
research teams across the United States (Ayanian et al., 2004; Boulware et al., 2003;

Brown et al., 2008b; Corbie-Smith et al., 2002; Epstein et al., 2000). Nurses need to carefully examine their own attitudes and actions to identify potential areas of covert and overt racism. Nurse managers and upper administration in transplant centers should cultivate an environment that does not tolerate racism. Specific experiences of racial discrimination should be investigated with discussion of potential changes in practice to reduce discrimination. The research team led by Ebony Boulware has repeatedly documented that health care providers need to improve understanding of health care system experiences among minorities in order to reduce incidence of racial discrimination (Boulware et al., 2002, Boulware et al., 2003; Boulware et al., 2005, Boulware et al., 2007). As providers, we should act on the findings of this research team. Regardless of the surgical procedure, living kidney donors experience pain. While further research about pain in living kidney donation may be helpful, we have considerable knowledge about the pain living kidney donors endure. Nurses who provide accurate pre-surgery education about the degree and duration of pain will be most helpful for living donors. This was identified by participants in my study and by Sanner (2005). Such education can reduce uncertainty and help donors plan for their recovery and resumption of daily activities. My study revealed that living donors with history of substance abuse need special assistance with pain control. Referrals to substance abuse specialists might be warranted for post-surgical care of these donors.

Findings of this study help to focus further research and improvements in nursing care for potential and actual living donors in the listed areas. Recommendations for both research and clinical applications can improve care to develop special considerations for 
Black American living kidney donors as we face the continued need for living donation in treating ESRD. 


\section{References}

Abecassis, M., Adams, M., Adams, P., Arnold, R., Atkins, C., Barr, M., et al. (2000). Consensus statement on the live organ donor. Journal of the American Medical Association, 284(22): 2919-2926. Doi: 00005407-20012130-00037

Achille, A., Soos, J., Fortin, M., Paquet, M., \& Hebert, M. (2007). Differences in psychological profiles between men and women living kidney donors. Clinical Transplantation, 21, 314-320. Doi: 10.1111/j.1399-0012.2007.00641.x

Alfani, D., Pretagostini, M., Rossi, M., Poli, L., Bruzzone, P., Colonnello, M., et al. (1997). Living unrelated kidney transplantation: A 12-year single center experience. Transplantation Proceedings, 29, 191-194.

Andersen, M. H., Bruserud, F., Mathisen, L., Wahl, A.K., Hanestad, B. R., \& Fosse. E. (2007) Follow-up interviews of 12 living kidney donors one year after open donor nephrectomy. Clinical Transplantation, 21: 702-709. Doi: 10.1111.j/13990012.2007.00726.x

Andersen, M. H., Mathisen. L., Oyen, O, Wahl, A. K., Hanestad, B. R., \& Fosse, E. (2004). Living donors' experiences 1 wk after donating a kidney. Clinical Transplantation, 19: 90-96. Doi: 10.1111/j.1399-0012.2004.00304.x

Angen, M. J. (2000). Evaluating interpretive inquiry: Reviewing the validity debate and opening the dialogue. Qualitative Health Research, 10, 378-395.

ATLAS.ti (2011). The knowledge workbench, Version 5.7.1. GmbH, Berlin.

Aulisio, M. P., DeVita, M., \& Luebke, D. (2007). Taking values seriously: ethical challenges in organ donation and transplantation for critical care professionals 
Critical Care Medicine, 35, Suppl., S95-S101. Doi:

10.1097/01.ccn.0000252915.76019.19

Ayanian, J. Z., Cleary, P. D., Keough, J. H., Noonan, S. J., David-Kasdan, J. A., \& Epstein, A. M. (2004). Physicians" beliefs about racial differences in referral for renal transplantation. American Journal of Kidney Diseases, 43, 350-357.

Doi: $10.1052 /$ j.ajkd.2003.10.022

Ayanian, J. Z., Cleary, P. D., Weissman, J. S., \& Epstein, A. M. (1999). The effect of patients' preferences on racial differences in access to renal transplantation. New England Journal of Medicine, 341, 1661-1669.

Bachmann, A., Wolff, T., Giannini, O., Dickenman, M., Roszat, T., Gürke, L., ... Sulser,T. (2006). How painful is donor nephectomy: Retrospective analysis of early pain and pain management in open versus laparoscopic versus retroperitoneoscopic nephrectomy. Transplantation, 81, 1735-1738. Doi: 10.1097/01.tp/0000225800.69089.b4

Bailey, E. J (2000). Medical Anthropology and African American Health. Westport, CT: Bergin \& Garvey

Baldwin, D. M. (2003). Disparities in health and health care: focusing efforts to eliminate unequal burdens. Online Journal of Issues in Nursing, 8, Retrieved from http://www.nursingworld.org.

Bay, W. H. \& Herbert, L. A. (1987) The living donor in kidney transplantation. Annals of Internal Medicine, 106, 719-727.

Beauchamp, T. L. \& Childress, J. F. (2001). Principles of biomedical ethics $\left(5^{\text {th }}\right.$ ed.). New York: Oxford University Press. 
Belmont Report. (1979) Ethical principles and guidelines for the protection of human subjects of research. Retrieved from http://wwwlhhs.gov/ohrp/humansubjects/guidance/belmont.htm Benner, P. (1994). Interpretive phenomenology. Thousand Oaks, CA: Sage Publishers. Bia, M., Ramos. E., Danovitch, G., Gaston, R., Harmon, W., Leichtman, A. (1995). Evaluation of living renal donors. Transplantation, 60, 322-327.

Biller-Andorno, N., Agich, G. J., Doepkens, K. \& Schauenburg, H. (2001). Who shall be allowed to give? Living organ donors and the concept of autonomy. Theoretical Medicine, 2, 351-68.

Biller-Andorno, N., \& Schauenburg, H. (2001). It's only love? Some pitfalls in emotionally related organ donation. Journal of Medical Ethics, 27, 162-164.

Binet, I., Bock, A. H., Vogelbach, P., Gasser, T., Kiss, A., Brunner, F., et al. (1997). Outcome in emotionally related living kidney donor transplantation. Nephrol Dial Transplant, 12, 1940-1948.

Bloemenbergen, W. E., Port, F. K., Mauger, E .A., Briggs, J. P., Leichtman, A. B. (1996). Gender discrepancies in living related renal transplant donors and recipients. Journal of the American Society of Nephrology, 7, 1139-1145.

Boudville, N., Prasad, G., Know. G., Muirhead, N., Thiessen-Philbrook, H., Yang, R., et al. (2006). Meta-analysis: risk for hypertension in living kidney donors. Annals of Internal Medicine, 145, 185-196.

Boulware, L. E., Cooper, L. A., Ratner, L. E., LaVeist, T. A., \& Powe, N. R. (2003). Race and trust in the health care system. Public Health Reports, 118, 358-365 
Boulware L. E., Meioni, L. A., Fink, N. E., Parekh, R. S., Kao, W. H., Klag, M. J., et al., (2005). Preferences, knowledge, communication and patient-physician discussion of living kidney transplantation in African American families. American Journal of Transplantation, 5, 1503-1512. Doi: 10.1111/j1600-6143.2005/00860.x

Boulware, L. E., Ratner, L. E., Cooper, L. A., Sosa, J. A., LaVeist, T. A., \& Powe, N. R.(2002). Understanding disparities in donor behavior: Race and gender differences in willingness to donate blood and cadaveric organs. Medical Care, 40, 85-95. Doi: 00005650-200202000-00003

Boulware, L. E., Troll, M. U., Wang, N.Y., \& Powe, N. R. (2007). Perceived transparency and fairness of the organ allocation system and willingness to donate organs: A national study. American Journal of Transplantation, 7, 1778-1787. Doi: 10.1111/j.1600-6143.2007.01848.x

Bratton, L. B. \& Griffin, L. W. (1994). A kidney donor's dilemma: The sibling who can donate - but doesn't. Social Work in Health Care, 20, 75-96.

Braun, W.E. (2007). The rocky road of limited immunosuppression for renal transplantation in African Americans. Transplantation, 83, 267-269. Doi 00007890-200702150-00007

Brown, J., Karley, M., Boudville, N., Bullas, R., Garg, A., Muirhead, N. (2008a) The experience of living kidney donors. Health \& Social Work, 33, 93-100.

Brown, J., Karley, M., Boudville, N., Bullas, R., Garg, A., Muirhead, N. (2008b). Living kidney donorse experiences with the health care system. Social Work in Health Care. 46, 53-67. Doi: 10.1300/J010v46n03_03 
Cabrer, C., Oppenhaimer, F., Manyalich, M., Paredes, D., Navarro, A., Trias, E., et al. (2003). The living kidney donation process: the donor perspective. Transplantation Proceedings, 35, 1631-1632. Doi: 10.1016/500411345(03)00697-3

Centers for Medicare and Medicaid Services (2007). Medicare program: conditions of participation: requirements for approval and re-approval of transplant centers to perform organ transplants; final rule. Retrieved from www.cms.hhs.gov/CertificationandCompliance/downloads/Transplantfinal.pdf

Chesla, C.A., \& Rungreangkulkij, S. (2001). Nursing research on family processes in chronic illness in ethnically diverse families: A decade review. Journal of Family Nursing, 7, 230-243.

Childress, J. F. and Liverman, C. T. (2006). Organ Donation Opportunities for Action. Washington, D. C., The National Academies Press.

Clarke, K. S., Klarenbach, S., Vlaicu, S., Yang, R. C., \& Garg, A. X. (2006). The direct and indirect economic costs incurred by living kidney donors - a systematic review. Nephrology, Dialysis, Transplantation, 21, 1952-1960. Doi: $10.1093 / \mathrm{ndt} / \mathrm{gf1} 069$

Clayman, R. V. (2005). Patients' attitudes about living donor transplantation and living donor nephrectomy. The Journal of Urology, 173, 481. Doi: 00005932200502000-00055

Clemens, K. K., Thiessen-Philbrook, H., Parikh, C., Yang, R., Karley, M., Boudville, N. et al. (2006). Psychosocial health of living kidney donors: A systematic review. 
American Journal of Transplantation, 6, 2965-2977. Doi: 10.1111/j.1600-

6143.2006.01567.x

Corbie-Smith, G., Thomas, S. B., Williams. M. V., Moody-Ayers, S. (1999). Attitudes and beliefs of African Americans toward participation in medical research. Journal of General Internal Medicine. 14, 537-546.

Corbie-Smith, G., Thomas, S. B., St. George, D. M. (2002). Distrust, race and research Archives of Internal Medicine, 162, 2458-2463. Doi: 00000779-200211250-00010

Corley, M. C., Elswick, R. K., Sargeant, C. C., \& Scott, S. (2000). Attitude, self-image, and quality of life of living kidney donors. Nephrology Nursing Journal, 27, 4350

Crist, J. D. \& Tanner, C. A. (2003). Interpretation/analysis methods in hermeneutic interpretive phenomenology. Nursing Research, 52, 202-205.

Dahm, F., Weber, M., Muller, B., Pradel, F. G., Laube, G. F., Neuhaus, T. J., et al. (2006). Open and laparoscopic living donor nephrectomy in Switzerland: a retrospective assessment of clinical outcomes and the motivation to donate. Nephrology Dialysis Transplantation, 21, 2563-8. Doi: 10.1093/ndt/gf1207

Davis, C. (2009). Living kidney donors: current state of affairs. Advances in Chronic Kidney disease. 16,242-249. Doi: 10.1053/jackd.2009.05.007.

DeAlmeida, P., Keitel, E., Gittar, A., Goldani, J., Santos, A., Neumann, J., et al. (1996). Long term evaluation of kidney donors. Transplantation Proceedings, 28, 93-94.

Delmonico, F. L. \& Dew, M. A. (2007) Living donor kidney transplantation in a global environment Kidney International, 71, 608-614. doi 10.1038/sj.ki.5002125

Diseases and Conditions (2006). Retrieved from http://www.cdc.gov.node.do/10900. 
Dula, A. (1994). Bioethics: the need for a dialogue with African Americans. In A. Dula \& S. Goering (Eds.), "It just ain't fair" The ethics of health care for African Americans (pp. 11-23). Westport, CT: Praeger Publishers.

Earl, C. E., \& Penney, P. J. (2001). The significance of trust in the research consent process with African Americans. Western Journal of Nursing Research, 23, 753762. Doi: $10.1177 / 01939450122045528$

Ellison, M. D., McBride, M. A., Taranto, S. E., Delmonico, F. L. \& Kauffman, H. M. (2002). Living kidney donors in need of kidney transplants: a report from the organ procurement and Transplantation network. Transplantation, 74, 1349-1351. Doi: 00007890-200211150-00025

Epstein, A. M., Ayanian, J. Z., Keogh, J. H., Noonan, S. J., Armistead, N., Cleary, P. D., et al. (2000). Racial disparities in access to renal transplantation - clinically appropriate or due to underuse or overuse? New England Journal of Medicine, $343,1537-1544$.

Ethics Committee of the Transplantation Society. (2004). The consensus statement of the Amsterdam Forum on the care of the living kidney donor. Transplantation, 78, 491-492. Doi: 00007890-200408270-00001

Farley, F. (1982). Altruism: A complex sociobiological concept applied to renal transplantation. American Association of Nephrology Nurses and Technicians Journal, 9, 53-58.

Fauchald, P., Sodal, G., Albrechtsen, D., Leivestad, T., Berg, K. J., Flatmark, A.(1991). The use of elderly living donors in renal transplantation. Transplant International, 4, 51-3. 
Feagin, J. R. \& Sikes, M. P. (1994). Living with racism: the black middle-class experience. Boston: Beacon Press.

Fehrman-Ekholm, I., Brink, B., Ericsson, C., Elinder, C. G., Duner, F, \& Lundgren, G. (2000). Kidney donors don't regret: follow-up of 370 donors in Stockholm since 1964. Transplantation, 69, 2067-2071. Doi: 00007890-200005270-00016

Fehrman-Ekholm, I., Elinder, C. G., Stenbeck, M., Tyden, G., \& Groth, C. G. (1997). Kidney donors live longer. Transplantation, 64, 976-78. doi 00007890197710150-00007

Fisher, P,, Kropp, D., \& Fleming, E. (2005). Impact on living kidney donors: quality of life, self-image and family dynamics. Nephrology Nursing Journal, 32, 489-500.

Foster, C. E., Philosophe, B., Schweitzer, E. J., Colonna, J. O., Farney, A. C., Jarrell, B., et al. (2002). A decade of experience with renal transplantation in African Americans. Annals of Surgery, 236, 794-804. Doi:

10.1097/01.sla.0000036882.91371.ea

Franklin, P. M., \& Crombie, A. K. (2003). Live related renal transplantation:

Psychological, social, and cultural issues. Transplantation,76, 1247-1252. Doi: 00007890-200310270-00024

Gadamer, H-G. (1975). Truth and Method. New York: Seabury Press.

Gambino, G., Gioviale, M. C., Maione, C., DiBona, A., Buffa, D., Virzi, C., et al. (2006). Use of marginal donors in kidney transplantation: our experience. Transplantation Proceedings, 38, 999-1000.

Gamble, V. (1997). Under the shadow of Tuskegee: African Americans and health care. American Journal of Public Health, 87, 1773-1778. 
Garg, P. P., Diener-West, M., \& Powe, N. R., (2001). Reducing racial disparities in transplant activation: whom should we target? American Journal of Kidney Diseases, 37, 921-931. Doi: 10.1053/ajkd.2001.23612

Gaston, R. S., Danovitch, G. M., Adams, P. L., Wynn, J. L., Merion, R. M., Deierhoi, M. H., et al. (2003). The report of a national conference on the wait list for kidney transplantation. American Journal of Transplantation, 3, 775-785.

Gibney, E. M., King, A. L., Maluf, D. G., Garg, A. X., \& Parikh, C. R. (2007). Living kidney donors requiring transplantation: focus on African Americans. Transplantation, 84, 647-649.

Giessing, M., Reuter, S. Schonberger, B., Deger, S., Tuerk, I. Hirte, I., et al. (2004) Quality of life of living kidney donors in Germany: a survey with the validated Short Form-36 and Geissen Subjective Complaints List -24 questions.

Transplantation, 78, 864-872. Doi: 00007890-200409271-00012

Gill, J. S., Gill, J., Rose, C., Zalunardo, N., \& Landsberg, D. (2006). The older living kidney donor: part of the solution to the organ shortage. Transplantation, 82, 1662-1666. Doi: 0000-200612270-00027

Gjertson, D. W. \& Cecka, J. M. (2000). Living unrelated donor kidney transplantation. Kidney International, 58, 491-499.

Glannon, W. \& Ross, L. F. (2002). Do genetic relationships create moral obligations in organ transplantation? Cambridge Quarterly of Healthcare Ethics, 11, 153-159.

Gordon, E. J. (2002). What "race" cannot tell us about access to kidney transplantation. Cambridge Quarterly of Healthcare Ethics, 11, 134-141. 
Gove, P.B. (Ed.). (1986). Webster's third new international dictionary of the English language unabridged. Springfield, Massachusetts: Miriam Webster, Inc.

Griffin, L. \& Bratton, L. B. (1995). Fewer black kidney donors: What's the problem? Social Work in Health Care, 22, 19-41.

Gutmann, T., Elsaesser, A., Gruendel, A., Land, W., Schneewind, K. A. \& Schroth, U. (1994) Living-kidney donation: safety by procedure. Clinical Transplantation, 11, $356-7$.

Haljamäe, U., Nyberg, G., \& Sjostrom, B. (2003). Remaining experiences of living kidney donors more than $3 \mathrm{yr}$ after early recipient graft loss. Clinical Transplantation, 17, 503-510.

Heck, G., Schweitzer, J., \& Seidel-Weisel, M. (2004). Psychological effects of living related kidney transplantation - risks and chances. Clinical Transplantation, 18, 716-21. Doi: 10/1111/j1399-0012.2004.00285.x

Hilhorst, M. T., Kranenburg, L. W., \& Busschbach, J. J. (2007). Should health care professionals encourage living kidney donation? Medical Health Care Philosophy, 10, 81-90. Doi: 10.1007/S11019-006-9002-x

Hiller J., Sroka, M., Weber, R., Morrison, A. S., \& Ratner, L. E. (1998). Identifying donor concerns to increase live organ donation. Journal of Transplant Coordination, 8, 51-54.

Hilton, A. \& Starzomski, R. C. (1994). Family decision making about living related kidney donation. ANNA Journal, 21, 346-355. 
Ibrahim, H., Foley, R., Tang, L. Rogers, T., Bailey, R., Guo, H., ...Matas, A. (2009). Long-term consequences of kidney donation. New England Journal of Medicine, 360, 459-469.

Ingelfinger, J. (2005). Risks and benefits to the living donor. New England Journal of Medicine, 353, 447-448.

Jacobs, C., Johnson, E., Anderson, K., Gillingham, K. \& Matas, A. (1998). Kidney transplants from living donors: How donation affects family dynamics. Advances in Renal Replacement Therapy, 5, 89-97.

Johnson, E., Anderson, J. K., Jacobs, C., Suh, F., Humar, A., Suhr, B. D. et al. (1999). Long term follow-up of living kidney donors: Quality of life after donation. Transplantation Proceedings, 67, 717-721.

Johnson, E. M., Remucal, M. J., Gillingham, K. J., Dahms, R. A., Najarian J. S. \& Matas, A. J.(1997). Complications and risks of living donor nephrectomy. Transplantation, 64, 1124-1128. Doi: 00007890-199710270-00007

Johnson, L. B. \& Staples, R. (2005). Black Families at the Crossroads Challenges and Prospects $\left(2^{\text {nd }}\right.$ ed.). San Franscisco: Jossey Bass

Johnson, M. E. (2000). Heidegger and meaning: implications for phenomenological research. Nursing Philosophy, 1, 134-146.

Johnson, S. R., Khwaja, K., Pavlakis, M., Monaco, A. P., \& Hanto, D. W. (2005). Older living donors provide excellent quality kidneys: a single center experience (older living donors). Clinical Transplantation, 19, 600-606. Doi: 10.1111/j.13990012.2004-00328.x 
Kaarfelt, H. M., Berg, U., Lindblad, F. I., \& Tyden, G. E. (1998). To be or not to be a living donor. Transplantation, 65, 915-918.

Kallich, J. D., \& Merz, J. F. (1994-1995). The transplant imperative: Protecting living donors from the pressure to donate. The Journal of Corporation Law, 20, 139154.

Karakayali, H., Moray, G., Demirağ, A., Yildrin, S., \& Belgin, N. (1998). Long-term follow-up of 102 living kidney donors. Transplantation Proceedings, 30, 721 723.

Kayler, L. K., Rasmussen, C. S., Dykstra, D. M., Ojo, A. O., Port, F. K., \& Wolfe, R. A., et al. (2003). Gender imbalance and outcomes in living donor renal transplantation in the United States. American Journal of Transplantation, 3, 452458.

Kayler, L. K., Meier-Kriesche, H., Punch, J. D., Campbell, D. A., Leichtman, A. B., Magee, J. C., et al. (2002). Gender imbalance in living donor renal transplantation. Transplantation, 73, 248-252. Doi: 00007890-200201270-00017

Khajehdehi, P. (1999). Living non-related versus related renal transplantation - its relationship to the social status, age and gender of recipients and donors. Nephrology Dailysis Transplantation, 14, 2621-2624.

King, W. D. (2003). Examining African Americans' mistrust of the health care system: Expanding the research question. Public Health Reports, 118, 366-367.

Klassen, A. C., Hall, A.G., Saksvig, B., Curbow, B., \& Klassen, D. K. (2002). Relationship between patients' perceptions of disadvantage and discrimination 
and listing for kidney transplantation. American Journal of Public Health, 92, 811-817.

Koch, T. (1995). Interpretive approaches in nursing research: the influence of Husserl and Heidegger. Journal of Advanced Nursing, 21, 827-836

Koch, T. \& Harrington, A. (1998). Reconecptualizing rigour: the case for reflexivity. Journal of Advanced Nursing, 28, 882-890.

Lennerling, A., Forsberg, A., \& Nyberg, G. (2003). Becoming a living kidney donor. Transplantation, 76, 1243-1247.

Lennerling, A., Forsberg, A., Meyer, K., \& Nyberg, G. (2004). Motives for becoming a living kidney donor. Nephrol Dial Transplant, 19, 1600-1605.

Lentine, K., Schnitzler, M., Xiao, H., Saab, G., Salvalaggio, P., Axelrod, D., ... Brennan, D. (2010). Racial variation in medical outcomes among living kidney donors. New England Journal of Medicine, 363, 724-732.

Lumsdaine, J. A., Wray, A., Power, M. J., Jamieson, N. V., Akyol, M., Bradley, J., et al.(2005). Higher quality of life in living donor kidney transplantation: prospective cohort study. Transplant International, 18, 975-80. Doi: $10.1111 / \mathrm{j} / 1432-2277.2005 .00175 . \mathrm{x}$

Lunsford, S. L., Shilling, L. M., Chavin, K. D., Martin, M. S., Miles, L. G., Norman, M. L., et al. (2007). Racial differences in the living kidney donation experience and implications for education. Progress in Transplantation, 17, 234-40.

Lunsford, S. L., Simpson, K. S., Chavin, K. D., Hildebrand, L. G., Miles, L. G., Shilling, L. M., et al. (2006). Racial differences in coping with the need for kidney 
transplantation and willingness to ask for live organ donation. American Journal of Kidney Diseases, 47, 324-331. Doi: 10.1053/j.ajkd.2005.10.018

Lunsford, S. L., Simpson, K.S., Chavin, K. D., Menching, K. J., Miles, L.G., Shilling, L.M., et al. (2006). Racial disparities in living kidney donation: Is there a lack of willing donors or an excess of medically unsuitable candidates? Transplantation, 82, 876-881. Doi: 00007890-200610150-00004

Lunsford, S. L., Simpson, K. S., Chavin, K. D., Menching, K. J., Miles, L. G., Schilling, L. M., et al. (2007). Can family attributes explain the racial disparity in living kidney donation? Transplantation Proceedings, 39, 1376-1380. Doi: 10.1016/j.transproceed.2007.03.017

Mandelbrot, D. A., Pavlakis, M., Danovitch, G. M., Johnson, S.R., Karp, S. J., Khwaja, $\mathrm{K}$, et al. (2007). The medical evaluation of living kidney donors: a survey of US transplant centers. American Journal of Transplantation, 7, 2219-2220.

Maluf, D., Archer, K., \& Mas, V. (2010). Kidney grafts from HCV-positive donors: advantages and disadvantages. Transplantation Proceedings, 42, 2436-2446. Doi: 10.1016/j.transproceed. 2010.04.056.

Mazaris, E. \& Papalois, V. (2003). Ethical issues in living donor kidney transplantation. Experimental and Clinical Transplantation. 4. Retrieved from http://www.extrx.org/forms/ectrxcontentshow.php?year=2006\&volume=4\&issue $=2$

Minkler, M. \& Fuller-Thomson, E. (2005). African American Grandparents Raising Grandchildren: A National Study Using the Census 2000 American Community Survey. Journal of Gerontology, 60, S82-92. 
Mischler, E. G. (1990). Validation in inquiry-guided research: The role of exemplars in narrative studies. Harvard Educational Review, 60, 415-442.

Morbidity and Mortality Weekly Report (MMWR). (2007). Centers for Disease Control. 56 (11) 253-256. Retrieved from www.cdc.gov/mmwr/preview

Morton, R. Tong, A., Howard, K., Snelling, P. Webster, A. (2010).

The views of patients and carers in treatment decision making for chronic kidney disease: systematic review and thematic synthesis of qualitative studies. British Medical Journal, 340. Doi: 10.1136.bmj.c112.

Najarian J. S., Chavers, B. M., McHugh L. E., \& Matas A. J. (1992). 20 Years of more of follow-up of living kidney donors. The Lancet, 340, 807-810.

Navaneethan, S. D. \& Singh, S. (2006). A systematic review of barriers in access to renal Transplantation among African Americans in the United States. Clinical Transplantation, 20, 769-775.

Nogueira, J., Weir, M., Jacobs. S., Haririan, A., Breault, D., Klassen, D., ...Cooper, M. (2009). A study of renal outcomes in African American living kidney donors. Transplantation, 88, 1371-1376. Doi: 10.1097/TP.0b013e181cle156

Nolan, M. T., Walton-Ross, B., Taylor, L., \& Dane, K. (2004). Living kidney donor decision making: State of the science and directions for future research. Progress in Transplantation, 14, 201-209.

O'Hara, J. F., Branstedt, K., Flechner, S., \& Goldfarb, D. (2007) Ethical issues surrounding high-risk kidney recipients: implications for the living donor. Progress in Transplantation, 17, 180-2. 
Olbrisch, M. E., Benedict, S. M,, Haller, D. L., Levenson, J. L. (2001). Psychosocial assessment of living organ donors: clinical and ethical considerations. Progress in Transplantation, 11, 40-49.

Olson, W. and Bogetti-Dumlao, A. (2001). Living donors' perception of their quality of health after donation. Progress in Transplantation, 11, 108-115.

OPTN (Organ Procurement and Transplantation Network). 2008. National Data Reports. Retrieved from www.optn.org/latestData

Packer, M. J. (1985). Hermeneutic inquiry in the study of human conduct. American Psychologist, 40, 1081-1093.

Pallet, N., Thervet, E., Alberti, C., Emal-Algae, V., Badrossian, J., Martinez, F., et al. (2005) Kidney transplant in black recipients: Are African Europeans different from African Americans? American Journal of Transplantation, 5, 2682-2687. Doi: $10.1111 / \mathrm{j} .1600-6143.2005 .01057 . x$

Patton, M. (2002). Qualitative Evaluation and Research Methods. $3^{\text {rd }}$ ed. Thousand Oaks, CA: Sage Publishers.

Papachristou, C., Walter, M., Dietrich, K., Danzer, G., Klupp, J., Klapp, B. F. et al. (2004). Motivation for living-donor liver transplantation from the donor's perspective: an in-depth qualitative research study. Transplantation, 78, 15061514. Doi: 00007890-200411270-00015

Parke, R. \& Clarke-Stewart, K. (2001). Effects of Parental Incarceration on Young Children. United States Department of Health and Human Services, Assistant Secretary for Planning and Evaluation, Substance Abuse and Mental 
Health Services Administration. Retrieved from:

http://aspe.hhs.gov/hsp/prison2home02parke-stewart

Peters, T. G., Repper, S. M., Jones, K. W., Walker, G. W., \& Hunter, V. M. (2000).

Living kidney donation: recovery and return to activities of daily living. Clinical Transplantation, 14, 433-438.

Pradel, F. G., Limcangco, M. R., Mullins, C. D., \& Bartlett, S. T. (2003). Patients' attitudes about living donor transplantation and living donor nephrectomy. American Journal of Kidney Diseases, 41, 849-858.

Reeves-Daniel, A., Freedman, B., Assimos. D., Hartmann, E., Bleyer, A., Adams, P., ... Daniel, K. (2010). Short-term renal outcomes in African American and Caucasian donors following live kidney donation. Clinical Transplantation, 24, 717-722. Doi: 10.1111.j.1399-0012.2009.01170.x

Reimer, J., Rensing, A., Haasen, C., Philipp,T., Pietruck, F., \& Franke, G. H. (2006). The impact of living-related kidney transplantation on the donor's life.

Transplantation, 81, 1268-1273.

Rodrigue, J. R., Bonk, V., \& Jackson, S. (2001). Psychological considerations of living organ donation. In J. R. Rodrigue (Ed). Biopsychosocial Perspectives on Transplantation (pp. 59-70). New York: Kulwer Academic/Plenum Publishers.

Rodrique, J. R., Widows, M. R., Guenther, R., Newman, R. C., Kaplan, B., \& Howard, R. J. (2006). The expectancies of living kidney donors: do they differ as a function of relational status and gender? Nephrology, Dialysis, Transplantation, 21, 1682-8. Doi: $10.1093 / \mathrm{ndt} / \mathrm{gf1024}$

Sabol, W., \& Couture, H. (2008). Prison Inmates at Midyear, 2007. Bureau of 
Justice Statistics Report. Retrieved from:

http://bjs.ojp.usdoi.gov/content/pub/pdf/pim07.pdf

Saha, S., Arbelaez, J. J., \& Cooper, L. A. (2003). Patient-physician relationships and racial disparities in the quality of health care. American Journal of Public Health., 93, 1713-1719.

Sahin, S., Manga, S. G., Turkmen, A. \& Sever, M. S. (2006). Utilization of elderly donors in living related kidney transplantation. Transplant Proceedings, 38, 385-387.

Sajjad, I., Baines, L., Salifu, M., \& Jindal, R. (2007). The dynamics of recipient-donor relationships in living kidney transplantation. American Journal of Kidney Diseases, 50, 834-854. Doi 10.1053/j.ajkd.2007.07.029.

Sanner, M. A. (2005). The donation process of living kidney donors. Nephrology, Dialysis, Transplantation, 20, 1707-13.

Scheper-Hughes, N. (2007). The tyranny of the gift: Sacrificial violence in living donor transplants. American Journal of Transplantation, 7, 507-511.

Schieppati, A., \& Remuzzi, G. (2005). Chronic renal diseases as a public health problem: epidemiology, social and economic implications. Kidney International Suppl., 98, S7-S10.

Schover, L. R., Streem, S. B., Boparai, N., Duriak, K., \& Novick, A. (1997). The psychosocial impact of donating a kidney: Long-term followup from a urology based center. Journal of Urology, 157, 1596-1601.

Scientific Registry of Transplant Recipients (SRTR). (2011). Retrieved from www.ustransplant.org/About.aspx 
Shelton, W., \& Balint, J. (Ed.). (2001). The ethics of organ transplantation (First ed. Vol. 7). Oxford, UK: Elsevier Science, Ltd.

Shilling, L. M., Norman, M., Chavin, K., Hildebrand, L., Lunsford, S., Martin, M. et al. (2006). Healthcare professionals se perceptions of barriers to living donor kidney transplant among African Americans. Journal of the National Medical Association, 98, 834-840.

Shokier, A. A. (2007). Open versus laparoscopic live donor nephrectomy: a focus on the safety of donors and the need for a donor registry. Journal of Urology, 178, 18606. Doi: $10.1016 /$ j.juro.207.07.008

Simforoosh, A., Basiri, A., Fattahi, M. R., Einollahi, B., Firouzan, A., Pour-Reza-Gholi, F., et al. (2006). Living unrelated versus living related kidney transplantation: 20 years ${ }^{\text {ee }}$ experience with 2155 cases. Transplantation Proceedings, 38, 422-425. Doi: $10.1016 /$ j.transproceed.2006.01.012

Siminoff, L. A., \& Arnold, R. (1999). Increasing organ donation in the African American community: altruism in the face of an untrustworthy system. Annals of Internal Medicine., 130, 607-609.

Siminoff, L. A. \& Saunders-Sturm, C. M. (2000). African-American reluctance to donate: Beliefs and attitudes about organ donation and implications for policy. Kennedy Institute of Ethics Journal, 10, 59-74.

Simmons, R. K., Klein, S. D., \& Simmons, R. L. (1977). Gift of life the social and psychological impact of organ transplantation: New Brunswick, NJ: Transaction Books. 
Simmons, R., Hickey, K., Kjellstrund, C., \& Simmons, R. L. (1971). Donors and nondonors: The role of the family and the physician in kidney transplantation. Seminars in Psychiatry, 3, 102-115.

Smedley, B. D., Stith, A. Y., \& Nelson, A. R. (2003). Unequal treatment: confronting racial and ethnic disparities in health care. Washington, D.C.: Institute of Medicine.

Smith, B. (1999). Ethical and methodologic benefits of using a reflexive journal in hermeneutic-phenomenologic research. Image: Journal of Nursing Scholarship, $31,359-363$.

Smith, G., Trauer, T., Kerr, P. G., \& Chadban, S. J. (2004). Prospective psychosocial monitoring of living kidney donors using the Short Form-36 Health Survey: Results at 12 months. Transplantation, 78, 1384-1389. Doi: 00007890200411150-00022

Smith, M., Kappell, D. F., Province, M. A., Hong, B. A., Robson, A. M., Dutton, S. et al. (1986). Living related kidney donors; A multicenter study of donor education, socioeconomic adjustment and rehabilitation. American Journal of Kidney Diseases, VIII(4), 223-233.

Spital, A. (2004). Donor benefit is the key to justified living organ donation. Cambridge Quarterly of Healthcare Ethics, 13, 105-109.

Spital, A. (2001). Ethical issues in living related donors. In W. Shelton, \& Balint, J. (Ed.), The ethics of organ transplantation (Vol. 7). Oxford, UK: Elsevier Science, Ltd.

Spital, A. (2000). Evolution of Attitudes at U.S. transplant centers toward kidney donation by friends and altruistic strangers. Transplantation, 69, 1728-1831. 
Steffen, P.R., McNeilly, M., Anderson, N., \& Sherwood, A. (2003). Effects of perceived racism and anger inhibition on ambulatory blood pressure in African Americans. Psychosomatic Medicine, 65, 746-750. Doi: 0.1097/01.psy.0000079380.95903.78

Steiner, R. W., \& Gert, B. (2000). Ethical selection of living kidney donors. American Journal of Kidney Diseases, 36, 677-686. Doi: 10.1053/ajkd.2000.17611

Stothers, L., Gourlay, W. A., \& Liu, L. (2005). Attitudes and predictive factors for live kidney donation: A comparison of live kidney donors versus nondonors. Kidney International, 67, 1105-1111.

Switzer, G. E., Dew, M. A., Butterworth, V. A., Simmons, R. G., \& Schimmel, M. (1997). Understanding donors' motivations: a study of unrelated bone marrow donors. Social Science in Medicine, 45, 137-147.

Taylor, R. J., Chatters. L. M., \& Levin, J. (2004). Religion in the lives of African Americans. Thousand Oaks, CA: Sage.

Taylor, L. A., \& McMullen, P. (2008). Living kidney organ donation: experiences of spousal support of donors. Journal of Clinical Nursing, 17: 232-241.

Terasaki, P. I., Cecka, J. M., Gjertson, D. W., \& Cho, Y. W. (1997). Spousal and other living renal donor transplants. Clinical Transplants, 269-284.

Topp, R., Newman, J. L., \& Jones, V. F. (2008). Including African Americans in health care research. Western Journal of Nursing Research, 30, 197-203. Doi: $10.1177 / 0193945907303063$

Trevitt, R., Whittaker, C., Ball, E. A., \& FitzGerald, L. (2001). Drop-out rate during living donor selection. EDTNA/ERCA Journal, 27, 88-91. 
Truog, R. D., (2005). The ethics of organ donation by living donors. New England Journal of Medicine, 353, 444-446.

Tuohy, K.A., Johnson, S., Khwaja, K., \& Pavlakis, M. (2006). Gender disparities in the live kidney donor evaluation process. Transplantation, 82, 1402-1407. Doi: 00007890-200612150-000003

Ulin, P. R., Robinson, E. T., \& Tolley, E. E. (2005). Qualitative methods in public health: a field guide for applied research. San-Francosco: Jossey-Bass.

U.S. Bureau of the Census. (2009). Retrieved from http://www.census.gov/ population/socdemo/race/black.html.

USRDS. (2006) 2006 Annual Data Report: Atlas of ESRD in the U.S., National Institutes of Health, National Institute of Diabetes and Digestive and Kidney Disease, Bethesda, MD 2006. Retrieved from http://www.usrds.org

USRDS. (2010) 2010 Annual Data Report: Atlas of ESRD in the U.S., National Institutes of Health, National Institute of Diabetes and Digestive and Kidney Disease, Bethesda, MD 2007. Retrieved from http://www.usrds.org

van Ryn, M., \& Fu, S. F. (2003). Paved with good intentions: Do public health and human service providers contribute to racial/ethnic disparities in health? American Journal of Public Health, 93, 248-255.

Veatch, R. M. (2000). Transplantation ethics (First ed.). Washington, D.C.: Georgetown University Press.

Walter, M., Dammann, G., Kuchenhoff, J., Frommer, J., Schoeneich, F., Danzer, G., et al. (2005). Psychosocial situation of living donors: moods, complaints, and self- 
image before and after liver transplantation. Medical Science Monitor, 11, CR503-9.

Walter, M., Papachristou, C, Pascher, A., Danzer, G., Neuhaus, P, Klapp, G. F., et al. (2006). Impaired psychosocial outcome of donors after living donor liver transplantation: a qualitative case study. Clinical Transplantation, 2006, 20, 410415. Doi: 10.1111/j.1399-0012.2006.00464.x

Walton-Moss, B. J., Taylor, L., \& Nolan, M. T. (2005). Ethical analysis of living organ donation. Progress in Transplantation, 15, 303-9.

Waterman, A. D., Covelli, T., Caisley, L., Zerega, W., Schnitzler, M., Adams, D., et al. (2004). Potential living kidney donors' health education use and comfort with donation. Progress in Transplantation, 14, 233-240.

Washington, H. A. (2006). Medical apartheid: the dark history of medical experimentation of Black Americans from colonial times to the present. New York: Doubleday.

White, R. M. (2005). Misrepresentations of the Tuskegee study of untreated syphilis. Journal of the National Medical Association, 97, 564-581.

Wiedebusch, S., Reiermann, S., Steinke, C., Muthny, f., Pavenstaedt, J., Schoene-Seifert, B., ... Buyx, A. (2009). Transplant Proceedings, 41, 1483-1488.

Wittig, D. R. (2001). Organ donation beliefs of African American women residing in a small southern community. Journal of Trans-cultural Nursing, 12, 203-210.

Yi, M. (2003). Decision-making process for living kidney donors. Journal of Nursing Scholarship, 35, 61-66. 
Yin, R. (2010). Qualitative Research from Start to Finish. Thousand Oaks, CA: Sage Publishers.

Young, C. J. \& Gaston, R. S. (2002). Medical progress: Renal transplantation in black Americans. The New England Journal of Medicine, 343, 1545-1552.

Young, C. J., \& Kew, C. (2005). Health disparities in transplantation: focus on the complexity and challenge of renal transplantation in African Americans. Medical Clinics of North America, 89, 1003-31, ix. Doi: 10.1016/j.mcna.2005.05.002

Zimmerman, D., Donnely, S., Miller, J., Stewart, D., \& Albert, S. E. (2000). Gender disparity in living renal transplant donation. American Journal of Kidney Diseases, 36, 534-540. Doi: 0272-6386/00/3603/0010

Zink, S., Weinreib, R., Sparling, T., Caplan, A. L. (2005). Living donation: focus on public concerns. Clinical Transplantation, 19, 581-585. 
Table 1. Overarching Themes, Themes, and Sub-themes

\begin{tabular}{|c|c|c|}
\hline $\begin{array}{l}\text { Overarching } \\
\text { Themes }\end{array}$ & Themes & Sub themes \\
\hline \multicolumn{3}{|l|}{$\begin{array}{l}\text { Context of Living } \\
\text { Kidney Donation }\end{array}$} \\
\hline & Interpersonal Milieu & $\begin{array}{l}\text { Relating to the potential recipient } \\
\text { Engaging in family and social life } \\
\text { Support from community members } \\
\text { Support from church congregations }\end{array}$ \\
\hline & $\begin{array}{l}\text { ESRD Threatens the Family"s } \\
\text { World }\end{array}$ & $\begin{array}{l}\text { Family routines disrupted } \\
\text { "Something could happen" to their loved one }\end{array}$ \\
\hline & Facing an Uncertain Future & $\begin{array}{l}\text { Searching for living donors } \\
\text { Financial concerns }\end{array}$ \\
\hline & $\begin{array}{l}\text { Spiritual \& Religious Beliefs } \\
\text { and Values }\end{array}$ & $\begin{array}{l}\text { Relying on spiritual beliefs } \\
\text { Using spiritual and religious practices to cope }\end{array}$ \\
\hline & Continuum of Caring & $\begin{array}{l}\text { Communication } \\
\text { Skilled care and skilled tasks } \\
\text { Trust issues }\end{array}$ \\
\hline \multicolumn{3}{|l|}{$\begin{array}{l}\text { Work of Living } \\
\text { Kidney Donors }\end{array}$} \\
\hline & Making the Decision to Donate & $\begin{array}{l}\text { Learning about the living donor evaluation } \\
\text { Deciding to be tested for donation }\end{array}$ \\
\hline & Preparing Family and Friends & $\begin{array}{l}\text { Encountering support and objections } \\
\text { Preparing the household }\end{array}$ \\
\hline & $\begin{array}{l}\text { Enduring the Surgery and } \\
\text { Recovery }\end{array}$ & $\begin{array}{l}\text { Living kidney donation hurts! } \\
\text { Learning about the condition of recipients } \\
\text { Returning to daily activities }\end{array}$ \\
\hline & Restoring an Imperfect World & $\begin{array}{l}\text { Striving to restore family routines } \\
\text { Renewing social and work connections }\end{array}$ \\
\hline & $\begin{array}{l}\text { Making Sense of the } \\
\text { Experience }\end{array}$ & $\begin{array}{l}\text { Advice for other potential donors } \\
\text { Looking toward future health } \\
\text { Second thoughts were rare } \\
\text { Drawing personal meaning from living } \\
\text { donation } \\
\text { Not a moral obligation to donate } \\
\text { Reflecting on "the good" of donating a kidney }\end{array}$ \\
\hline
\end{tabular}


Table 2. Demographic Information

\begin{tabular}{|l|l|c|}
\hline & $\mathrm{N}=8$ & $\%$ \\
\hline Gender & & 75 \\
\hline Female & 2 & 25 \\
\hline Male & 2 & \\
\hline Marital status at time of donation & 5 & 62.5 \\
\hline Married & 1 & 12.5 \\
\hline Widowed & 2 & 25 \\
\hline Single & & \\
\hline Educational level & 4 & 50 \\
\hline High School & 2 & 25 \\
\hline Some college & 1 & 12.5 \\
\hline Associate's Degree & 1 & 12.5 \\
\hline Master's Degree & & 25 \\
\hline Location & 2 & 37.5 \\
\hline Rural or small city & 3 & 37.5 \\
\hline Urban & 3 & 25 \\
\hline Suburban & & 37.5 \\
\hline Kidney recipient & 2 & 12.5 \\
\hline Husband & 3 & 12.5 \\
\hline Child (18 or over) & 1 & 12.5 \\
\hline Parent & 1 & 87.5 \\
\hline Uncle & 1 & 12.5 \\
\hline Sister-in law & 7 & 25 \\
\hline Employed at time of donation & 1 & 25 \\
\hline Unemployed at time of donation & & 37.5 \\
\hline Time span from donation to interviews & 2 & 12.5 \\
\hline Less than 12 months & 2 & \\
\hline 1 to 5 years & 3 & \\
\hline 5 to 20 years & 1 & \\
\hline Over 20 years & 5 & \\
\hline Current function of donated kidneys & & \\
\hline Effective, healthy function & & \\
\hline Kidney rejection & & \\
\hline
\end{tabular}


Figure 1. Key Events and Overarching Themes in Process of Living Kidney Donation

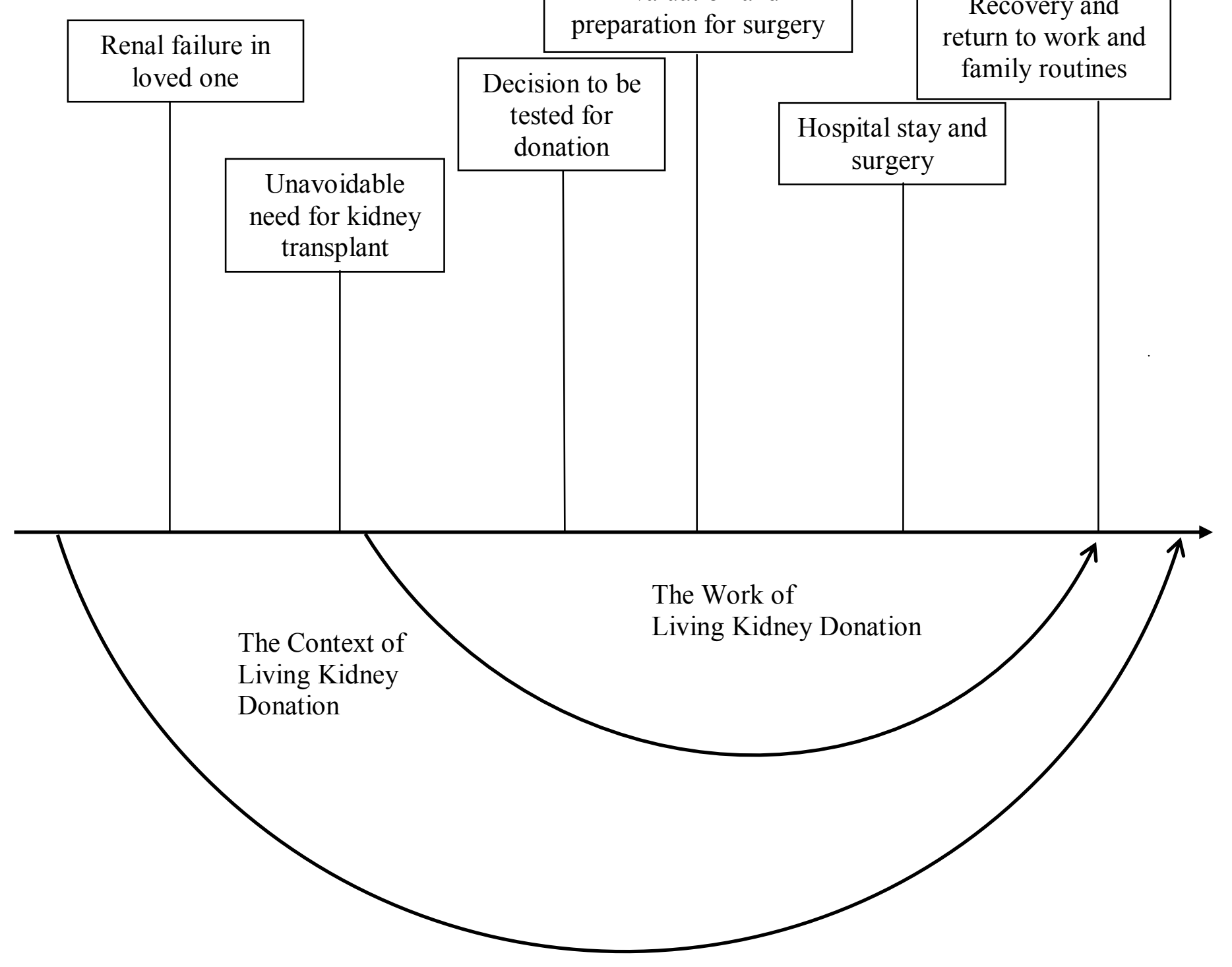


Appendix A

Black American Participation in Research Cited in this Study

*ND: Data regarding Black American participation not reported

\begin{tabular}{|c|c|c|c|c|}
\hline Author and Year & Purpose of Research & $\begin{array}{l}\text { Qualitative } \\
\text { Studies }\end{array}$ & $\mathrm{N}$ & $\begin{array}{c}\% \text { Black } \\
\text { Americans }\end{array}$ \\
\hline Achille et al.(2007) & $\begin{array}{l}\text { Identify gender differences in } \\
\text { living kidney donors }\end{array}$ & & 39 & ND* \\
\hline $\begin{array}{l}\text { Ayanian et al. } \\
\text { (1999) }\end{array}$ & $\begin{array}{l}\text { Assess patient preferences about } \\
\text { transplant by race }\end{array}$ & & 1,392 & $51.7 \%$ \\
\hline $\begin{array}{l}\text { Ayanian et al. } \\
(2004)\end{array}$ & $\begin{array}{l}\text { Determine physician views on } \\
\text { access to transplant }\end{array}$ & & 187 & $5 \%$ \\
\hline $\begin{array}{l}\text { Bloembergen et al. } \\
\text { (1996) }\end{array}$ & $\begin{array}{l}\text { Assess relationship of gender to } \\
\text { transplant rates }\end{array}$ & & 6,193 & ND \\
\hline $\begin{array}{l}\text { Boudville et al. } \\
(2006)\end{array}$ & $\begin{array}{l}\text { Compare hypertension risks for } \\
\text { donors and non-donors }\end{array}$ & & $\begin{array}{c}48 \\
\text { Studies }\end{array}$ & $\begin{array}{l}\text { Meta-analysis, } \\
\text { ND } \\
\end{array}$ \\
\hline $\begin{array}{l}\text { Boulware et al. } \\
(2002)\end{array}$ & $\begin{array}{l}\text { Assess public concerns about } \\
\text { living donation risks }\end{array}$ & & 385 & $47 \%$ \\
\hline $\begin{array}{l}\text { Boulware et al. } \\
(2003)\end{array}$ & $\begin{array}{l}\text { Measure trust in physicians, health } \\
\text { plans, and hospitals }\end{array}$ & & 118 & $42 \%$ \\
\hline $\begin{array}{l}\text { Boulware et al. } \\
(2005)\end{array}$ & $\begin{array}{l}\text { Explore communication with } \\
\text { physicians about living kidney } \\
\text { transplant }\end{array}$ & & 182 & $100 \%$ \\
\hline $\begin{array}{l}\text { Boulware et al. } \\
(2007)\end{array}$ & $\begin{array}{l}\text { Assess public perceptions of organ } \\
\text { allocation, discrimination and } \\
\text { willingness to donate }\end{array}$ & & 845 & $12 \%$ \\
\hline Clarke et al. (2006) & $\begin{array}{l}\text { Measure direct and indirect costs } \\
\text { of living donation }\end{array}$ & & $\begin{array}{c}48 \\
\text { studies }\end{array}$ & $\begin{array}{l}\text { Meta-analysis, } \\
\text { ND }\end{array}$ \\
\hline $\begin{array}{l}\text { Clemens et al. } \\
(2006)\end{array}$ & $\begin{array}{l}\text { Measure pyschosocial function in } \\
\text { living kidney donors }\end{array}$ & & $\begin{array}{c}51 \\
\text { studies }\end{array}$ & $\begin{array}{c}\text { Meta-analysis, } \\
\text { ND }\end{array}$ \\
\hline $\begin{array}{l}\text { Corbie-Smith et al. } \\
\text { (1999) }\end{array}$ & $\begin{array}{l}\text { Describe barriers to participation } \\
\text { in research }\end{array}$ & & 55 & $100 \%$ \\
\hline $\begin{array}{l}\text { Corbie-Smith et al. } \\
(2002)\end{array}$ & $\begin{array}{l}\text { Examine differences in health care } \\
\text { distrust by race }\end{array}$ & & 909 & $57 \%$ \\
\hline Corley et al. (2000) & $\begin{array}{l}\text { Assess attitude, self-image, and } \\
\text { quality of life of living kidney } \\
\text { donors }\end{array}$ & & 55 & $29 \%$ \\
\hline $\begin{array}{l}\text { Ellison et al. } \\
(2002)\end{array}$ & $\begin{array}{l}\text { Describe renal wait list candidates } \\
\text { who were living kidney donors }\end{array}$ & & 56 & ND \\
\hline $\begin{array}{l}\text { Epstein et al. } \\
(2000)\end{array}$ & $\begin{array}{l}\text { Analyze racial disparities in access } \\
\text { to kidney transplant }\end{array}$ & & 1,518 & $52.1 \%$ \\
\hline Fisher et al (2005) & $\begin{array}{l}\text { Increase understanding of the } \\
\text { impact of living kidney donation } \\
\text { on the donor }\end{array}$ & & 87 & $12.8 \%$ \\
\hline Foster et al. (2002) & $\begin{array}{l}\text { Evaluate strategies to increase } \\
\text { transplant rates among Black } \\
\text { Americans }\end{array}$ & & 2,167 & $43 \%$ \\
\hline
\end{tabular}




\begin{tabular}{|c|c|c|c|c|}
\hline Author and Year & Purpose of Research & $\begin{array}{c}\text { Qualitative } \\
\text { Studies }\end{array}$ & $\mathrm{N}$ & $\begin{array}{c}\% \text { Black } \\
\text { Americans }\end{array}$ \\
\hline Garg et al. (2001) & $\begin{array}{l}\text { Examine trends in access to kidney } \\
\text { transplant }\end{array}$ & & 2,613 & $34 \%$ \\
\hline $\begin{array}{l}\text { Gibney et al. } \\
(2007)\end{array}$ & $\begin{array}{l}\text { Describe characteristics of living } \\
\text { donors needing transplants }\end{array}$ & & 102 & $44 \%$ \\
\hline Gill et al. (2006) & $\begin{array}{l}\text { Determine outcomes of living } \\
\text { transplant and donor age }\end{array}$ & & 73,073 & $20 \%$ \\
\hline $\begin{array}{l}\text { Gjertson \& Cecka } \\
(2000)\end{array}$ & $\begin{array}{l}\text { Describe recipient results of living } \\
\text { unrelated donation }\end{array}$ & & 30,281 & $\begin{array}{c}\text { Secondary } \\
\text { data, ND }\end{array}$ \\
\hline Gouge et al. (1990) & $\begin{array}{l}\text { Examine quality of life of donors } \\
\text { and recipients }\end{array}$ & & 118 & $28 \%$ \\
\hline $\begin{array}{l}\text { Griffin and Bratton } \\
\text { (1995) }\end{array}$ & $\begin{array}{l}\text { Explore factors in relativese } \\
\text { decisions about donation }\end{array}$ & $\mathrm{X}$ & 10 & $100 \%$ \\
\hline Hiller et al. (1998) & $\begin{array}{l}\text { Identify health and socio-economic } \\
\text { concerns for donors }\end{array}$ & & 61 & ND \\
\hline $\begin{array}{l}\text { Hilton \& } \\
\text { Starzomski (1994) }\end{array}$ & $\begin{array}{l}\text { Explore family decision-making } \\
\text { about living donation }\end{array}$ & $\mathrm{X}$ & 10 & ND \\
\hline $\begin{array}{l}\text { Ibrahim et al. } \\
(2009)\end{array}$ & $\begin{array}{l}\text { Investigate donors " lifetime risk of } \\
\text { ESRD, prevalence of hypertension, } \\
\text { general health and quality of life }\end{array}$ & & 255 & ND \\
\hline Jacobs et al. (1998) & $\begin{array}{l}\text { Analyze effect of living donation } \\
\text { on family dynamics }\end{array}$ & & 524 & $2.8 \%$ \\
\hline $\begin{array}{l}\text { Johnson et al. } \\
\text { (1997) }\end{array}$ & $\begin{array}{l}\text { Examine peri-operative morbidity } \\
\text { of living donation }\end{array}$ & & 871 & ND \\
\hline $\begin{array}{l}\text { Johnson et al. } \\
\text { (1999) }\end{array}$ & $\begin{array}{l}\text { Determine quality of life of living } \\
\text { kidney donors }\end{array}$ & & 587 & $15 \%$ \\
\hline $\begin{array}{l}\text { Johnson et al. } \\
(2005)\end{array}$ & $\begin{array}{l}\text { Assess graft function with kidneys } \\
\text { donated by older age living donors }\end{array}$ & & 78 & ND \\
\hline Kayler et al. (2002) & $\begin{array}{l}\text { Compare gender demographics of } \\
\text { living donors }\end{array}$ & & 1,182 & ND \\
\hline Kayler (2003) & $\begin{array}{l}\text { Analyze gender demographics and } \\
\text { outcomes in living donors }\end{array}$ & & 30,258 & $\begin{array}{c}\text { Secondary } \\
\text { data ND }\end{array}$ \\
\hline Kayler et al. (2005) & $\begin{array}{l}\text { Analyze volunteerism and } \\
\text { exclusion among living donor } \\
\text { candidates by gender }\end{array}$ & & 144 & $45 \%$ \\
\hline $\begin{array}{l}\text { Klassen et al. } \\
(2002)\end{array}$ & $\begin{array}{l}\text { Explore wait-list decisions in } \\
\text { transplant-eligible patients }\end{array}$ & & 114 & $71 \%$ \\
\hline $\begin{array}{l}\text { Lunsford, } \\
\text { Simpson, Chavin, } \\
\text { Hildebrand et al. } \\
(2006)\end{array}$ & $\begin{array}{l}\text { Analyze racial differences in } \\
\text { ESRD patients coping with need } \\
\text { for transplant }\end{array}$ & & 333 & $61 \%$ \\
\hline $\begin{array}{l}\text { Lunsford, } \\
\text { Simpson, Chavin, } \\
\text { Menching et } \\
\text { al.(2006) }\end{array}$ & $\begin{array}{l}\text { Identify reasons for racial } \\
\text { disparities in living kidney } \\
\text { donation }\end{array}$ & & 1,050 & $62.6 \%$ \\
\hline $\begin{array}{l}\text { Lunsford, Shilling } \\
\text { et al. (2007) }\end{array}$ & $\begin{array}{l}\text { Assess living kidney donor } \\
\text { thoughts and feelings about } \\
\text { donation }\end{array}$ & $\mathrm{X}$ & 18 & $50 \%$ \\
\hline
\end{tabular}




\begin{tabular}{|c|c|c|c|c|}
\hline Author and Year & Purpose of Research & $\begin{array}{c}\text { Qualitative } \\
\text { Studies }\end{array}$ & $\mathrm{N}$ & $\begin{array}{c}\% \text { Black } \\
\text { Americans }\end{array}$ \\
\hline $\begin{array}{l}\text { Lunsford, Simpson } \\
\text { et al. (2007) }\end{array}$ & $\begin{array}{l}\text { Determine relation of family } \\
\text { closeness to living kidney donation }\end{array}$ & & 328 & $39 \%$ \\
\hline Maluf et al. (2010) & $\begin{array}{l}\text { Database review about effects of } \\
\text { using hepatitis C positive grafts }\end{array}$ & & 78,767 & $24 \%$ \\
\hline $\begin{array}{l}\text { Mandelbrot et al. } \\
(2007)\end{array}$ & $\begin{array}{l}\text { Document medical evaluation of } \\
\text { living kidney donors }\end{array}$ & & $\begin{array}{c}132 \\
\text { centers }\end{array}$ & $\begin{array}{c}\text { Transplant } \\
\text { centers, ND }\end{array}$ \\
\hline $\begin{array}{l}\text { Najarian et al. } \\
\text { (1992) }\end{array}$ & $\begin{array}{l}\text { Compare renal function in living } \\
\text { donors and non-donors }\end{array}$ & & 78 & ND \\
\hline $\begin{array}{l}\text { Nogueria et al. } \\
(2009)\end{array}$ & $\begin{array}{l}\text { Investigate renal outcomes in } \\
\text { African American living kidney } \\
\text { donors }\end{array}$ & & 39 & $100 \%$ \\
\hline $\begin{array}{l}\text { Olson \& Bogetti- } \\
\text { Dumlao (2001) }\end{array}$ & $\begin{array}{l}\text { Describe perceptions of quality of } \\
\text { life in living donors }\end{array}$ & & 62 & $1.7 \%$ \\
\hline Peters et al. (2000) & $\begin{array}{l}\text { Determine donor recovery and } \\
\text { activities of daily living }\end{array}$ & & 42 & ND \\
\hline Peters et al. (2002) & $\begin{array}{l}\text { Define current issues and outcome } \\
\text { of living kidney donation }\end{array}$ & & 100 & $27 \%$ \\
\hline Pradel et al. (2003) & $\begin{array}{l}\text { Explore attitudes towards } \\
\text { laparoscopic kidney donation }\end{array}$ & & 461 & $24 \%$ \\
\hline $\begin{array}{l}\text { Reeves-Daniel et } \\
\text { al. (2010) }\end{array}$ & $\begin{array}{l}\text { Record review for short term renal } \\
\text { outcomes of living kidney donors }\end{array}$ & & 336 & $18.7 \%$ \\
\hline $\begin{array}{l}\text { Rodrigue et al. } \\
(2006)\end{array}$ & $\begin{array}{l}\text { Assess donor expectancy as } \\
\text { function of relation to recipient and } \\
\text { gender }\end{array}$ & & 362 & $20 \%$ \\
\hline Saha et al. (2003) & $\begin{array}{l}\text { Explore contribution of patient- } \\
\text { physician relationships to racial } \\
\text { disparities in quality of care }\end{array}$ & & 7,299 & $16 \%$ \\
\hline Sajjad et al. (2007) & $\begin{array}{l}\text { Investigate psychosocial issues in } \\
\text { kidney transplant donors and } \\
\text { recipients }\end{array}$ & & $\begin{array}{c}36 \\
\text { studies }\end{array}$ & $\begin{array}{c}\text { Meta-analysis, } \\
\text { ND }\end{array}$ \\
\hline $\begin{array}{l}\text { Schover et al. } \\
\text { (1997) }\end{array}$ & $\begin{array}{l}\text { Assess psychosocial impact of } \\
\text { living kidney donation }\end{array}$ & & 167 & $11 \%$ \\
\hline Shokier (2007) & $\begin{array}{l}\text { Compare physiologic and financial } \\
\text { factors for laparoscopic and open } \\
\text { nephrectomy procedures }\end{array}$ & & $\begin{array}{c}69 \\
\text { Studies }\end{array}$ & $\begin{array}{c}\text { Meta-analysis, } \\
\text { ND }\end{array}$ \\
\hline $\begin{array}{l}\text { Siminoff \& Arnold } \\
\text { (1999) }\end{array}$ & $\begin{array}{l}\text { Examine racial differences in } \\
\text { organ donation }\end{array}$ & & 444 & $28 \%$ \\
\hline $\begin{array}{l}\text { Simmons et al. } \\
\text { (1971) }\end{array}$ & $\begin{array}{l}\text { Document family decision-making } \\
\text { process in living kidney donation }\end{array}$ & & 79 & ND \\
\hline $\begin{array}{l}\text { Simmons et al. } \\
(1977)\end{array}$ & $\begin{array}{l}\text { Describe process of living kidney } \\
\text { donation }\end{array}$ & & 130 & ND \\
\hline Smith et al. (1986) & $\begin{array}{l}\text { Determine consequences of living } \\
\text { related donation }\end{array}$ & & 536 & $6.7 \%$ \\
\hline Spital (2000) & $\begin{array}{l}\text { Assess attitudes about unrelated } \\
\text { living donation }\end{array}$ & & $\begin{array}{c}129 \\
\text { centers }\end{array}$ & $\begin{array}{c}\text { Transplant } \\
\text { centers, ND }\end{array}$ \\
\hline $\begin{array}{l}\text { Switzer et al. } \\
\text { (1997) }\end{array}$ & $\begin{array}{l}\text { Examine motives of bone marrow } \\
\text { donors }\end{array}$ & & 343 & ND \\
\hline Taylor \& & Explore process of living donation & $\mathrm{X}$ & 11 & $0 \%$ \\
\hline
\end{tabular}




\begin{tabular}{|c|c|c|c|c|}
\hline Author and Year & Purpose of Research & $\begin{array}{l}\text { Qualitative } \\
\text { Studies }\end{array}$ & $\mathrm{N}$ & $\begin{array}{c}\% \text { Black } \\
\text { Americans }\end{array}$ \\
\hline McMullen (2008) & experienced by husbands & & & \\
\hline $\begin{array}{l}\text { Terasaki et al. } \\
\text { (1997) }\end{array}$ & $\begin{array}{l}\text { Determine graft survival of living } \\
\text { donor transplants }\end{array}$ & & 1,000 & ND \\
\hline Tuohy et al. (2005) & $\begin{array}{l}\text { Assess gender disparities in } \\
\text { donation evaluation process }\end{array}$ & & 506 & ND \\
\hline $\begin{array}{l}\text { Waterman et al. } \\
(2004)\end{array}$ & $\begin{array}{l}\text { Determine concerns and benefits } \\
\text { of potential living kidney donors }\end{array}$ & & 91 & $13.2 \%$ \\
\hline Wittig (2001) & $\begin{array}{l}\text { Discover culture care, beliefs, and } \\
\text { meanings of deceased or living } \\
\text { organ donation }\end{array}$ & $\bar{X}$ & 10 & $100 \%$ \\
\hline $\begin{array}{l}\text { Zimmerman et al. } \\
(2000)\end{array}$ & $\begin{array}{l}\text { Determine factors related to gender } \\
\text { disparity of living kidney donation }\end{array}$ & & 144 & ND \\
\hline
\end{tabular}




\section{Appendix B}

International Research Cited in this Study

\begin{tabular}{|c|c|c|c|c|}
\hline Author and Year & Purpose of Research & $\begin{array}{l}\text { Qualitative } \\
\text { Studies }\end{array}$ & $\mathrm{N}$ & Nationality \\
\hline Alfani et al. (1997) & $\begin{array}{l}\text { Compare graft survival } \\
\text { between related and unrelated } \\
\text { donors }\end{array}$ & & 153 & Italian \\
\hline $\begin{array}{l}\text { Andersen et al. } \\
(2005)\end{array}$ & $\begin{array}{l}\text { Explore physical and } \\
\text { psychosocial issues of living } \\
\text { donors }\end{array}$ & $\mathrm{X}$ & 12 & Norwegian \\
\hline $\begin{array}{l}\text { Andersen et al. } \\
(2007)\end{array}$ & $\begin{array}{l}\text { Explore physical and } \\
\text { psychosocial issues of living } \\
\text { donors, one year after donation }\end{array}$ & $\mathrm{X}$ & 12 & Norwegian \\
\hline $\begin{array}{l}\text { Bachmann et al. } \\
\text { (2006) }\end{array}$ & $\begin{array}{l}\text { Evaluate early postoperative } \\
\text { pain and pain management for } \\
\text { donors }\end{array}$ & & 203 & Swiss \\
\hline Binet et al (1997) & $\begin{array}{l}\text { Compare outcomes in } \\
\text { emotionally-related kidney } \\
\text { donation with deceased and } \\
\text { genetically-related donors }\end{array}$ & & 23 & Swiss \\
\hline Brown et al. (2008a) & $\begin{array}{l}\text { Describe experiences, feelings, } \\
\text { and ideas of living kidney } \\
\text { donors }\end{array}$ & $\mathrm{X}$ & 12 & Canadian \\
\hline Brown et al. (2008b) & $\begin{array}{l}\text { Explore living donors } \\
\text { experiences with the health } \\
\text { care system }\end{array}$ & $\mathrm{X}$ & 12 & Canadian \\
\hline Cabrer et al. (2003) & $\begin{array}{l}\text { Evaluate process of living } \\
\text { donation using donor opinions } \\
\text { about their quality of life }\end{array}$ & & 22 & Spanish \\
\hline Dahm et al. (2006) & $\begin{array}{l}\text { Explore impact of laparoscopic } \\
\text { technique on living donors }\end{array}$ & & 108 & Swiss \\
\hline $\begin{array}{l}\text { D'Almeida et al. } \\
\text { (1996) }\end{array}$ & $\begin{array}{l}\text { Evaluate long-term renal } \\
\text { function in living donors }\end{array}$ & & 110 & Brazilian \\
\hline Fauchald et al. 1991) & $\begin{array}{l}\text { Evaluate safety and results of } \\
\text { using older living donors }\end{array}$ & & 235 & Norwegian \\
\hline $\begin{array}{l}\text { Ferhman-Eckholm et } \\
\text { al (2000) }\end{array}$ & $\begin{array}{l}\text { Examine donor views about } \\
\text { donation and their health }\end{array}$ & & 370 & Swedish \\
\hline $\begin{array}{l}\text { Franklin \& Crombie } \\
\text { (2003) }\end{array}$ & $\begin{array}{l}\text { Assess psychologic and socio- } \\
\text { cultural aspects of living } \\
\text { donation }\end{array}$ & $\bar{X}$ & 60 & British \\
\hline $\begin{array}{l}\text { Giessing et al. } \\
\text { (2004) }\end{array}$ & $\begin{array}{l}\text { Assess quality of life for living } \\
\text { kidney donors }\end{array}$ & & 106 & German \\
\hline $\begin{array}{l}\text { Haljamäe et al. } \\
(2003)\end{array}$ & $\begin{array}{l}\text { Assess and describe } \\
\text { experiences of donors with } \\
\text { recipient graft loss }\end{array}$ & $\mathrm{X}$ & 10 & Swedish \\
\hline Heck et al. (2004) & $\begin{array}{l}\text { Examine psychosocial effects } \\
\text { of donation }\end{array}$ & & 31 & German \\
\hline
\end{tabular}




\begin{tabular}{|c|c|c|c|c|}
\hline Author and Year & Purpose of Research & $\begin{array}{l}\text { Qualitative } \\
\text { Studies }\end{array}$ & $\mathrm{N}$ & Nationality \\
\hline Kaarfelt et al. (1998) & $\begin{array}{l}\text { Evaluate effect of kidney } \\
\text { transplant on parents of } \\
\text { recipients }\end{array}$ & & 76 & Swedish \\
\hline Khajehdehi (1999) & $\begin{array}{l}\text { Compare motives, financial } \\
\text { need, and access between } \\
\text { living related and non-related } \\
\text { kidney donors }\end{array}$ & & 78 & Iranian \\
\hline $\begin{array}{l}\text { Lennerling et al. } \\
(2003)\end{array}$ & $\begin{array}{l}\text { Explore motives for becoming } \\
\text { a living donor }\end{array}$ & $\mathrm{X}$ & 12 & Swedish \\
\hline $\begin{array}{l}\text { Lennerling et al. } \\
(2004)\end{array}$ & $\begin{array}{l}\text { Investigate motives for } \\
\text { becoming a living donor }\end{array}$ & & 154 & Swedish \\
\hline $\begin{array}{l}\text { Lennerling \& } \\
\text { Nyberg (2004) }\end{array}$ & $\begin{array}{l}\text { Analyze written information } \\
\text { for potential living kidney } \\
\text { donors }\end{array}$ & & $\begin{array}{c}16 \\
\text { brochures }\end{array}$ & 14 countries \\
\hline $\begin{array}{l}\text { Lumsdaine et al. } \\
(2005)\end{array}$ & $\begin{array}{l}\text { Investigate quality of life for } \\
\text { donors, non-donors and } \\
\text { recipients }\end{array}$ & & 104 & British \\
\hline Morton et al. (2010) & $\begin{array}{l}\text { Synthesize studies of decision } \\
\text { making about treatment for } \\
\text { kidney disease }\end{array}$ & $\bar{X}$ & $\begin{array}{c}18 \\
\text { studies }\end{array}$ & $\begin{array}{c}\text { International } \\
\text { Thematic } \\
\text { analysis } \\
\end{array}$ \\
\hline Pallet et al. (2005) & $\begin{array}{l}\text { Evaluate effect of race and } \\
\text { ethnicity on graft outcomes }\end{array}$ & & 992 & French \\
\hline $\begin{array}{l}\text { Papachristou et al. } \\
(2004)\end{array}$ & $\begin{array}{l}\text { Assess factors contributing to } \\
\text { motives of living liver donors }\end{array}$ & $\mathrm{X}$ & 28 & German \\
\hline Reimer et al. (2006) & $\begin{array}{l}\text { Illuminate decision-making } \\
\text { process of donors and family } \\
\text { life }\end{array}$ & & 65 & German \\
\hline Sahin et al. (2006) & $\begin{array}{l}\text { Investigate recipient outcomes } \\
\text { from older living donors }\end{array}$ & & 296 & Turkish \\
\hline Sanner (2005) & $\begin{array}{l}\text { Explore donation experience of } \\
\text { related and unrelated donors }\end{array}$ & $\mathrm{X}$ & 39 & Swedish \\
\hline $\begin{array}{l}\text { Schnitzbauer et al. } \\
(2007)\end{array}$ & $\begin{array}{l}\text { Detect differences in quality of } \\
\text { life for donors with mini- } \\
\text { incision surgery }\end{array}$ & & 70 & German \\
\hline $\begin{array}{l}\text { Simforoosh et al. } \\
(2006)\end{array}$ & $\begin{array}{l}\text { Compare recipient results from } \\
\text { related and unrelated donors }\end{array}$ & & 2,155 & Iranian \\
\hline Smith et al. (2004) & $\begin{array}{l}\text { Assess prospective } \\
\text { psychosocial outcome in living } \\
\text { donors }\end{array}$ & & 48 & Australian \\
\hline Stothers et al. (2005) & $\begin{array}{l}\text { Quantify factors contributing to } \\
\text { likelihood of living donation }\end{array}$ & & 341 & Canadian \\
\hline Walter et al. (2006) & $\begin{array}{l}\text { Investigate impaired } \\
\text { psychosocial outcome in living } \\
\text { donors }\end{array}$ & $\mathrm{X}$ & 6 & German \\
\hline $\begin{array}{l}\text { Wiedebusch et al. } \\
(2009)\end{array}$ & $\begin{array}{l}\text { Explore well-being after living } \\
\text { donation }\end{array}$ & & 161 & German \\
\hline Yi (2003) & $\begin{array}{l}\text { Explore experiences, issues and } \\
\text { concerns of living donors }\end{array}$ & $\mathrm{X}$ & 10 & Korean \\
\hline
\end{tabular}


Appendix C

Informed Consent for Research Participants

Participant

IRB Number

15726

Principal Investigator

Sheila A. Leander, RN, MSN

PI's Phone Number $\quad 314-977-8984$

Title of Project: $\quad$ The Experiences of Black American Living Kidney Donors

Sheila A. Leander, R.N., M.S.N., with phone number 314-977-8984, would like you to be part of this research study because you are a living kidney donor. This consent form may have words that you do not understand. Please ask Mrs. Leander to explain anything about this form.

\section{WHY IS THIS RESEARCH STUDY BEING DONE?}

The reason for the study is to understand what Black American living kidney donors go through when donating a kidney to someone related by blood, or emotional/family ties. There is a great need for kidney donors and there is very little research about Black American living kidney donors. Mrs. Leander hopes that to improve care for living kidney donors through this study. The study will include up to 10 living kidney donors.

\section{WHAT AM I BEING ASKED TO DO?}

Your part in the study will be 3 tape-recorded interviews with Mrs. Leander. Interviews will be at a place and time of your choice. Each one will last about one and one-half hours. You can ask Mrs. Leander to stop the tape at any time. At no time will your name be on the tape. Only a code number will be used. You can read notes from the interview, if you choose.

\section{HOW LONG WILL I BE IN THE RESEARCH STUDY?}

The time you may spend on this study will be 3 to 5 hours over 3 months.

\section{WHAT ARE THE RISKS?}

Risks to you as part of this study may include some discomfort at questions Mrs. Leander asks. You have the right to choose not to answer any questions or talk about any part of your experience. This will not affect your being part of the study. Mrs. Leander is willing to talk with you about any questions you have about these risks and discomfort. It is possible that your personal information such as name or address could be revealed to a person outside the study. In order to keep that from happening, all personal information will be kept on paper, only, not in a computer. In addition, that paper will be kept in a locked file, in a locked office, on a locked floor. 
ARE THERE BENEFITS TO BEING IN THIS RESEARCH STUDY?

Being part of the study may help you because you get to tell your story. You may be able to help others if the study changes the way doctors and nurses take care of living donors. WHAT OTHER OPTIONS ARE THERE?

You may choose not to be in this research study.

WILL MY INFORMATION BE KEPT PRIVATE?

Your name and address were collected by Mrs. Leander. Your name will have a code number. That code number, not your name, will be on other study papers. Your information is protected by being kept in a locked file cabinet in a locked office on a locked floor. Computer files are saved with passwords and protected by a firewall. The results of the study may be published, but your name will not be revealed and your information will remain private. Mrs. Leander will destroy all study papers and audiotapes by two years after the study.

The Institutional Review Boards at the University of Missouri and Saint Louis University are responsible to protect people who take part in research studies and may review your research study records. State laws or court orders may require that your research records are released.

\section{WHAT ARE THE COSTS AND PAYMENTS?}

There are no costs for you being part of the study and you will not be paid for being in the study.

\section{WHAT HAPPENS IF I AM INJURED BECAUSE I TOOK PART IN THIS RESEARCH STUDY?}

If you are injured by being in the study, please contact Mrs. Leander and/or the Chairperson of the Institutional Review Board listed in section 10. Saint Louis University will provide medical treatment in the event that an injury results because of your being part of this research; but the University reserves the right to make decisions about payment for medical treatment for injuries solely and directly relating to the study. A "research-related injury" means injury caused by the procedures required by the study which you would not have had happen if you had not been part of the study. You have not waived your legal rights by signing this form. If you have questions, please call the Saint Louis University General Counsel's office at 314-977-5767.

\section{WHO CAN I CALL IF I HAVE QUESTIONS?}

If you have any questions or concerns about the study, you can call Sheila A. Leander at 314-977-8984. If you have any questions about your rights being part of a study or if you believe you have been injured as a result of being part of the study, you may contact the Chairperson of the Saint Louis University Behavioral and Social Sciences Institutional Review Board (314-977-2029), who will discuss your questions with you or will send you to someone else who will review the matter with you, and provide further information about how to proceed. 


\section{WHAT ARE MY RIGHTS AND WHAT ELSE SHOULD I KNOW AS A RESEARCH STUDY VOLUNTEER?}

Being part of this research is your choice. You can choose not to be part of the study. There is no penalty if you choose not to take part. You may leave the study at any time. The research study staff will let you know of any new information that may affect whether you want to continue to be part of the study.

\section{AM I SURE THAT I UNDERSTAND?}

I have read this consent document and have been able to ask questions and state any concerns. The researcher has answered my questions and concerns. I believe I understand the research study and the potential benefits and risks that are involved.

\section{Statement of Consent}

I give my informed and voluntary consent to take part in this research study. I will be given a copy of this consent document for my records.

$\overline{\text { Consent Signature of Research Participant }}$

Date

\section{Print Name of Participant}

\section{SAINT LOUIS UNIVERSITY - INSTITUTIONAL REVIEW BOARD - APPROVAL STAMP}

This form is valid only if the IRB's approval stamp is shown below.

I certify that I have explained to the above individual(s) the nature and purpose of the research study and the possible benefit and risks associated with participation. I have answered any questions that have been raised and the subject/patient has received a copy of this signed consent document.

Signature of Principal Investigator

Date

Print Name of Principal Investigator 
Appendix D

Demographic Data Collection Tool

(Items 1-5 were obtained from medical record)

1. Name:

Ethnicity

2.

Address

$-$

3. Date of birth

4. Date of donation surgery

5. Relationship to recipient

(Items 5-8 were obtained from participant after first interview)

5. What is your relationship to the kidney recipient?

(i.e., husband, brother, sister, etc.

6. What is the highest grade you reached in school?

7. What are your current health conditions, aside from the kidney donation surgery?

8. Did the health conditions occur after the donation?

Code number (to be assigned by researcher) 


\section{Appendix E}

Interview Guides

This guide is organized into three sections: (a) overview of the experience, (b) overall context of the kidney donation, and (c) experiences with the health care system and transplant professionals. The topic areas were addressed as appropriate within the context of the interviews. Some questions were repeated to give recipients the opportunity to elaborate on earlier responses as trust developed between researcher and participant.

Overview of the Experience

1) Tell me how your kidney donation experience started.

2) When did you find out that (name of recipient will be inserted here) needed a kidney transplant?

3) When did you start thinking of yourself as a potential kidney donor?

a) What was it like to think of yourself in that way?

b) After you thought about being a potential donor, who did you first tell about your idea?

c) When did you tell (name of recipient will be inserted here) about your idea?

d) How did (name of recipient will be inserted here) respond to your offer?

4) What was it like to be evaluated to be a kidney donor?
a) Tell me about that experience.
b) Tell me about how you were treated during the evaluation.
c) How much time did your evaluation take?
d) Did you think that was too much time or too little time? 
e) What were you told about donation while you were being evaluated?

f) How were you counseled during that period of time?

5) What kind of messages did you get from health care providers in terms of your potential eligibility to donate?

6) When you learned you were eligible to donate, tell me about how you made the decision to donate.

a) Did you make a quick decision, or did you think about it for some time?

b) Some people believe, when a person is eligible, that there is a moral obligation to donate. Tell me what you think about that.

c) Tell me about the possible alternatives you considered before deciding to donate.

d) Tell me about any concerns you might have had regarding:

i) family relationships as you made the decision to donate

ii) your health as you made the decision to donate.

iii) and finances as you made the decision to donate.

7) What was it like when you scheduled the kidney donation surgery?

a) What were your thoughts?

b) How were you feeling?

8) Tell me about your time in the hospital before your surgery.
a) Did you go to the hospital on the day of surgery or before?
b) What do you remember about the day of surgery?
c) What were your thoughts?
d) How were you feeling?
e) Who was with you? 
f) Did you feel supported?

i) If yes, how?

ii) If no, in what way?

9) What were your experiences like with the hospital staff before surgery?

a) Tell me about how they talked with you and prepared you on the day of surgery.

b) Tell me about anything that you wished they had done for you before the surgery.

10) Tell me about your experiences in the hospital after the surgery.

a) How long did you stay in the hospital?

b) Tell me about the pain you had while you were in the hospital.

c) How was your pain managed or mis-managed?

d) What were your experiences like with the hospital staff after surgery?

e) Do you believe you were treated fairly in the hospital?

f) Tell me about anything that may have worried you while you were in the hospital.

g) Tell me about anything that you may have been afraid of while you were in the hospital.

11) Did you perceive that you experienced any racial discrimination while in the hospital?

12) Were you able to see the recipient or find out how he/she was doing?

a) What worries, if any, did you have about the recipient?

b) What information, if any, did the physicians or nurses give you about how the recipeint was doing?

13) Tell me about your trip home.

a) Who brought you home?

b) How far did you have to travel? 
c) How was your pain managed or mis-managed during the trip?

d) What was it like going home from the hospital?

e) What kind of information, if any, did the hospital staff give you when you were discharged?

f) What sort of written information, if any, were you given that you could read later?

i) Was this information helpful?

(1) If yes, why?

(2) If no, why not?

g) What types of things did you have to figure out on your own?

h) How did you figure things out on your own?

14) Tell me about your first week at home.

a) Who helped you during this time?

b) What type of assistance did you need?

c) Who helped you with things such as food and laundry?

d) Tell me about how you got up, dressed, bathed, and ate meals during your first week at home.

e) Tell me about the pain you had at home.

f) How was your pain managed or mis-managed?

15) What was it like recovering and getting back to your normal everyday life?
a) Tell me about how you got along in the first few weeks after surgery.
b) Describe how people treated you after the donation.
c) Describe how you felt about that.
d) How long did it take you to get "out and about" after surgery? 
e) How long would you estimate it took you to get back to your everyday activities after surgery?

f) How did that time period compare to what you were told by the physicians and nurses?

16) Did you and the recipient stay in the same home after the surgery?

a) When did the recipient come home, at the same time or after you?

b) Tell me about your contact with the recipient after you were both home.

c) How did you get along with the recipient afterwards?

17) If you had to be re-hospitalized, what were the circumstances surrounding that event?

a) What were your thoughts about being re-hospitalized?

b) Tell me about your worries and concerns at that time.

c) When re-hospitalized, did you feel the physicians and nurses understood what you were going through?

d) Tell me about when you went home from the hospital the second time.

18) Did you ever have second thoughts about donating?

a) If yes:

i) When?

ii) What were those thoughts about?

iii) How did you deal with your doubts?

iv) What made you donate anyway?

b) If no:

i) Why do you think you were so confident?

ii) What sorts of things do you think would have shaken your confidence? 


\section{Overall Context of the Donation}

1) What was your relationship with the recipient before he/she got sick and needed a kidney transplant?

2) Tell me about how you reached the decision to donate.

a) Who did you talk to before making the decision to donate?

b) Tell me about any spiritual beliefs that may have influenced your decision.

c) Tell me about concerns you had when deciding about donation.

d) Tell me about concerns that led you away from donating.

3) Tell me about people who offered advice about the decision to donate.

a) What kind of advice did they offer?

b) How did you use their advice?

4) Before you became aware of a need to donate, what did you know about living donation?

5) Tell me about other possible donors.

6) What did you think (recipient's name) health would be like after donation?

7) When you were approved for donation, tell me about how (recipient's name) reacted.

8) How do you think you would have felt if you were not approved for donation?

9) How did your family/friends support you or not support you during this time?

10) Did anyone try to talk you out of donating?

a) If yes, tell me about that experience.

11) What were your worries about donation?

12) What potential problems did you consider before donating?

a) Financial 
b) Current health

c) Future health

d) Work

e) Household responsibilities during recovering

f) Recipient feeling like they "owe" you something

13) Did you have second thoughts about donating?
a) What were your thoughts?
b) What was that like?
c) How did you work through those thoughts?

\section{Experiences with Health Care System and Transplant Professionals}

1) Before this, what kinds of experiences did you have with health care providers?

2) Did you have surgery before this?
a) If so, what kind?
b) What was that experience like?

3) Have there been any instances in which you felt racially discriminated against within the health care system.

a) If yes, tell me about that.

4) Tell me about any instances, if any, in which you felt racial discrimination during the kidney donation process.

5) Do you think you have been treated unfairly by people in the health care system?
a) If yes, tell me about that.

6) What was it like to be evaluated for kidney donation?

a) What happened when you were evaluated? 
b) What kinds of things were you taught about in relationship to donation?

c) Were they helpful?

7) Describe what happened to you the day of surgery.

a) Did the surgery happen as planned?

b) Were there delays?

8) Describe what happened in the hospital after your surgery.

a) Describe what your pain was like.

b) Was it what you expected, worse or easier?

c) How did you think the pain was compared with your previous experiences of pain?

9) Describe your relationship with your surgeon and other health team members.

a) Do you think they understood what you were going through as a living donor?

b) What makes you say that?

10) Tell me about your interactions with the transplant team after the surgery.

11) Did they give you a chance to talk about things that were on your mind?

12) What did you discuss with your surgeon after the operation?

13) Do you think you were treated differently by the transplant team because you are a Black American?

14) Were there any issues that you were concerned about that were not addressed by the health care professionals?

15) Tell me about anything you wish they had told you ahead of time.

16) Tell me about things that surprised you in the hospital.

17) Tell me how you were treated by the people in the hospital. 
18) Do you think the other people in the hospital, aside from the transplant team, understood what you were going through as a living donor?

a) What makes you say that?

19) Based on the care that you received, do you think your health care providers had taken care of many living donors before you?

20) Do you think that you were treated differently than other people in the hospital?

21) As you look back, what are your thoughts about donation?

22) Would you encourage others to donate?

23) What was it like to be a healthy person who goes through a major operation?

24) What are your thoughts about your future health with one kidney?

25) In your opinion, what is the biggest misconception people have about living kidney donors?

26) Were you working at the time of the donation?

a) If yes, tell me about that.

b) If no, tell me about your life prior to donation.

27) Tell me about important people in your life at the time of your donation.

a) Tell me about things they might have done to help you during this time.

28) As you look back, what are your thoughts about donation?

29) Is there anything else you would like to tell me about your experience? 
Born into a venerable New England family, Sheila was raised in New Jersey and moved to the midwest with her parents and siblings. She earned a BSN from the University of Missouri, Columbia in 1973 and started a nursing career in a rural, underserved area of east Kentucky. After two years, she entered the Intensive Care unit of a St. Louis hospital. One year later, she pursued her prevailing interest in community nursing and accepted a position to establish certified nurse midwife-based maternal infant care for the uninsured in Jefferson County, Missouri. Sheila entered graduate school and earned an M.S. in Nursing of Children from Saint Louis University in January, 1980. She accepted a C.H.N. Consultant position with the State of Missouri as part of an interprofessional team establishing perinatal care throughout the state.

Two years later, Sheila moved into home health services, administrator for a private provider. She was recruited hired by Missouri Baptist Medical Center to start their own home health agency. Sheila continued in home health services for 14 years, in administration and management, finishing with four years as Director of Nursing at Visiting Nurse Association of St. Louis.

In 1995, she donated a kidney to her husband and left nursing management. In 1998, she joined the faculty at Saint Louis University. Sheila taught part time for eight years and started doctoral studies. She chose Black Americans because the population is under-studied and there is substantial need for living kidney donors. Sheila joined the full time faculty at Saint Louis University in 2006, continues to teach, and serves as Coordinator of the Accelerated BSN program. 